\title{
Reactivity of Radiolytically-Produced Nitrogen Oxide Radicals Toward Aromatic Compounds
}

\author{
Gracy Elias
}

May 2010

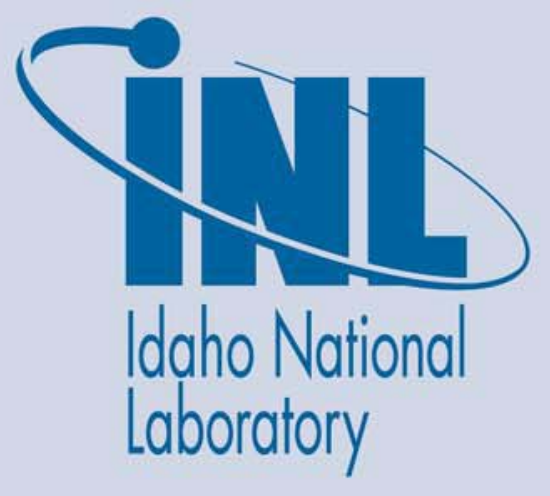

The INL is a U.S. Department of Energy National Laboratory operated by Battelle Energy Alliance 


\title{
Reactivity of Radiolytically-Produced Nitrogen Oxide Radicals Toward Aromatic Compounds
}

\author{
Gracy Elias
}

May 2010

\begin{abstract}
Idaho National Laboratory
Idaho Falls, Idaho 83415
\end{abstract}

http://www.inl.gov

Prepared for the

U.S. Department of Energy

Through the INL LDRD Program

Under DOE Idaho Operations Office

Contract DE-AC07-05ID14517 


\title{
REACTIVITY OF RADIOLYTICALLY-PRODUCED NITROGEN OXIDE RADICALS TOWARD AROMATIC COMPOUNDS
}

\author{
A Dissertation \\ Presented in Partial Fulfillment of the Requirements for the \\ Degree of Doctor of Philosophy \\ with a \\ Major in Chemistry \\ in the \\ College of Graduate Studies \\ University of Idaho \\ by \\ Gracy Elias
}

May 2010

Major Professor: Chien M. Wai, Ph. D. 


\section{AUTHORIZATION TO SUBMIT DISSERTATION}

This dissertation of Gracy Elias, submitted for the degree of Doctor of Philosophy with a major in Chemistry and titled "Reactivity of Radiolytically-Produced Nitrogen Oxide Radicals toward Aromatic Compounds," has been reviewed in final form. Permission, as indicated by the signature and dates given below, is now granted to submit final copies to the College of Graduate Studies for approval.

Major Professor

Date

\section{Chien M. Wai}

Committee

Members

Date

Bruce J. Mincher

Date

Thomas E. Bitterwolf

Date

Vivek P. Utgikar

Department

Administrator

Ray von Wandruszka

Discipline's

College Dean

Date

Scott A. Wood

Final Approval and Acceptance by the College of Graduate Studies

Date

Margrit von Braun 


\begin{abstract}
The nitration of aromatic compounds in the gas phase is an important source of toxic, carcinogenic, and mutagenic species in the atmosphere and has therefore received much attention. Gas phase nitration typically occurs by free-radical reactions.

Condensed-phase free-radical reactions, and in particular nitrite and nitrate radical chemistry, have been studied far less. These condensed-phase free-radical reactions may be relevant in fog and cloud water in polluted areas, in urban aerosols with low $\mathrm{pH}$, in water treatment using advanced oxidation processes such as electron beam (e-beam) irradiation, and in nuclear waste treatment applications. This study discusses research toward an improved understanding of nitration of aromatic compounds in the condensed phase under conditions conducive to free-radical formation. The results are of benefit in several areas of environmental chemistry, in particular nuclear waste treatment applications.
\end{abstract}

The nitration reactions of anisole and toluene as model compounds were investigated in $\gamma$-irradiated acidic nitrate, neutral nitrate, and neutral nitrite solutions. Cs7SB, 1-(2,2,3,3,-tetrafluoropropoxy)-3-(4-sec-butylphenoxy)-2-propanol, is used as a solvent modifier in the fission product extraction (FPEX) formulation for the extraction of $\mathrm{Cs}$ and $\mathrm{Sr}$ from dissolved nuclear fuel. The formulation also contains the ligands calix[4]arene-bis-(tert-octylbenzo-crown-6) (BOBCalixC6) for Cs extraction and 4,4',(5')-di-(t-butyldicyclohexano)-18-crown-6 (DtBuCH18C6) for Sr extraction, all in Isopar L, a branched-chain alkane diluent. FPEX solvent has favorable extraction efficiency for Cs and Sr from acidic solution and was investigated at the Idaho National Laboratory (INL) for changes in extraction efficiency after $\gamma$-irradiation. Extraction 
efficiency decreased after irradiation. The decrease in solvent extraction efficiency was identical for $\mathrm{Cs}$ and $\mathrm{Sr}$, even though they are complexed by different ligands. This suggests that radiolysis of the modifier (Cs-7SB), which solvates both metal complexes, is responsible for this change. These reactions presumably occur due to reactions with radiolytically-produced nitrogen-centered radicals like ${ }^{\circ} \mathrm{NO},{ }^{\circ} \mathrm{NO}_{2}$ and ${ }^{\circ} \mathrm{NO}_{3}$.

Anisole $\left(\mathrm{C}_{6} \mathrm{H}_{5}-\mathrm{OCH}_{3}\right)$ was used in this study as a surrogate for Cs-7SB, since both are aryl ethers. Toluene was used as a surrogate for Cs-7SB because of the alkyl group on the benzene ring in both molecules. Anisole, highly reactive in acids, is a small molecule compared to Cs-7SB and the nitration products are easier to identify compared to those for the larger Cs-7SB molecule. Toluene is less reactive than anisole. Therefore, the highly reactive anisole and the less reactive toluene were considered in this study as model compounds to compare the reaction mechanisms and the nitrated products in acidic media under irradiation.

Experiments were designed to elucidate the mechanism of the nitration of aromatic rings in $\gamma$-irradiated aqueous nitric acid. Since a suite of radical and ionic reactive species are produced in this condensed-phase system, solutions of nitric acid, neutral nitrate and neutral nitrite were irradiated in separate experiments to isolate selected reactive species. Product nitration species were assessed by high performance liquid chromatography (HPLC) with a reversed phase C-18 column and photodiode array detector. The nitrated anisole product distributions were the same with and without radiation in acidic solution, although more products were formed with radiation. In the irradiated acidic condensed phase, radiation-enhanced nitrous acid-catalyzed nitrosonium ion electrophilic aromatic substitution followed by oxidation reactions dominated over 
radical addition reactions. In contrast, the distribution of nitrated derivatives for toluene showed nitronium ion electrophilic substitution in the unirradiated acidic medium as a result of thermal nitration only at elevated temperatures, and free-radical reaction products with irradiation. These ionic/free-radical mechanisms would predominate in acidic solutions such as urban atmospheric aerosols and nuclear fuel dissolutions for similar organic compounds.

Neutral nitrate anisole and toluene solutions were dominated by mixed nitrosonium/nitronium ion electrophilic aromatic substitution reactions, but with lower product yields. Solutions such as these might be encountered in water treatment by ebeam irradiation. Irradiation of neutral nitrite anisole and toluene solutions, on the other hand, resulted in a statistical substitution pattern for nitroanisole and nitrotoluene products, suggesting non-electrophilic free-radical reactions involving the ${ }^{\mathrm{N}} \mathrm{NO}_{2}$ radical. Although often proposed as an atmospheric nitrating agent, ${ }^{\circ} \mathrm{NO}_{2}$ radical is unlikely to have an important effect in the acidic condensed phase in the presence of more reactive, competing species such as nitrous acid due to its low reaction rate constants with aromatic compounds.

Cs-7SB was also irradiated in nitric acid solution. Its possible nitration reactions are discussed in comparison to the results for anisole and toluene. 


\section{ACKNOWLEDGEMENTS}

The author wants to thank Professor Chien Wai for his guidance, direction, and encouragement in the successful completion of her Ph. D. program. She appreciates his wisdom and advice that helped her through her research toward this degree.

The author wants to thank Dr. Bruce Mincher for his valuable scientific insight, resourcefulness, guidance, and encouragement throughout her Ph. D. research. Dr. Mincher's professional judgment, wisdom, direction, and unwavering support were invaluable in the successful completion of this dissertation.

The author appreciates the support of Dr. Steve Mezyk, California State University, Long Beach, CA, in her research, particularly the experimental work at the University of Notre Dame. Dr. Jim Muller supported the author in her experimental work at the University of Utah. Dr. Ray von Wandruszka, University of Idaho was very supportive in fulfilling the requirements for her Ph. D. program. Special thanks go to the author's Ph. D. dissertation committee for their time and effort in the review of the Ph. D. research proposal and dissertation.

The author would like to acknowledge the support of the Idaho National Laboratory (INL) management in the pursuit of her Ph. D. program. Dr. William Bauer deserves special thanks for his support and encouragement.

This research was funded by the INL-LDRD program, sponsored by the U. S. Department of Energy (DOE), Office of Nuclear Energy, Science and Technology under DOE Idaho Operations Office contract DE-AC07-05ID14517. 


\section{TABLE OF CONTENTS}

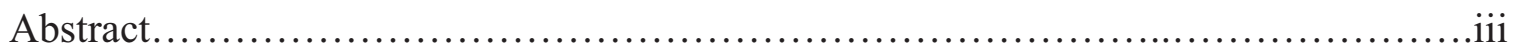

Acknowledgements.......................................................vi

Dedication.....................................................................

Table of Contents....................................................................

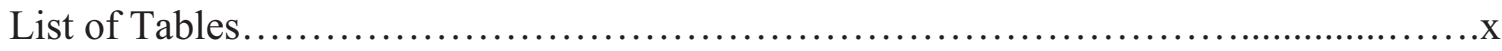

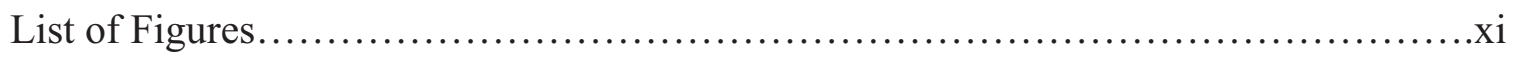

List of Reaction Schemes................................................ xv

Chapter $1 \quad$ Introduction.....................................................

Chapter 2 Aromatic Nitration...............................................

2.1 Electrophilic Aromatic Substitution................................ 10

2.2 Nitronium Ion Nitrations..................................... 12

2.3 Effect of Nitrous Acid in Aromatic Nitration............................17

2.4 Free-radical Nitrations..........................................22

2.4.1 Radiolysis.............................................22

2.4.2 Possible Nitration Mechanisms with Nitrogen Trioxide Radical..26

2.4.3 Postulated Nitration Mechanisms with Nitrite Radical...........28

2.4.4 Suggested Nitration Mechanisms with Superoxide Radical.......28

2.4.5 Examples of Free-radical Reactions........................29

Chapter $3 \quad$ Experimental.................................................. 35

3.1 Steady State Radiolysis......................................... 35

3.2 Pulse Radiolysis ........................................... 38

3.3 Chemicals and Reagents....................................42 


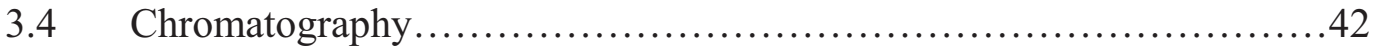

3.5 Fourier Transform Infrared Spectroscopy (FTIR) .....................50

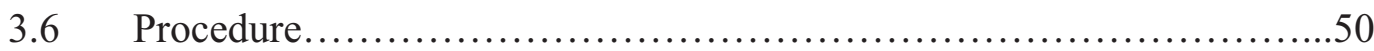

Chapter 4 Reactions of Radiolytically-Produced Nitrogen Oxide Radicals with Anisole and Toluene ................................................52

4.1 Anisole and Toluene Model Compounds............................52

4.1.1 Anisole and toluene - Kinetic Investigations...................52

4.1.2 Steady-state anisole irradiation in acidic nitrate solution ..........57

4.1.3 Steady-state toluene irradiation in acidic nitrate solution...........66

4.1.4 Anisole irradiation in neutral nitrate solution...................71

4.1.5 Toluene in irradiated neutral nitrate solution....................72

4.1.6 Anisole in irradiated neutral nitrite solution.....................73

4.1.7 Toluene in neutral nitrite solution............................74

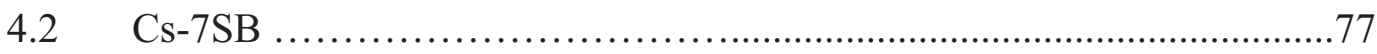

4.2.1 Cs-7SB Gamma-Irradiation..................................77

4.2.2 Cs-7SB Pulse Radiolysis - Kinetic Study ........................79

Chapter $5 \quad$ Common Results of Anisole and Cs-7SB $\ldots \ldots \ldots \ldots \ldots \ldots \ldots \ldots \ldots \ldots \ldots . \ldots 1$

Chapter $6 \quad$ Conclusion....................................................... 90

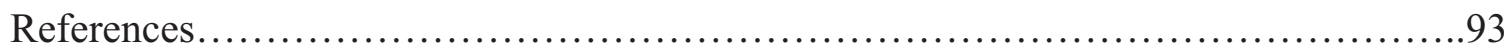

Appendix A List of Papers Published in Refereed Journals and Symposium Series...100 


\section{LIST OF TABLES}

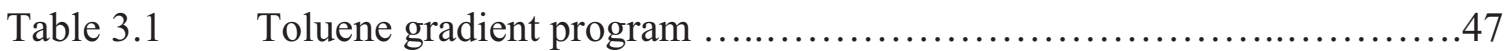

Table $3.2 \quad$ Cs-7SB gradient program...................................... 48

Table 4.1 Second-order rate constants $(k)\left(\mathrm{M}^{-1} \mathrm{~s}^{-1}\right)$ for the reactions of ${ }^{\circ} \mathrm{NO}_{2}$ and $\mathrm{NO}_{3}$ radicals with anisole, toluene and analogous compounds............57

Table 4.2 Aqueous bimolecular rate constants for reaction of the oxidizing radical products of aqueous nitric acid with Cs-7SB .......................8 80 


\section{LIST OF FIGURES}

Figure $1.1 \quad$ Structure of toluene...............................................

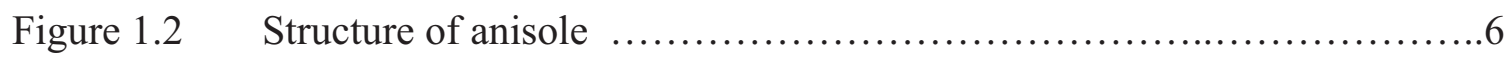

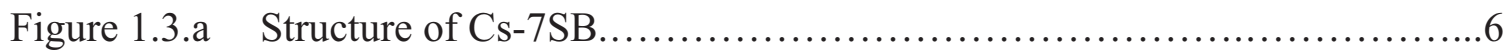

Figure 1.3.b Structure of BOBCalixC6.......................................

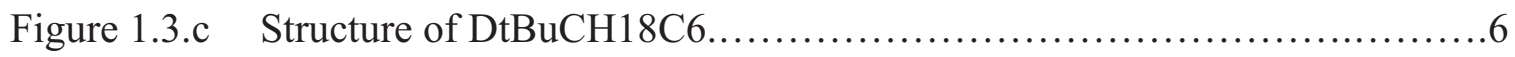

Figure $3.1 \quad$ Nordion Gammacell 220E..................................... 37

Figure 3.2.a Schematic of the pulse radiolysis set-up-University of Notre Dame......40

Figure 3.2.b LINAC - Electron Pulse Radiolysis, University of Notre Dame...........40

Figure 3.2.c LINAC - Electron Pulse Radiolysis (Another view).....................41

Figure 3.3 Schematic of an HPLC system..................................... 44

Figure $3.4 \quad$ Shimadzu HPLC system..................................... 44

Figure 3.5 Schematic of a GC-MS system.................................46

Figure 3.6 Shimadzu GC-MS system.................................... 46

Figure 3.7 Schematic of an LC (UPLC)-MS (ESI/APCI /TOF) system..............49

Figure 3.8 Waters LC (UPLC)-MS (ESI/APCI /TOF) system, University of Utah...49

Figure 4.1.a Room temperature transient absorption spectra for ${ }^{\circ} \mathrm{NO}_{3}\left(\square, \mathrm{N}_{2} \mathrm{O}\right.$ saturated $\left.6 \mathrm{M} \mathrm{HNO}_{3}\right)$ and ${ }^{\bullet} \mathrm{NO}_{2}\left(\mathrm{O}, \mathrm{N}_{2} \mathrm{O}\right.$-saturated $\left.0.10 \mathrm{M} \mathrm{NaNO}_{2}, \mathrm{pH} 7\right)$ radicals in aqueous solution. Absorption coefficient values calculated as described in text. Dashed line corresponds to literature ${ }^{\circ} \mathrm{NO}_{2}$ radical

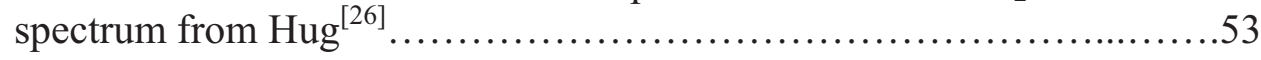

Figure 4.1.b Transient decay kinetics of ${ }^{\bullet} \mathrm{NO}_{3}$ radical with $93(\square), 203(\mathrm{O}), 328(\Delta)$, and $661(\nabla) \mu \mathrm{M}$ anisole added.....................................53

Figure 4.1.c ln A vs. time to find the first order rate constant. Slope of the line is the first order rate constant............................................54

Figure 4.1.d Concentration of anisole vs. first order $\mathrm{k}$ to find the second order rate constant. Slope of the line is the second-order rate constant. 
Figure 4.2.a HPLC chromatogram of 1/100 diluted solution of anisole and $6 \mathrm{M}$ nitric acid at $0 \mathrm{kGy}$ (not irradiated) irradiation dose. Peaks: (1) Mixture of nitric acid and dinitrophenol (2) unknown, possibly impurity in the solvent (3) 4-nitrophenol (4) 2-nitroanisole (5) 4-nitroanisole (6) anisole. HPLC conditions: reverse-phase C-18 column, 55:45 methanol/water, column temperature: $55^{\circ} \mathrm{C}$, Flow rate: $0.5 \mathrm{~mL} /$ minute, isocratic elution and $\mathrm{UV}$

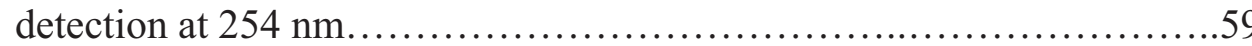

Figure 4.2.b HPLC chromatogram of 1/100 diluted solution of anisole and $6 \mathrm{M}$ nitric acid after irradiation at $28.6 \mathrm{kGy}$ dose. Peaks: (1) Mixture of nitric acid and dinitrophenol (2) nitrous acid (3) 4-nitrophenol (4) 2-nitroanisole (5) 4-nitroanisole (6) anisole. HPLC conditions are same as in Figure 4.2.a

Figure 4.2.c HPLC results of anisole and $6 \mathrm{M} \mathrm{HNO}_{3}$ : The trend of ingrowth of 2and 4-nitroanisoles, 4-nitrophenol and dinitrophenol.

Figure 4.2.d The loss of anisole (A) and production of 2-nitroanisole (2-NA) and 4nitroanisole (4-NA) for irradiated anisole in $6 \mathrm{M}$ nitric acid solution...

Figure 4.3.a Chromatogram (GC-MS) of anisole and $6 \mathrm{M} \mathrm{HNO}_{3}$ (methylene chloride extract) at $4.07 \mathrm{kGy}$ irradiation dose. Peak information with mass spectra in Figure 4.3.b.

Figure 4.3.b Mass spectra of nitro compounds (2-nitroanisole (1), 4-nitroanisole (2), 2,4dinitrophenol (3), 2,6-dinitrophenol (4), and 4-nitrophenol (5) produced with anisole and $6 \mathrm{M} \mathrm{HNO}_{3}$ shown in Figure 4.3.a identified from NIST library.

Figure 4.4 The ingrowth of 2-nitroanisole (2-NA) and 4-nitroanisole (4-NA) for thermal anisole reaction with $6 \mathrm{M} \mathrm{HNO}_{3}$ in the presence and absence of the nitrous acid scavenger hydrazine $(\mathrm{H})$.

Figure 4.5 The production of nitrous acid with irradiation of nitric acid of different concentrations. Reported errors are the standard deviations of triplicate measurements.

Figure 4.6 HPLC-UV chromatogram of toluene and $6 \mathrm{M}$ nitric acid before (T0, $0 \mathrm{kGy}$ irradiation dose) and after irradiation (T4, $8.45 \mathrm{kGy}$ ). Peaks: (1) Mixture of nitric acid and dinitrophenol, (2), (3), and (5) Nitrophenol-like UV spectrum, (4) nitrous acid, (6) nitrobenzene, (7) \& (8) 2-nitrotoluene-like UV spectra, (9) 2-nitrotoluene, (10) 4-nitrotoluene, (11) unknown, (12) toluene. HPLC conditions: reverse-phase C-18 column, 55:45 methanol/water, column temperature: $55^{\circ} \mathrm{C}$, Flow rate: $0.5 \mathrm{~mL} / \mathrm{minute}$, isocratic elution and UV detection at $254 \mathrm{~nm}$. 
Figure 4.7 The loss of toluene (T) and production of 2-nitrotoluene (2-NT) and 4nitrotoluene (4-NT) for irradiated toluene in $6 \mathrm{M}$ nitric acid solution......68

Figure 4.8 UPLC - ESI/APCI (+ and - ion mode) with UV and TOF. Chromatogram of toluene and nitric acid with $43.8 \mathrm{kGy}$ absorbed dose. Peaks: (1) 2,4- and 2,6-dinitrophenol, (2) and (3) dinitrocresol, (4) benzaldehyde with trace of benzaldehyde oxime, (5) trinitrotoluene, (6) nitrobenzene, (7), (8) \& 9 tetryl. UPLC conditions: reverse-phase $\mathrm{C}-18$ column, methanol/water-gradient elution, column temperature: $50^{\circ} \mathrm{C}$, Flow rate: $0.4 \mathrm{~mL} /$ minute, UV

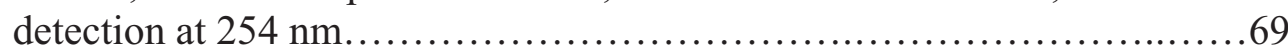

Figure 4.9 Anisole and 6 M sodium nitrate solution at $18.2 \mathrm{kGy}$ absorbed dose.......72

Figure 4.10 The production of 2-nitroanisole (2-NA), 3-nitroanisole (3-NA), and 4 nitroanisole (4-NA) as a function of absorbed dose in irradiated anisole in 1.0 M sodium nitrite solution. Reported errors are the standard deviations of triplicate measurements .74

Figure 4.11 The production of 2-nitrotoluene (2-NT), 3-nitrotoluene (3-NT), and 4nitrotoluene (4-NT) as a function of absorbed dose in irradiated toluene in $0.5 \mathrm{M}$ sodium nitrite solution. Reported errors are the standard deviations

of triplicate measurements..................................... 75

Figure 4.12.a Growth of meta nitroanisole as a function of nitrite concentration at an

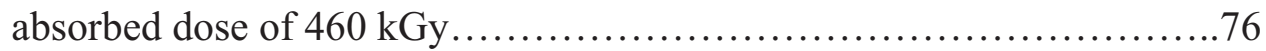

Figure 4.12.b Growth of meta nitrotoluene as a function of nitrite concentration at an

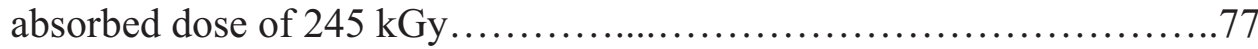

Figure 4.13 GC-ECD chromatograms for FPEX and Cs-7SB modifier samples irradiated to $400 \mathrm{kGy}$ in the presence and absence of $1.5 \mathrm{M}$ nitric acid....78

Figure 5.1 Thermal nitration

(a) anisole and $6 \mathrm{M} \mathrm{HNO}_{3}$ with (clear) and without hydrazine (yellow) (b) Cs-7 SB and $3 \mathrm{M} \mathrm{HNO}_{3}$ with (third bottle from the left - clear) and without hydrazine (first bottle from the left - higher concentration and orange/yellow; second bottle from the left - lower concentration and light yellow)

(c) far left-toluene $+6 \mathrm{M} \mathrm{HNO}_{3}$ (no color), anisole with $6 \mathrm{M} \mathrm{HNO}_{3}$ (second bottle from the left), anisole $+6 \mathrm{M} \mathrm{HNO}_{3}+$ hydrazine (third bottle from the left), anisole $+8 \mathrm{M} \mathrm{HNO}_{3}$ (fourth bottle from the left, deeper yellow-orange color), yellow solid formation in anisole and acid after several months (two bottles at the far right)...................84

Figure 5.2 Unirradiated (left bottle) and irradiated (right bottle) FPEX solution with 


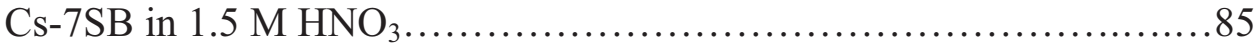

Figure 5.3 FTIR spectra of modifier, yellow/orange modifier layer, anisole, and yellow solid from anisole............................................. 85

Figure 5.4.a Chromatogram of Cs-7SB orange layer at $254 \mathrm{~nm}$ (LC-UV-MS). Peaks identified are Cs-7SB (3.54 and 5.24 minutes), hydroxylated nitro Cs-7SB compound $\mathrm{Na}$ salt (3.06 minutes, the mass spectrum at this point)........86

Figure 5.4.b Mass spectra of Cs-7SB orange layer compounds. Mass peaks for Cs-7SB: 339 (3.54 minute), Na salt of Cs-7SB hydroxylated nitro compound: 422

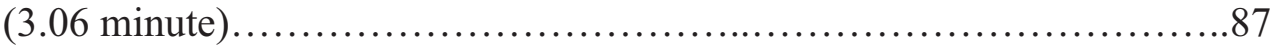




\section{LIST OF REACTION SCHEMES}

Scheme 1. Nitrous acid-catalyzed electrophilic substitution mechanism in anisole .................................................. 18

Scheme 2. Mechanism of the nitrous acid catalyzed nitration of phenol.......30

Scheme 3. Reactions of anisole with ${ }^{\circ} \mathrm{OH}$ and ${ }^{\circ} \mathrm{NO}_{2}$ radicals.................32 


\section{Chapter 1}

\section{Introduction}

The nitration of aromatic compounds can occur by both free-radical and ionic mechanisms and has been the subject of study for many decades. Mechanisms that rely on nitronium ion sources in the condensed phase are well-known because of their utility in synthetic procedures. The nitration of aromatic compounds in the gas phase is an important source of toxic, carcinogenic and mutagenic species in the atmosphere and has therefore also received much attention in recent years. Photolytically-produced ${ }^{\circ} \mathrm{NO}_{3}$ and $\mathrm{NO}_{2}$ radicals are reported to add to aromatic rings in the gas phase, resulting in nitrated aromatic products. ${ }^{[1,2,3]}$ These addition reactions may be direct, or mediated by hydroxyl $(\mathrm{OH})$ radicals. ${ }^{[4,5]}$ In the mediated mechanism, the initial addition reaction of the highly reactive ${ }^{\circ} \mathrm{OH}$ radical produces a hydroxylated cyclohexadienyl radical, which may then add ${ }^{\circ} O_{x}$ as shown in equation $1 .{ }^{[1]}$ The addition product eliminates water to form a stable nitrated aromatic product. ${ }^{[6]}$ Similarly, ${ }^{\circ} O_{3}$ radical may initiate the addition reaction of $\mathrm{NO}_{2}$ and eliminates nitric acid (equation 2).
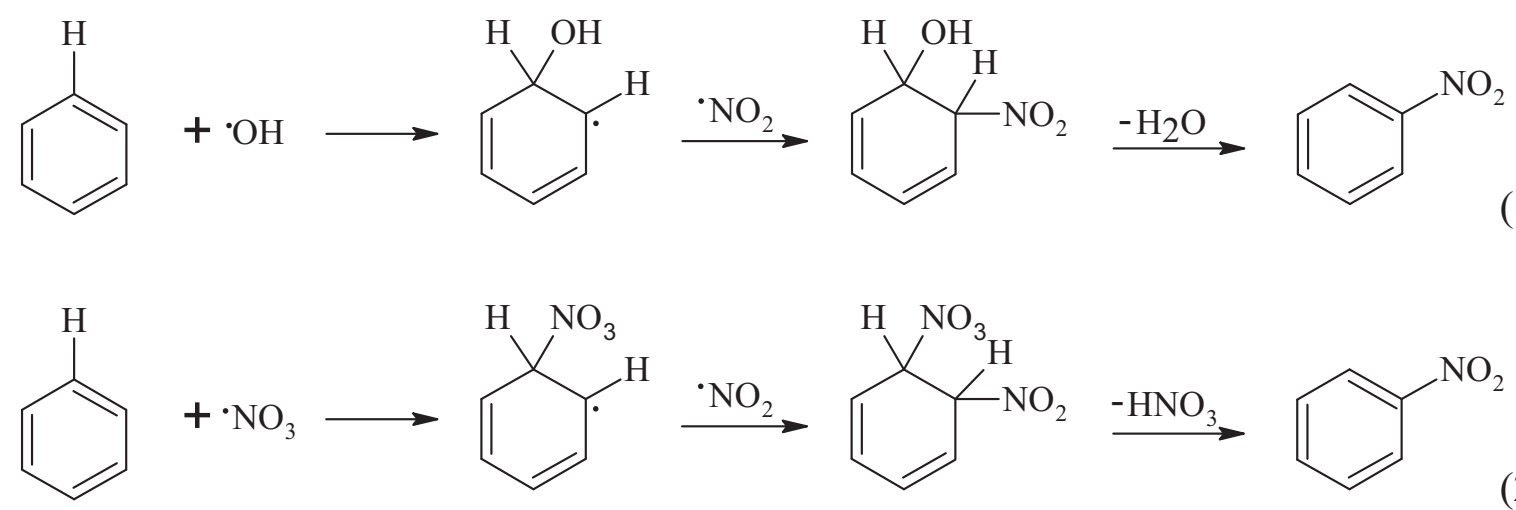
Condensed phase free-radical reactions have been studied far less than those in the gas phase, ${ }^{[4,7]}$ although nitrite and nitrate photochemistry can also be relevant in fog and cloud water in polluted areas. ${ }^{[8]}$ Condensed phase nitric acid reactions also occur in the atmosphere, as urban aerosols with low $\mathrm{pH}$ (as low as -1.2) have been reported. ${ }^{[9]}$ Condensed phase reactions are reported to occur by ${ }^{\circ} \mathrm{NO}_{2}$ radical addition, or by reaction with $\mathrm{N}_{2} \mathrm{O}_{4} \cdot{ }^{[5]}$ These latter two species are interchangeable with regard to nitration as shown in equation $3 .^{[10]}$

$$
\mathrm{N}_{2} \mathrm{O}_{4} \rightleftharpoons \cdot \mathrm{NO}_{2}+\cdot \mathrm{NO}_{2}
$$

Similarly, water treatment using advanced oxidation processes such as e-beam irradiation $^{[11]}$ rely on the generation of radical species to oxidatively degrade organic contaminants. The presence of nitrate and nitrite in treated water may result in the formation of unwanted nitroaromatic compounds. ${ }^{[12]}$ These reactions occur under neutral or only slightly acidic conditions. The nature of the free-radical nitration mechanisms under these conditions has often been debated. ${ }^{[8]}$

The nitration of aromatic compounds in the condensed phase is also of interest in nuclear waste treatment applications. The ligands proposed for use in nuclear fuel reprocessing will be exposed to highly radioactive aqueous nitric acid solutions, and many have been shown to undergo nitration in irradiated acidic solution. ${ }^{[13,14,15]}$ These reactions presumably occur due to reactions with radiolytically-produced nitrogencentered radicals like ${ }^{\circ} \mathrm{NO},{ }^{\circ} \mathrm{NO}_{2}$ and ${ }^{\circ} \mathrm{NO}_{3}$ radicals. An improved understanding of nitration in the condensed phase under conditions conducive to free-radical formation would clearly be of benefit in several areas of environmental chemistry. 
The nitration of aromatic compounds by either ionic or free-radical mechanisms involves the substitution of a nitro group for a hydrogen atom on the aromatic ring. Conventional "thermal" nitration occurs with high positional selectivity through electrophilic aromatic substitution via the nitronium ion, shown in equations $4-5 .^{[10]}$

$$
2 \mathrm{HNO}_{3} \rightarrow \mathrm{NO}_{2}^{+}+\mathrm{NO}_{3}^{-}+\mathrm{H}_{2} \mathrm{O}
$$

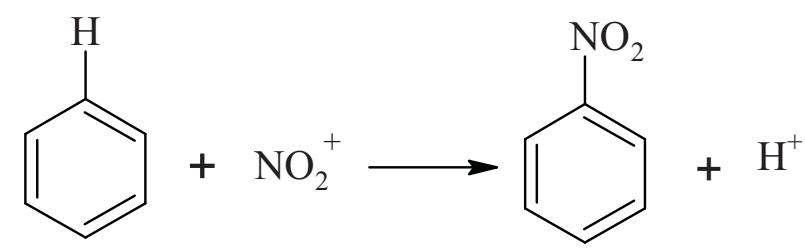

Electrophilic nitration in nitric acid solution may also be catalyzed by nitrous acid.

Under conditions of high acidity, nitrous acid hydrolyzes to produce the nitrosonium ion $\mathrm{NO}^{+}$, shown in equation 6 .

$$
\mathrm{HNO}_{2}+\mathrm{H}^{+} \rightarrow \mathrm{NO}^{+}+\mathrm{H}_{2} \mathrm{O}
$$

The nitrosonium ion is electrophilic and reacts with aromatic compounds with electron donating groups as shown in equation 7 and 8 to produce a nitroso product. ${ }^{[16]}$<smiles></smiles>

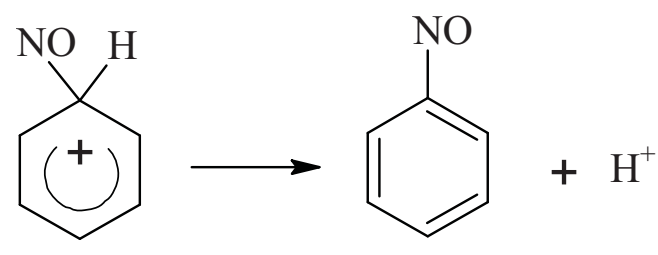


Nitroso species are readily oxidized to form the corresponding nitro products (equation 9). ${ }^{[17]}$<smiles></smiles>

Nitrous acid is continually generated in nitric acid solution via nitric acid oxidation of solutes. Thus, in acidic solution, nitration may occur by a combination of $\mathrm{NO}_{2}{ }^{+}$and $\mathrm{NO}^{+}$ electrophilic aromatic substitution reactions, with low yields of meta products.

In contrast, the nitration of aromatic compounds by the less electrophilic ${ }^{\mathrm{N}} \mathrm{O}_{2}$ radical is reported to occur without positional selectivity, resulting in a statistical distribution of $40 \%$ ortho, $40 \%$ meta and $20 \%$ para-substituted products for toluene, ${ }^{[18]}$ except when steric considerations reduce the abundance of the ortho-isomer. Halfpenny and Robinson, ${ }^{[19]}$ for example, reported predominantly meta nitro-substitution by ${ }^{\circ} \mathrm{NO}_{2}$ radical for a number of aromatic compounds. The direct reaction with aromatic compounds is shown in equation $10-11 .^{[20]}$<smiles>O=[N+]([O-])c1ccccc1[N+](=O)[O-]</smiles><smiles>O=[N+]([O-])c1ccccc1</smiles> 
Alternately, a two step reaction may occur, wherein hydrogen abstraction precedes radical addition, as shown in equation 12 and 13.

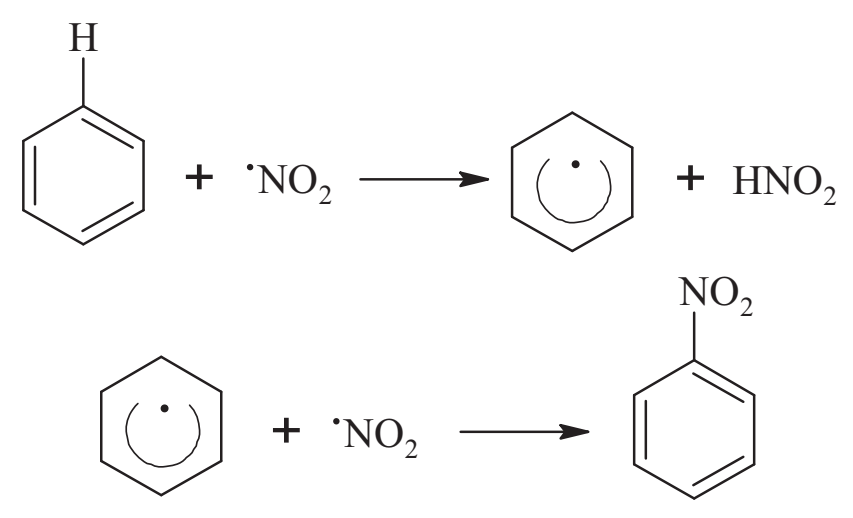

The $\mathrm{NO}_{3}$ radical is more electrophilic and more reactive than the $\mathrm{NO}_{2}$ radical. ${ }^{[20]}$ Its reactions with organic compounds are generally reported to occur via hydrogen atom abstraction and electron transfer to produce carbon-centered radical products. ${ }^{[7]}$ However, the possibility that it also directly nitrates aromatic rings in the condensed phase, in analogy with equation 10 , must be considered. A subsequent reaction to reduce the resulting nitrogen trioxide substituted-product to a stable nitro aromatic product would then be required. One possible such reaction involving oxygen elimination is shown in equation 14.

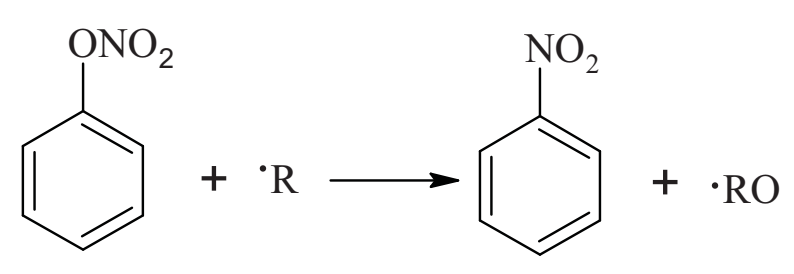

In this study, experiments were designed to elucidate the mechanism of the nitration of aromatic rings in $\gamma$-irradiated aqueous nitric acid. Since a suite of radical and ionic reactive species are produced in this condensed-phase system, solutions of nitric acid, neutral nitrate and neutral nitrite were irradiated in separate experiments to isolate 
selected reactive species. The nitration of anisole was considered because it is a surrogate for Cs-7SB, the modifier, proposed for use in nuclear fuel reprocessing. The nitration of toluene was examined because it is a species of environmental concern and also a surrogate for Cs-7SB. Toluene (Figure 1.1) occurs naturally in petroleum crude oil and is used in paint products. Toluene evaporates when exposed to air and is present in the atmosphere. Anisole (Figure 1.2), an aryl ether, and toluene an alkyl benzene, are simple surrogates for the solvent modifier 1-(2,2,3,3-tetrafluoropropoxy)-3-(4-secbutylphenoxy)-2-propanol (Cs-7SB), shown in Figure 1.3.a, used in fission product extraction from highly radioactive solutions ${ }^{[13]}$ in a process called Fission Product Extraction (FPEX).<smiles>Cc1ccccc1</smiles>

Figure 1.1 Structure of toluene

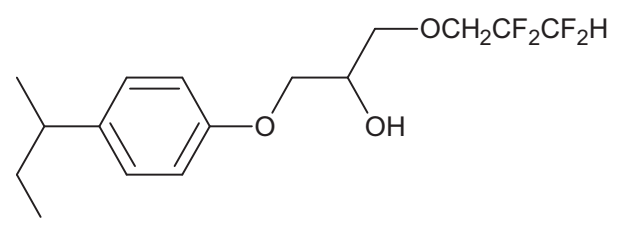

Figure 1.3.a Structure of Cs-7SB

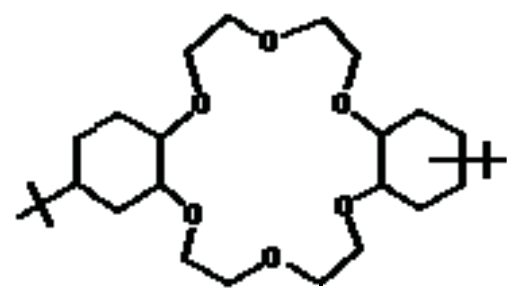

Figure 1.3.c Structure of DtBuCH18C6
Figure 1.2 Structure of anisole

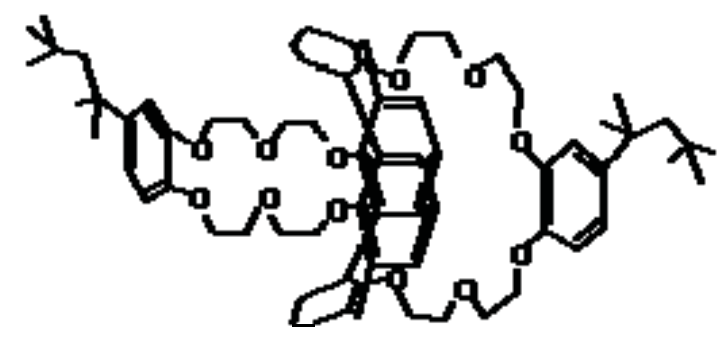

Figure 1.3.b Structure of BOBCalixC6 
Fission Product Extraction (FPEX) process uses a solvent formulation for the extraction of $\mathrm{Cs}$ and $\mathrm{Sr}$ from dissolved nuclear fuel. The formulation contains the solvent modifier Cs-7SB, and the ligands calix[4]arene-bis-(tert-octylbenzo-crown-6) (BOBCalixC6) (Figure 1.3.b) for Cs extraction and 4,4',(5')-di-(t-butyldicyclohexano)18-crown-6 (DtBuCH18C6) (Figure 1.3.c) for Sr extraction, all in Isopar L, a branchedchain alkane diluent. It was found that the extraction effectiveness of Cs from BOBCalixC6 is strongly linked to the hydrogen bond donor (HBD) ability of the modifier. The presence of electron-withdrawing substituents attached to the alcohol carbon atom increase the HBD strength of the alcohol, and the electron-withdrawing power of the substituent increases as the number of electronegative fluorine atoms proximal to the hydroxyl group increases. The relationship between the modifier HBD strength and cesium extraction efficiency suggests that solvation of the BOBCalixC6-Csanion complex may occur via hydrogen-bonding interactions. ${ }^{[21]}$ Irradiation of the FPEX formulation decreased the extraction efficiency of both $\mathrm{Cs}$ and $\mathrm{Sr}$ in the same manner giving indication that radiolysis of Cs-7SB, the modifier is a reason for this effect. Anisole, the surrogate model compound for Cs-7SB, is known to be highly reactive due to its activating methoxy group, and thus large amounts of products may be generated at moderate absorbed radiation doses. The methyl group of toluene is a less activating group, by comparison. Following irradiation, the resulting stable reaction products were identified and quantified. The goal of this research was not only to determine the products of nitration reactions for these aromatic species in the irradiated acidic condensed phase, but also to measure kinetic parameters for reactions of the ${ }^{\circ} \mathrm{NO}_{2}$ and ${ }^{\circ} \mathrm{NO}_{3}$ radicals with these and related compounds using pulse radiolysis techniques. 
This combination of steady state and pulse radiolysis experiments was expected to allow for the elucidation of the nitration reaction mechanisms in irradiated acidic solution. This information can be applied to better understand the radiation effects of the FPEX formulation, in particular the Cs-7SB. 


\section{Chapter 2}

\section{Aromatic Nitration}

Faraday ${ }^{[10]}$ was probably the first to perform the nitration of benzene with nitric acid. From early on, nitration with nitric acid was found to be applicable to a variety of aromatic compounds, and such nitrations were facilitated by the addition of sulfuric acid. Mixed acid nitration became the most common method for nitration of aromatics and was first applied on an industrial scale by Mansfield ${ }^{[10]}$ Mixed acid nitration mechanisms are shown in equations 15-17.

$$
\mathrm{HONO}_{2}+2 \mathrm{H}_{2} \mathrm{SO}_{4} \leftrightarrow \mathrm{H}_{3} \mathrm{O}^{+}+2 \mathrm{HSO}_{4}^{-}+\mathrm{NO}_{2}^{+}
$$
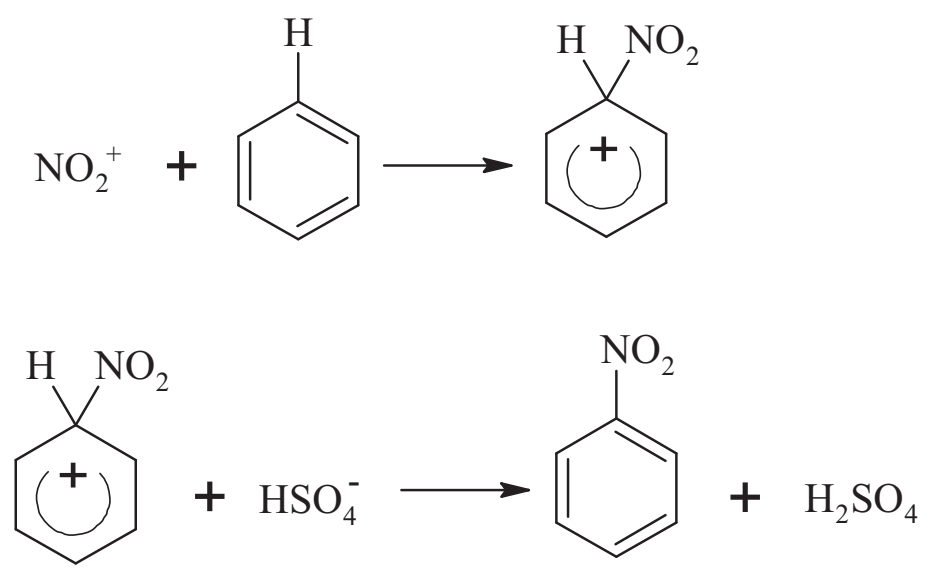

Ingold $^{[22]}$ has pointed out some of the main reasons why aromatic nitration has been particularly useful in studying reaction mechanisms. Under most reaction conditions, nitrations are affected by the same reactive species-the nitronium ion $\left(\mathrm{NO}_{2}{ }^{+}\right)$. However, nitrite and nitrate media under radiolysis and photolysis produce reactive nitrogen oxide free-radicals, ${ }^{[23]}$ which are also possible nitrating species. In the following 
sections, the various possible condensed phase nitrating species reaction mechanisms are discussed.

\subsection{Electrophilic Aromatic Substitution}

Electrophilic substitution is the most common reaction type to occur on aromatic rings. In the fundamental reaction, an electrophile $\mathrm{E}^{+}$is generated by any of several reagents. The electrophile accepts a pair of electrons from the aromatic ring to generate a cyclohexadienyl cation as shown in equation $18 .{ }^{[24]}$ Rather than add a nucleophile to yield an addition product, the cyclohexadienyl cation loses a proton to regenerate the aromatic system. The result is that $\mathrm{E}^{+}$substitutes for a hydrogen atom, as shown in equation $19 .{ }^{[24]}$ This is the essence of electrophilic aromatic substitution .<smiles>FC1C=CC=C[C+]1c1ccccc1</smiles>

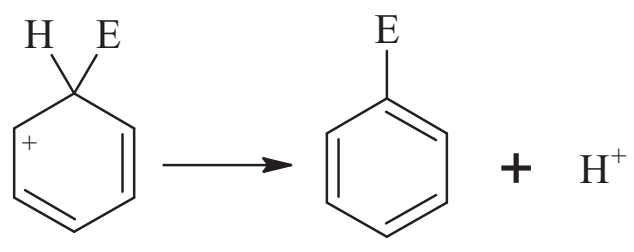

In mixed acid nitration, the electrophile is the $\mathrm{NO}_{2}{ }^{+}$(equations 16-17) as previously discussed.

Groups attached to the aromatic ring destroy the six-fold symmetry of the ring, and the incoming electrophile has three possible locations to substitute relative to the group. Groups $(\mathrm{G})$ attached to the aromatic ring (equation 20) influence both the 
reactivity of the ring and the location of attack by the electrophile. If a group reduces the electron density of the ring by either resonance or induction, the ring will be less reactive than benzene. Groups that increase the electron density of the ring by resonance or induction will be more reactive than benzene.

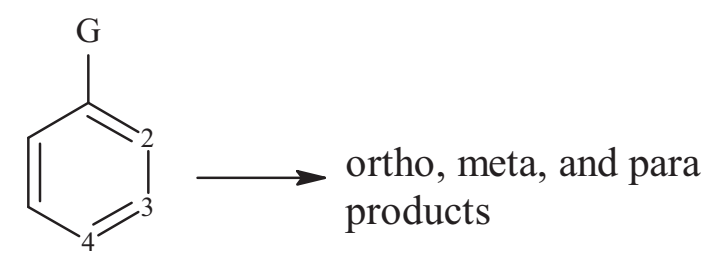

Electron donating groups increase the electron density at the ortho (2) and para (4) positions more than at the meta (3) position (equation 20), leading electrophiles to preferentially attack those positions. For electron withdrawing groups, electron density is reduced more at the ortho and para positions than it is reduced at the meta position, rendering the meta position as the most susceptible to electrophilic attack. Resonance has the greatest influence on the electron density of the aromatic ring. Groups that have an atom with non-bonded electrons next to the aromatic ring increase the electron density as illustrated by the generalized resonance form shown in equation $21 .^{[24]}$

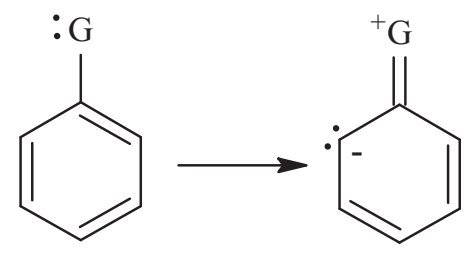

Methoxy benzene (anisole) is an example of such a compound. They are more reactive than benzene, and are ortho/para directors. 
The activation hardness concept predicts the orientation of electrophilic aromatic substitution. ${ }^{[25]}$ The activation hardness is described based on molecular orbital theory. It is based on the energy difference between the lowest unoccupied molecular orbital (LUMO) and the highest occupied molecular orbital (HOMO) of molecules involved in a chemical reaction. A large HOMO-LUMO gap implies high stability. High stability of a molecule reflects its low reactivity toward chemical reactions. When the species is more stable, the greater is its absolute hardness and its reactivity is lower. Transfer of electrons from a donor (D) to an acceptor (A) is facilitated when the HOMO of D is closer in energy to the LUMO of A. With an activation hardness suitably defined, the smaller the activation hardness is, the faster the reaction is. The activation hardness at the ortho, meta, and para positions of several aromatic molecules has been calculated. ${ }^{[25]}$ The calculation is based on different parameters such as electronic energy, number of electrons, ionization potential, electron affinity, and activation energy in the participating molecules. The activation hardness of ortho-para directing molecules showed the lowest activation hardness at the para position, then ortho, with the highest value at the meta position. Thus, substitution patterns for $\mathrm{NO}_{2}{ }^{+}$nitration of a compound like anisole will favor ortho and para products.

\subsection{Nitronium Ion Nitrations}

According to Ingold, electrophilic aromatic nitration in nitric acid consists of four steps (equation 22-23, and 16-17). ${ }^{[10]}$

$$
\begin{gathered}
\mathrm{HNO}_{3}+\mathrm{HA} \leftrightarrow \mathrm{H}_{2} \mathrm{NO}_{3}{ }^{+}+\mathrm{A}^{-} \\
\mathrm{H}_{2} \mathrm{NO}_{3}{ }^{+} \leftrightarrow \mathrm{NO}_{2}{ }^{+}+\mathrm{H}_{2} \mathrm{O}
\end{gathered}
$$



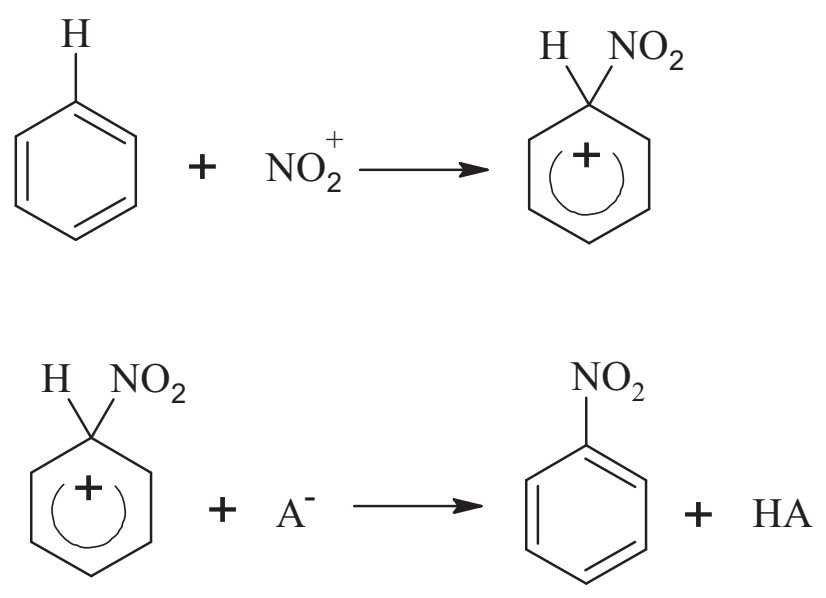

These equations are analogous to those shown in equation $15-17$ for mixed acid nitration.

Nitronium ion, $\mathrm{NO}_{2}{ }^{+}$, is formed in equation 23. When the nitration of aromatic compounds is performed in this system, the rate of reaction slows with time. This is due to water produced in the reaction mixture (equation 23), which dilutes the acid. In the acid systems, electrophilic aromatic nitrations produce an equivalent amount of acid as a byproduct due to proton elimination from the aromatic compounds (equation 17). Small concentrations of nitronium ion $\left(\mathrm{NO}_{2}{ }^{+}\right)$occur in anhydrous nitric acid, while large concentrations occur in the presence of $\mathrm{H}_{2} \mathrm{SO}_{4}$ because $\mathrm{H}_{2} \mathrm{SO}_{4}$ is a stronger acid than $\mathrm{HNO}_{3}$ and ionizes $\mathrm{HNO}_{3}$ as $\mathrm{NO}_{2}{ }^{+}$and $\mathrm{OH}^{-}$, rather than $\mathrm{H}^{+}$and $\mathrm{ONO}_{2}{ }^{-[24]}$ As the water concentration increases in nitric acid, the concentration of nitronium ion decreases (equation 23). ${ }^{[26]}$

Nitronium salts are also an extremely active source of nitronium ion for nitrating aromatic compounds as shown in equation 24.

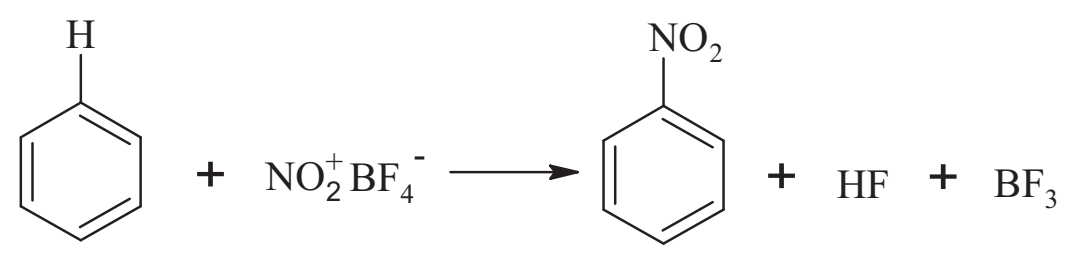


The isomer distributions for toluene nitration by nitronium salts show that there are varying substitution patterns with respect to the ortho/para ratios; meta is always $\sim 3 \%$. ${ }^{[27]}$ Thus, nitronium ion nitration occurs with high positional selectivity. Extreme ortho/para ratios are 2.19 and 0.50 , but the main body of the ratios ranges from 2.1 to 1.6. The absolute value of the ratio of the ortho/para product abundances is influenced by the source of nitronium ion. Steric factors such as the bulkiness of the effective nitrating agent (increasing the abundance of the para product) are one reason for the observed variations. ${ }^{[27]}$ Additionally, substitution of the aromatic ring, such as for toluene, may result in steric inhibition of ortho substitution.

However, in the nitration of anisole with nitric acid or mixed acid at somewhat elevated temperatures, lower ortho/para ratios have been observed. For anisole, mixed acid nitration resulted in an ortho/para ratio ranging from 1.8 to 0.71 , with lower ratios at higher sulfuric acid concentrations. ${ }^{[28]}$ This may be a consequence of nitration via nitrosation and reflects the much weaker electrophilic nature of $\mathrm{NO}^{+}$(as compared to $\mathrm{NO}_{2}{ }^{+}$) and its reaction through an intermediate arenium ion-like transition state of highest energy. ${ }^{[10,29,30,31]}$ Meta product formation remains very low under all ionic electrophilic nitration conditions. Kochi et al. ${ }^{[32,33]}$ describes different nitration mechanisms with preequilibrium charge-transfer complexes of various aromatic donors with electron acceptors like $\mathrm{NO}_{2}{ }^{+}$, and $\mathrm{NO}^{+}$as shown in the example below (equation 25).

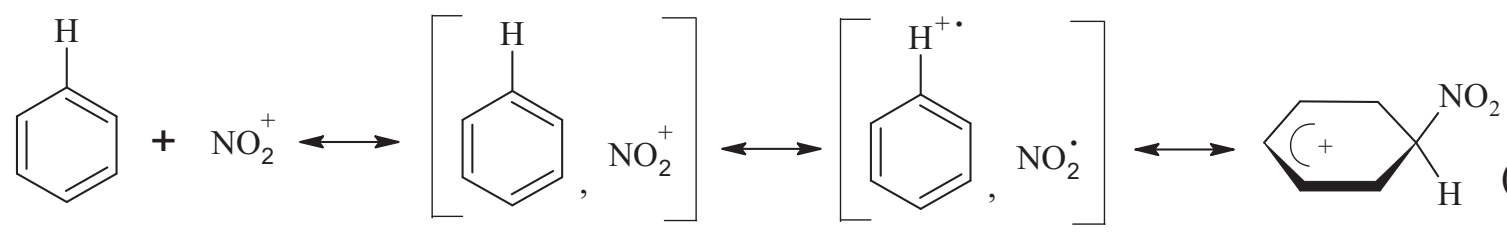


Kochi et al. ${ }^{[34]}$ also explained the outer-sphere and inner-sphere mechanisms with charge transfer concepts. X-ray crystallography together with spectral measurements helped elucidate the organic electron donor (D) and acceptor (A) behavior of various intermolecular encounter complexes like outer-sphere and inner-sphere mechanisms. The outer-sphere mechanism is by weak donor/acceptor coupling and the inner-sphere mechanism is from moderate donor/acceptor bindings with bridged-activated complexes.

If a radical cation is formed from an $\mathrm{ArH} / \mathrm{NO}_{2}{ }^{+}$reaction, it is formed via an innersphere electron transfer (ET) mechanism through bridged activated intermediates $[10,34,35,36,37]$ as shown in equation 26 .

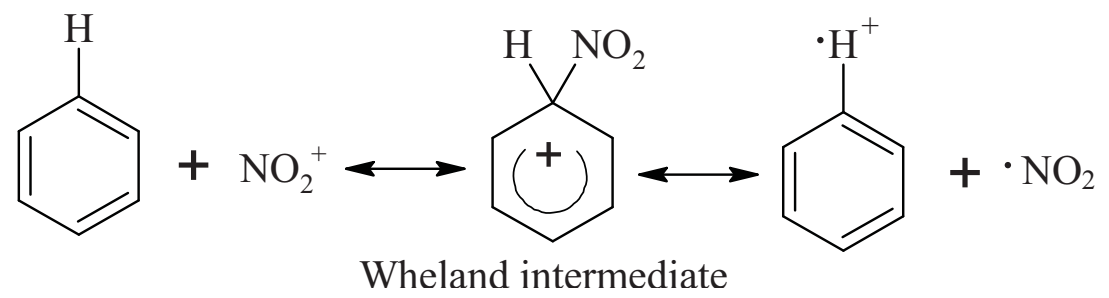

The association step is via a Wheland intermediate shown in equation 26. A Wheland intermediate is considered to be a $\sigma$-complex, indicating that a new $\sigma$-bond is formed using $2 \pi$ electrons from the aromatic ring. This intermediate is equivalent to the formation of the bridged intermediate. The dissociation step to give a radical cation $\left(\mathrm{ArH}^{+}\right)$and ${ }^{\circ} \mathrm{NO}_{2}$ is equivalent to the transfer of the electron from one site to another. In contrast, because of the fast nitration rates of prepared $\mathrm{NO}_{2}{ }^{+}$salts with aromatic compounds, the formation step (Wheland intermediate formation) is excluded and the rate-determining step can be nothing other than interaction of the salt with the aromatic substrate. Protonated methyl nitrate obtained from chemical ionization reacts with an aromatic compound as shown in equation 27. 


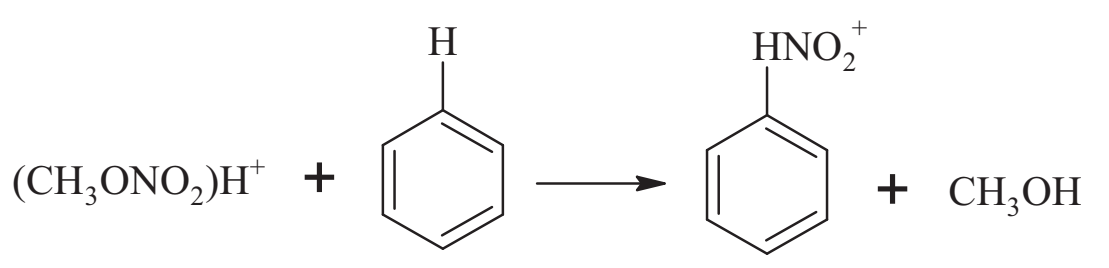

Similarly, time-resolved (picosecond) spectroscopy identified the naphthalene cation radical $\left({ }^{\circ} \mathrm{NAPH}^{+}\right)$as the critical reactive intermediate in charge-transfer nitration. ${ }^{[38]}$ Fourier transform ion cyclotron resonance mass spectrometry found benzene nitration with $\left(\mathrm{RONO}_{2}\right) \mathrm{H}^{+}$reactants as a two step mechanism, involving a fast, preliminary electron and proton transfer between $\left(\mathrm{RONO}_{2}\right) \mathrm{H}^{+}$and $\mathrm{C}_{6} \mathrm{X}_{6}(\mathrm{X}=\mathrm{H}, \mathrm{D})$, followed by the rate-determining attack of the $\mathrm{C}_{6} \mathrm{X}_{6}{ }^{+}$and $\mathrm{C}_{6} \mathrm{X}_{6} \mathrm{H}^{+}$daughters on the nucleophilic centers of $\mathrm{RONO}_{2} \cdot{ }^{[39]}$

Dinitrogen tetraoxide, $\mathrm{N}_{2} \mathrm{O}_{4}$, the dimer of the ${ }^{\circ} \mathrm{NO}_{2}$ radical, dissociates into nitrite and nitronium ions, or into nitrate and nitrosonium ions (equation 28-29).

$$
\begin{aligned}
& \mathrm{N}_{2} \mathrm{O}_{4} \rightleftharpoons \mathrm{NO}_{2}^{+}+\mathrm{NO}_{2}^{-} \\
& \mathrm{N}_{2} \mathrm{O}_{4} \rightleftharpoons \mathrm{NO}^{+}+\mathrm{NO}_{3}^{-}
\end{aligned}
$$

Accordingly, $\mathrm{N}_{2} \mathrm{O}_{4}$ has been widely used for aromatic nitrations as a source of nitronium ion. The mechanistic pictures valid for nitronium ion aromatic nitrations are (i) the classical two-step mechanism, or (ii) a multistep mechanism, proceeding through the ${ }^{\circ} \mathrm{ArH}^{+}$radical cation trapping an $\mathrm{NO}_{2}$ (or an $\mathrm{NO}$ ) radical before collapsing to the Wheland intermediate. Both these mechanistic extremes share the fast last step; the deprotonation of the Wheland intermediate into the final reaction product. In general, alkylbenzenes are nitrated $\sim 50 \%$ ortho and $50 \%$ para. However, ${ }^{\circ} \mathrm{NO}$ or ${ }^{\circ} \mathrm{NO}_{2}$ radicals react with the unpaired electrons in the toluene radical cation with the formation of ipso, 
(nitration at a position already carrying a substituent, for example, formation of nitrobenzene as a result of the dealkylation of toluene), ortho, meta, and para nitrotoluenes. A higher percentage of para nitrotoluene observed in these reactions indicates the latter position as the favored site of attack. ${ }^{[40]}$

\subsection{Effect of Nitrous Acid in Aromatic Nitration}

The effect of nitrous acid, $\mathrm{HNO}_{2}$ in $\mathrm{HNO}_{3}$ solution is manifested by its anticatalytic effect on nitronium ion nitration. ${ }^{[16]}$ Under these conditions the nitration of very reactive aromatic compounds proceeds by an indirect mechanism via nitrosation or oxidative radical-cation formation. ${ }^{[10]}$

In aqueous $\mathrm{H}_{2} \mathrm{SO}_{4}$ or $\mathrm{HClO}_{4}$ solutions of less than $50 \% \mathrm{HNO}_{3}, \mathrm{HNO}_{2}$ is predominantly in its molecular form, with some $\mathrm{N}_{2} \mathrm{O}_{3}$ (anhydrous $\mathrm{HNO}_{2}$ ) also present in equilibrium with ${ }^{\mathrm{NO}}$ and ${ }^{\circ} \mathrm{NO}_{2}$ (equation 30$) .{ }^{[41,42]}$

$$
\mathrm{N}_{2} \mathrm{O}_{3} \rightleftharpoons{ }^{\circ} \mathrm{NO}+{ }^{\cdot} \mathrm{NO}_{2}
$$

In acid solutions above $60-65 \% \mathrm{HNO}_{3}, \mathrm{HNO}_{2}$ is essentially present as the $\mathrm{NO}^{+}$ion ${ }^{[10]}$ as shown in equation 6. In an excess of $\mathrm{HNO}_{3}, \mathrm{HNO}_{2}$ exists essentially as $\mathrm{N}_{2} \mathrm{O}_{4}$, which is nearly completely ionized (equation 29$).{ }^{[41,42]}$

In organic solvent- $\mathrm{HNO}_{3}$ systems, however, $\mathrm{N}_{2} \mathrm{O}_{4}$ is little ionized. Studies by Ingold et al. ${ }^{[43]}$ have shown that in the nitration of phenols and anilines and related compounds in $\mathrm{AcOH}$ (acetic acid) solution, two reactions take place: the zero-order $\mathrm{NO}_{2}{ }^{+}$ ion nitration of the reactive aromatics and a new second order reaction that has the form in equation 31.

$$
\text { Rate }=\mathrm{k}[\mathrm{ArH}]\left[\mathrm{HNO}_{2}\right]
$$


Evidently, it is the latter reaction that causes positive catalysis of the reaction. Analysis of the reaction mixture at intermediate stages did not show any nitrosoarenes. Thus, if formed as intermediates, they must be rapidly oxidized to nitroarenes. Zollinger ${ }^{[10]}$ assumed the nitration proceeds through an initial $\mathrm{ArH} \rightarrow \mathrm{NO}^{+} \pi$-complex, however Kochi $^{[44]}$ assumes it to be charge-transfer (CT) complex formation, followed by electron transfer-oxidation leading to the cation radical complex $\left[{ }^{\circ} \mathrm{ArH}^{+} \mathrm{NO}_{2}\right]$, collapsing to the arenium ion. The major conclusions for electron transfer (ET) nitration proposed by Eberson and Radner ${ }^{[45]}$ can be applied here in the $\mathrm{NO}^{+}$aromatic nitration. The question why only reactive aromatic compounds such as phenols and anilines show catalysis of their nitration by $\mathrm{HNO}_{2}$ can be answered by recognizing that these aromatics are highly reactive toward electrophilic reagents in general. Under similar conditions, benzene and toluene were shown not to display such catalysis. ${ }^{[10]}$

Electrophilic nitration in nitric acid solution is catalyzed by nitrous acid under conditions of high acidity. Nitrous acid protonates and dissociates to produce the nitrosonium ion $\mathrm{NO}^{+}$as shown in equation 6 . The nitrosonium ion is electrophilic and reacts with aromatic compounds as shown in equation 7 and 8 to produce a nitroso product. ${ }^{[30]}$ Nitroso species are readily oxidized to form the corresponding nitro products (equation 9). ${ }^{[31]}$ Nitrous acid is continually generated in nitric acid solution via oxidation of solutes. Nitrous acid-catalyzed electrophilic substitution of ortho-para directing molecules like anisole is depicted ${ }^{[29]}$ in the following reaction mechanism where $\mathrm{N}^{\mathrm{III}}$ represents $\mathrm{HNO}_{2}$ and $\mathrm{N}^{\mathrm{v}}$ represents $\mathrm{HNO}_{3}$ (Scheme 1). 


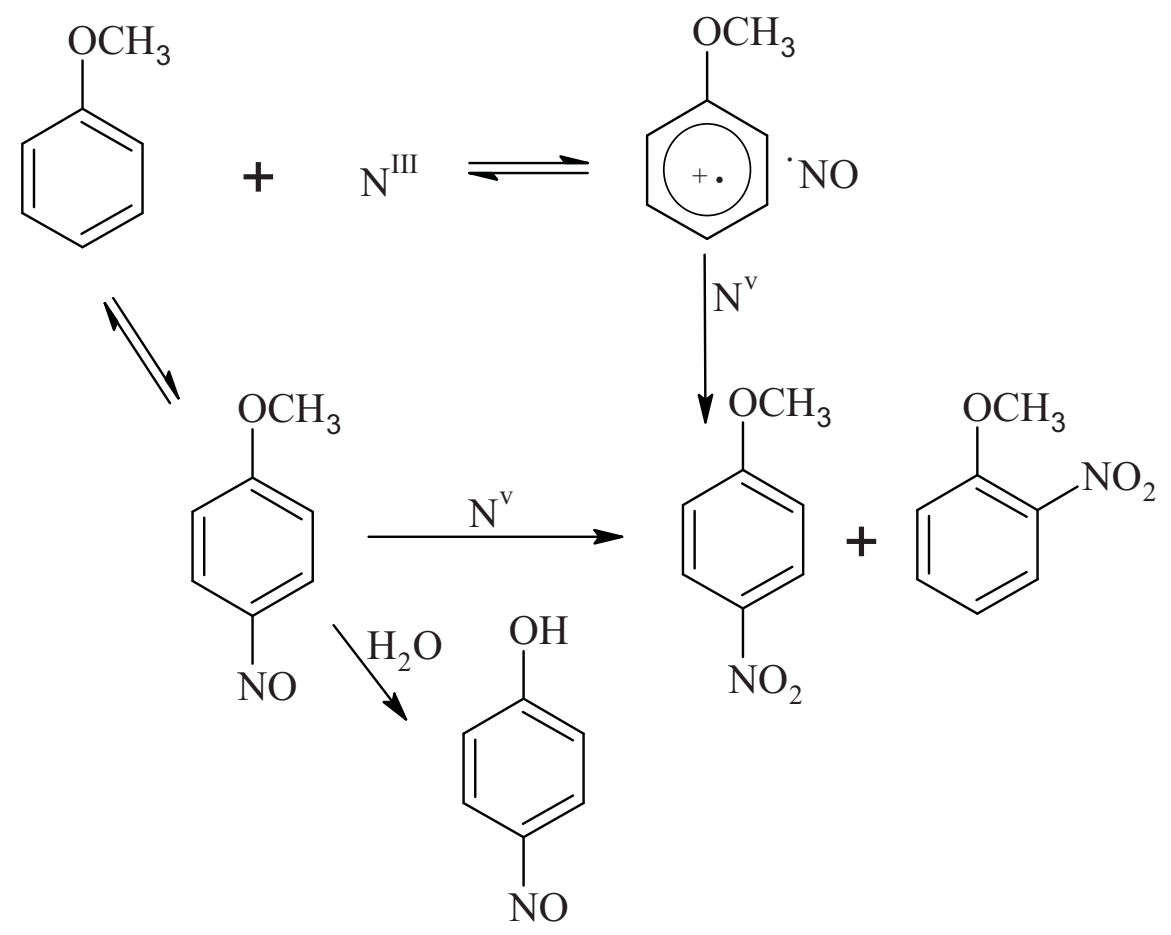

Scheme 1. Nitrous acid-catalyzed electrophilic substitution mechanism in anisole ${ }^{[29]}$

As can be seen in Scheme 1, nitrosation by $\mathrm{N}^{\mathrm{III}}$ is followed by oxidation by $\mathrm{N}^{\mathrm{V}}$. This involves a nitrosation-oxidation pathway at low acidities (in the presence of $\mathrm{H}_{2} \mathrm{O}$ ) giving p-nitrophenol as a major product. At higher acidities, a pathway involving the aromatic radical cation species produces the nitroanisoles.

In this process, the step in which $\mathrm{N}^{\mathrm{v}}\left(\mathrm{HNO}_{3}\right)$ acts as an oxidant can be ratelimiting. Para-nitroanisole results from the nitrosation-oxidation pathway, by oxidation of p-nitroso anisole. Hydrolysis and demethylation of p-nitrosoanisole form $\mathrm{p}$ nitrophenol. It could be argued that the p-nitrosoanisole from this pathway would account for some of the p-nitroanisole obtained and that o-nitroanisole would be formed by direct nitration by nitronium ion at the higher acidities. However, a consideration of the rates of nitration of anisole in the absence of nitrous acid under these conditions 
suggests that only a small fraction $(<10 \%)$ of the ortho isomer obtained actually comes via nitration by nitronium ion ${ }^{[29]}$

Mixed ${ }^{\circ} \mathrm{NO}_{3} /{ }^{\circ} \mathrm{NO}_{2}$ reactions of toluene and anisole in the presence of acid may also produce the aromatic radical cation and give ortho/para nitro products (Kyodai nitration). ${ }^{[31]}$ In Kyodai nitration, a ${ }^{\circ} \mathrm{NO}_{3}$ mediated cyclohexadienyl ion adds ${ }^{\circ} \mathrm{NO}_{2}$ to form the nitroaromatic compound.

Kinetic study of the nitrosation reactions of phenol and phenolic compounds shows that the reactivity of these nitrosatable substrates appears to depend on three main structural factors: ${ }^{[46]}$ (i) the preferred para-orientation of the hydroxyl group of phenol for the electrophilic attack of $\mathrm{NO}^{+} / \mathrm{NO}_{2} \mathrm{H}_{2}{ }^{+}$nitrosating agents, (ii) the hyperconjugative effect of any methyl substituents, which causes electronic charge to flow into the aromatic nucleus, as well as the opposite electron withdrawing effect of any halogen substituents, and (iii) the steric hindrance of any alkyl substituents flanking the active site of nitrosation, which reduces or even prevents nitrosation. ${ }^{[46]}$

Electrophilic $\mathrm{NO}_{2}{ }^{+}$and nitronium "carriers" $\mathrm{NO}_{2} \mathrm{Y}$ such as nitric acid, acetyl nitrate, dinitrogen pentoxide, nitryl chloride, N-nitropyridinium, tetranitromethane, etc. with $\mathrm{Y}=\mathrm{OH}^{-}, \mathrm{OAc}^{-}, \mathrm{NO}_{3}{ }^{-}, \mathrm{Cl}^{-}, \mathrm{Py}^{-}$, and $\mathrm{C}\left(\mathrm{NO}_{2}\right)_{3}{ }^{-}$, respectively are all electron deficient and thus capable of serving as effective electron acceptors in common with other nitro compounds. ${ }^{[34]}$ Electron donor acceptor (EDA) complexes can be formed with different types of electron-rich donors including aromatic hydrocarbons shown in equation 32-35 in photophysical and photochemical processes, where $\mathrm{K}_{\mathrm{EDA}}$ is the equilibrium constant for the EDA complex reactions and $\mathrm{h} v_{\mathrm{CT}}$ is the charge transfer excitation of aromatic EDA complexes. ${ }^{[33]}$ Such EDA complexes are frequently referred to as charge-transfer 
(CT) complexes, since they are often colored and exhibit intermolecular absorption bands that have been spectroscopically characterized by Mulliken. ${ }^{[47,48]}$
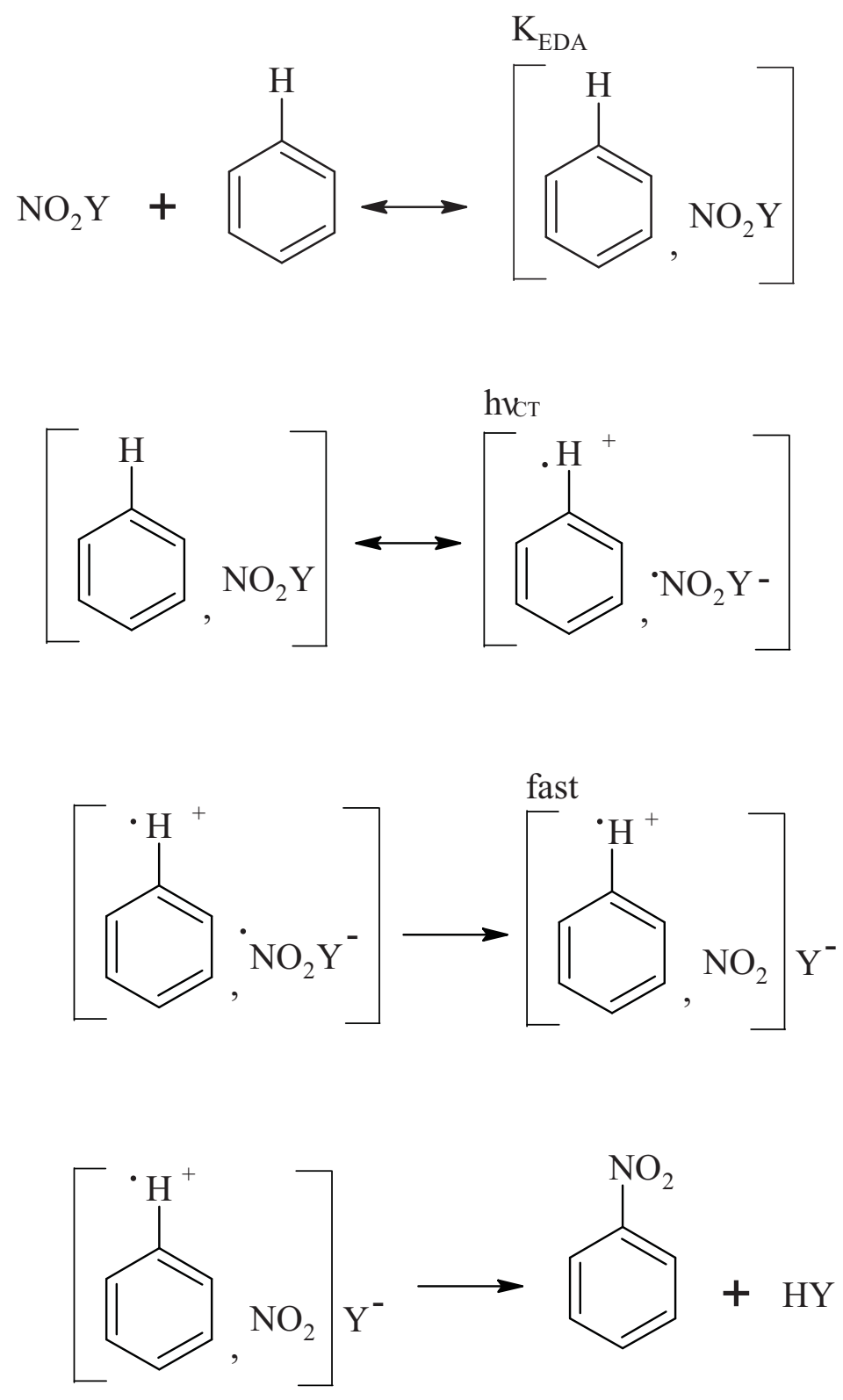

The same concept can also be used for nitrosonium ion $\left(\mathrm{NO}^{+}\right) \cdot{ }^{[33]}$ Boughriet et al. also discuss the inner-sphere electron transfer/charge transfer concept of $\mathrm{NO}_{2}{ }^{+}$and 
$\mathrm{NO}^{+} \cdot{ }^{[10]}$ According to Kochi, ${ }^{[33]}$ demethylation of the methoxy group in anisole to afford nitrophenols is through the charge transfer mechanism.

\subsection{Free-radical Nitrations}

\subsubsection{Radiolysis}

A high-energy photon or electron $(\mathrm{keV}-\mathrm{MeV})$ is capable of initiating thousands of secondary reactions as it deposits energy. On the order of $10^{-7} \mathrm{sec}$ after a low linear energy transfer (LET) particle such as an x-ray, $\gamma$-ray, or electron ( $\beta^{-}$particle) passes through neutral water, the species shown in equation 36 exist in a homogenous distribution. $^{[49]}$

$$
\mathrm{H}_{2} \mathrm{O}-\mathrm{W} \rightarrow[0.28]^{\circ} \mathrm{OH}+[0.27] \mathrm{e}_{\mathrm{aq}}^{-}+[0.06]^{\circ} \mathrm{H}+[0.07] \mathrm{H}_{2} \mathrm{O}_{2}+[0.27] \mathrm{H}_{3} \mathrm{O}^{+}+
$$

[0.05] $\mathrm{H}_{2}$

The efficiency of conversion of radiation energy to chemical products is defined as the $G$ value $\left(\mu \mathrm{mol} \mathrm{J} \mathrm{J}^{-1}\right)$, given in brackets in equation 36 .

Massive, highly charged particles such as $\alpha$-particles have short ranges and higher LET and therefore deposit energy in local regions of high radical concentrations. This allows many to undergo recombination resulting in higher yields of molecular species and lower yields of radicals. The types of species produced are the same, but their yields are different. $^{[50]}$

Flash photolysis has been well-known for many years as a very powerful means to detect and observe transient phenomena in photochemistry. In radiation research, high-energy ionizing radiation is used as the irradiation source instead of a light source. Therefore, not only excitation but also ionization and super excitation can be caused by high-energy radiation. Pulse radiolysis techniques make it possible to detect transient 
species generated by ionizing radiation including ions, radicals and excited states. A short pulse of ionizing radiation is introduced to a sample cell to generate excited states, ions, and radicals, which are directly or indirectly detected and observed by various methods before the disappearance of these active entities. This is the essential feature of the "pulse radiolysis" method. ${ }^{[51]}$ Pulse radiolysis is used to study reactions occurring on timescales faster than approximately $10^{-4}-10^{-3} \mathrm{~s}$; the optimum is between $10^{-9}$ and $10^{-3}$ $\mathrm{S}^{[52]}$ after energy absorption. The experimental techniques which have been used to monitor fast reactions following pulse radiolysis include optical absorption spectroscopy and light scattering, time-resolved electrical conductivity, polarography, and electron spin resonance spectroscopy. ${ }^{[10]}$

In electron pulse radiolysis, the technique involves exposing a sample of material to a beam of highly accelerated electrons, where the beam is generated by a linear accelerator (LINAC). The ${ }^{\circ} \mathrm{NO}_{2}$ and ${ }^{\circ} \mathrm{NO}_{3}$ radicals generated during radiolysis and ${ }^{\circ} \mathrm{NO}_{3}$ radicals generated during photolysis have been studied in nitrate and nitric acid solutions. ${ }^{[23]}$ In a pulse radiolysis study of aqueous nitric acid and nitrate solutions, a fast process completed during the electron pulse and a slow one occurring on the microsecond time range were observed for the generation of the $\mathrm{NO}_{3}$ radical. ${ }^{[53]}$ The fast one was observed both in nitric acid and nitrate salt solution and the slow one only in nitric acid. The fast one is a result of nitrate ion direct radiolysis as in equation 37 and the slow one is due to the indirect reaction of radiolytically-produced ${ }^{\circ} \mathrm{OH}$ radicals with undissociated nitric acid as shown in equation $38 .^{[54]}$

$$
\begin{gathered}
\mathrm{NO}_{3}^{-}--\mathrm{WM}^{-} \rightarrow \mathrm{e}_{\mathrm{aq}}^{-}+{ }^{\circ} \mathrm{NO}_{3} \\
\mathrm{HNO}_{3}+{ }^{\circ} \mathrm{OH} \rightarrow{ }^{-} \mathrm{NO}_{3}+\mathrm{H}_{2} \mathrm{O} \quad k_{38}=1.3 \times 10^{8} \mathrm{M}^{-1} \mathrm{~s}^{-1}
\end{gathered}
$$


The transient absorption spectrum of the $\mathrm{NO}_{3}$ radical with a maximum absorbance at $640 \mathrm{~nm}$ was found only in nitric acid at a concentration above $0.05 \mathrm{M} \mathrm{HNO}_{3}$ and not in neutral and alkaline nitrate salt solutions. Instead, the transient absorption spectrum of the $\mathrm{NO}_{2}$ radical with a maximum at $400 \mathrm{~nm}$ was found in these solutions. ${ }^{[54]}$ In acidic nitrate solutions, the yield of ${ }^{\circ} \mathrm{NO}_{3}$ radical increased compared to neutral nitrate solution. $^{[55]}$

The most reactive water radiolysis species produced are the oxidizing hydroxyl radical $\left({ }^{\circ} \mathrm{OH}\right)$ and hydrogen peroxide $\left(\mathrm{H}_{2} \mathrm{O}_{2}\right)$ and the reducing aqueous electron $\left(\mathrm{e}^{-}{ }_{\mathrm{aq}}\right)$ and hydrogen atom $\left({ }^{\circ} \mathrm{H}\right)$ (equation 36). However, whether an irradiated aqueous system is predominantly oxidizing or reducing depends on solution characteristics such as its $\mathrm{pH}$, concentration of dissolved oxygen, and the presence of other solutes that scavenge these primary species. Under the acidic, aerated conditions of the nuclear solvent extraction process, the aqueous electrons produced would be scavenged according to the fast reactions in equation 39 and $40 .{ }^{[56]}$

$$
\begin{array}{ll}
\mathrm{e}_{\mathrm{aq}}^{-}+\mathrm{H}^{+} \rightarrow{ }^{\circ} \mathrm{H} & k_{39}=2.3 \times 10^{10} \mathrm{M}^{-1} \mathrm{~s}^{-1} \\
\mathrm{e}_{\mathrm{aq}}^{-}+\mathrm{O}_{2} \rightarrow{ }^{\cdot} \mathrm{O}_{2}^{-} & k_{40}=1.9 \times 10^{9} \mathrm{M}^{-1} \mathrm{~s}^{-1}
\end{array}
$$

Thus, irradiated acidic solutions are oxidizing environments, especially in the presence of oxygen.

Additional radical types are produced by nitric acid radiolysis. The direct radiolysis of nitrate anion produces $\mathrm{NO}_{3}$ as shown in equation $37 .{ }^{[53]}$ However, the nitrate ion may also capture electrons, to produce a divalent anion which hydrolyzes to produce the $\mathrm{NO}_{2}$ in irradiated solution (equation 41 and 42). ${ }^{[57,58]}$

$$
\mathrm{e}^{-}{ }_{\mathrm{aq}}+\mathrm{NO}_{3}^{-} \rightarrow \mathrm{NO}_{3}^{-2} \quad k_{41}=9.7 \times 10^{9} \mathrm{M}^{-1} \mathrm{~s}^{-1}
$$




$$
\mathrm{NO}_{3}{ }^{-2}+\mathrm{H}^{+} \rightarrow \mathrm{NO}_{2}+\mathrm{OH}^{-} \quad k_{42}=2 \times 10^{10} \mathrm{M}^{-1} \mathrm{~s}^{-1}
$$

While the addition of nitrogen-centered free-radicals to aromatic rings is known from the gas phase, condensed phase reaction mechanisms are less certain. Reaction of ${ }^{\circ} \mathrm{NO}_{2}$ and ${ }^{\circ} \mathrm{NO}_{3}$ radicals may be merely another source of $\mathrm{NO}_{2}{ }^{+}$ion (equation 43). ${ }^{[53,59]}$

$$
\mathrm{NO}_{3}+{ }^{-} \mathrm{NO}_{2} \rightarrow \mathrm{N}_{2} \mathrm{O}_{5} \rightarrow \mathrm{NO}_{3}{ }^{-}+\mathrm{NO}_{2}^{+} \quad k_{43}=1.7 \times 10^{9} \mathrm{M}^{-1} \mathrm{~s}^{-1}
$$

$\mathrm{N}_{2} \mathrm{O}_{4}$, the addition product of ${ }^{\circ} \mathrm{NO}_{2}$, is another source of $\mathrm{NO}_{2}^{+}$(equation 28).

The direct radiolysis of nitric acid also produces the $\mathrm{NO}_{3}$ radical, as shown in equation $44 .^{[55]}$

$$
\mathrm{HNO}_{3}--\mathrm{WW}_{\rightarrow} \mathrm{H}^{+}+\mathrm{e}^{-}{ }_{\mathrm{aq}}+{ }^{\cdot} \mathrm{NO}_{3} /{ }^{\circ} \mathrm{H}+{ }^{\circ} \mathrm{NO}_{3}
$$

The concentration of ${ }^{\circ} \mathrm{NO}_{3}$ produced by direct radiolysis is limited by the concentration of nitric acid. The $\mathrm{NO}_{3}$ is also produced via reaction of nitric acid with the hydroxyl radical product of water radiolysis as was shown in equation $38 .{ }^{[7,60]}$ The importance of this reaction in producing $\mathrm{NO}_{3}$ is evidenced by its much higher formation in nitric acid solution than in nitrate salt solutions. ${ }^{[7]}$ The aqueous electron product reacts rapidly with nitrate anion, as shown in equation 41 to produce the nitrogen trioxide radical anion. ${ }^{[61]}$ The nitrogen trioxide radical anion undergoes rapid hydrolysis as shown in equation 42 and 45 and is thus not available for reaction under acidic conditions. ${ }^{[57,62,63]}$

$$
\mathrm{NO}_{3}{ }^{-2}+\mathrm{H}_{2} \mathrm{O} \rightarrow{ }^{\circ} \mathrm{NO}_{2}+2 \mathrm{OH}^{-} \quad k_{45}=1 \times 10^{5} \mathrm{M}^{-1} \mathrm{~s}^{-1}
$$

However, the nitrite radical, the hydrolysis product of equation 42 and 45, can also react with solutes under the acidic conditions of interest here.

The hydrogen atom product also reacts with oxygen as shown in equation $46 .^{[64]}$

$$
{ }^{\circ} \mathrm{H}+\mathrm{O}_{2} \rightarrow{ }^{\circ} \mathrm{HO}_{2} \quad k_{46}=2.1 \times 10^{10} \mathrm{M}^{-1} \mathrm{~s}^{-1}
$$


The products of equation 40 and 46 are the superoxide radical anion and its conjugate acid, which exist as their protonated form in equation 47.

$$
{ }^{\cdot} \mathrm{HO}_{2}+\mathrm{H}^{+} \rightarrow{ }^{\cdot} \mathrm{H}_{2} \mathrm{O}_{2}^{+} \quad \mathrm{pKa} \sim 1.2
$$

Thus, a moderately concentrated aqueous nitric acid solution produces the radical products ${ }^{\circ} \mathrm{NO}_{3},{ }^{\circ} \mathrm{NO}_{2}$, and ${ }^{\circ} \mathrm{H}_{2} \mathrm{O}_{2}{ }^{+}$. As acidity is decreased below $6 \mathrm{M}$ nitric acid, the presence of hydroxyl radical becomes more important because of the less availability of $\mathrm{HNO}_{3}$ for equation 38. There are only few available references to reactions of the protonated superoxide radical anion conjugate acid $\left(\mathrm{CH}_{2} \mathrm{O}_{2}{ }^{+}\right)$, although it is likely to be a strong oxidizing agent. ${ }^{[65]}$

The literature contains many examples of the radiolytic nitration of organic compounds under acidic conditions. For example, it is well-known that tri-n-butyl phosphate (TBP), the most common ligand used in nuclear solvent extraction applications, reacts under irradiation to produce nitrated derivatives. ${ }^{[66]}$ Similarly, the alkane diluents such as dodecane used in TBP extractions add nitrite and nitrate groups under radiolysis, which interfere with back extraction of the actinides, and result in decreased separation factors from fission products. ${ }^{[67,68]}$ In recent work on the calixarenes used for cesium extraction from radioactive solutions, nitration of phenyl groups has been shown to occur based on mass spectrometric analysis. ${ }^{[15]}$ This radiolytically induced reaction decreases extraction efficiency of Cs.

\subsubsection{Possible Nitration Mechanisms with Nitrogen Trioxide Radical}

Despite the obvious importance of nitration in these irradiated acidic systems, very little is known about the mechanisms of these reactions. For the nitrogen trioxide radical, three possible reaction mechanisms with organic molecules in the condensed 
phase have been suggested. They are hydrogen abstraction, addition, and electron transfer, as shown in equation 48,49 , and 50 , respectively. ${ }^{[7]}$

$$
\begin{array}{ll}
\mathrm{CH}_{3} \mathrm{CH}_{2} \mathrm{OH}+{ }^{\circ} \mathrm{NO}_{3} \rightarrow \mathrm{CH}_{3}{ }^{\circ} \mathrm{CHOH}+\mathrm{HNO}_{3} & k_{48}=1.4 \times 10^{6} \mathrm{M}^{-1} \mathrm{~s}^{-1} \\
\mathrm{CH}_{2}=\mathrm{CHCONH}_{2}+{ }^{-\mathrm{NO}_{3} \rightarrow \mathrm{CH}_{2} \mathrm{NO}_{3}{ }^{\cdot} \mathrm{CHCONH}}{ }_{2} & k_{49}=3.4 \times 10^{6} \mathrm{M}^{-1} \mathrm{~s}^{-1} \\
\mathrm{C}_{6} \mathrm{H}_{5} \mathrm{OCH}_{3}+{ }^{-} \mathrm{NO}_{3} \rightarrow{ }^{\cdot}\left[\mathrm{C}_{6} \mathrm{H}_{5} \mathrm{OCH}_{3}\right]^{+}+\mathrm{NO}_{3}{ }^{-} & k_{50}=3.2 \times 10^{9} \mathrm{M}^{-1} \mathrm{~s}^{-1}
\end{array}
$$

The reaction with aromatic ring-containing anisole in equation 50 was predicted by Neta and Huie ${ }^{[7]}$ to undergo electron transfer with the fast rate constant shown. However, based on the addition reaction with acrylamide shown in equation 49 , it is possible that ${ }^{\circ} \mathrm{NO}_{3}$ radical would also add to phenyl rings. Alternately, the addition of ${ }^{\circ} \mathrm{NO}_{3}$ radical to aromatic carbon-centered radicals (equation 51), produced by other radiolytic processes, is also likely.

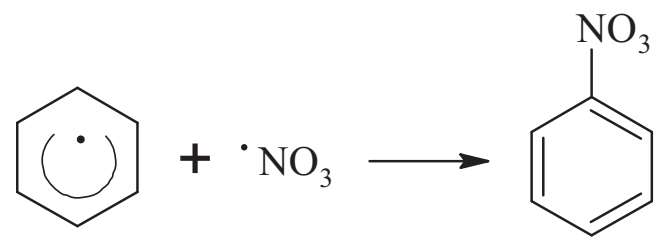

This is analogous to the $\mathrm{NO}_{2}$ addition reaction shown in equation 13 . This radical addition reaction requires prior creation of a carbon-centered radical, which occurs as shown in equation 52 , where ${ }^{\circ} \mathrm{X}$ may be ${ }^{\circ} \mathrm{OH},{ }^{\circ} \mathrm{H},{ }^{\circ} \mathrm{NO}_{2}$, or ${ }^{\circ} \mathrm{NO}_{3}$. However, as was

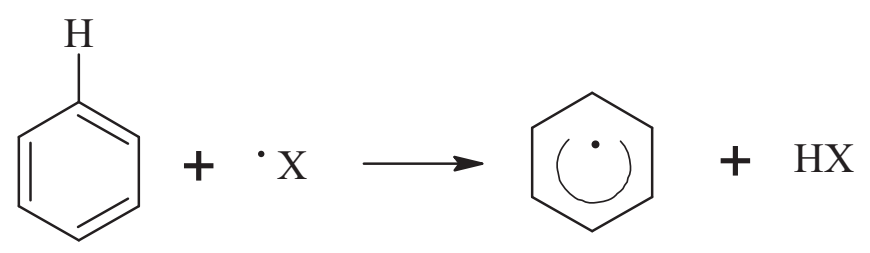

mentioned previously, the $\mathrm{NO}_{3}$-substituted ring would not be a stable product and requires reduction to produce a nitro-species. 


\subsubsection{Possible Nitration Mechanisms with Nitrite Radical}

Although little work has been done with nitrite radical, similar reactions can be postulated for its reaction with aromatic compounds, equation 12, 10, and 53 and 13.

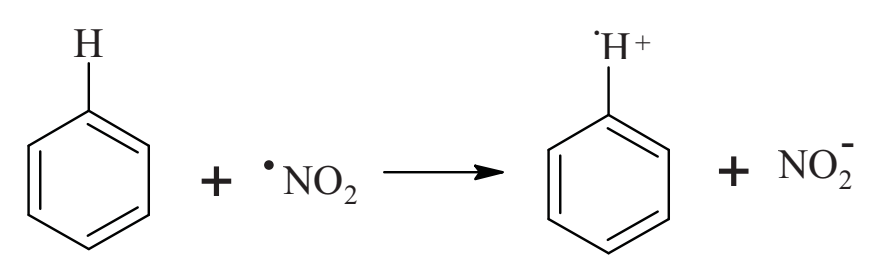

The radical products of equation 12 and 10, stabilize through loss or acquisition of a hydrogen atom, while the radical cation product of equation 53 stabilizes by charge transfer forming the final nitrated aromatic compound in equation 13. If the reaction shown in equation 51 occurs, subsequent reactions of the product may also result in nitrated aromatic compounds, but require a mechanism for loss of an oxygen atom from the $\mathrm{NO}_{3}$ group.

\subsubsection{Suggested Nitration Mechanisms with Superoxide Radical}

Another source of reactive nitrogen oxide cations is from free-radical reactions suggested by the presence of the strongly oxidizing superoxide radical anion conjugate acid product of equation 47. Oxidation of the nitrogen-centered radicals, with the production of the corresponding cation is shown in equation 54.

$$
{ }^{\circ} \mathrm{H}_{2} \mathrm{O}_{2}{ }^{+}+{ }^{-} \mathrm{NO}_{\mathrm{x}} \rightarrow \mathrm{H}_{2} \mathrm{O}_{2}+\mathrm{NO}_{\mathrm{x}}{ }^{+}
$$

This pathway could be extremely important since as discussed before, $\mathrm{NO}_{\mathrm{x}}{ }^{+}$reacts with aromatic rings to directly nitrate them. Another possible route is shown in equation 5557.

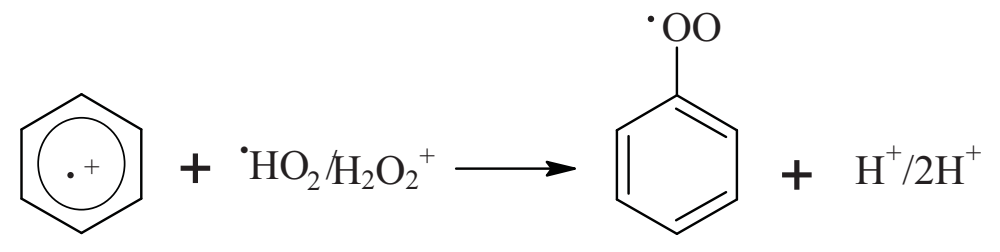




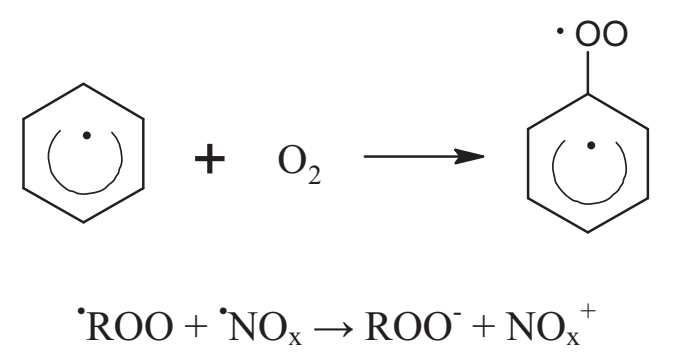

Peroxyl radicals (of the general form ${ }^{\circ}$ ROO) react via a number of mechanisms, including possibly by reaction with nitrogen-containing radicals as shown in equation 57 . The reaction of peroxyl radicals with cyclic nitroxides such as 2,2,6,6-tetramethylpiperidinyl1-oxy free radical has been reported. ${ }^{[69]}$ Vione et al. discuss nitration induced by peroxynitrous acid, HOONO with benzene, naphthalene ${ }^{[70]}$ and phenol ${ }^{[5]}$ under irradiation. The reaction mechanisms for the nitro products were found to be comparable for benzene and naphthalene, but are slightly different for phenol ${ }^{[8]}$ because hydroxyl radical scavengers decreased nitrophenol production. These scavengers did not inhibit the photonitration of benzene or naphthalene, suggesting an ${ }^{\circ} \mathrm{OH}$ radical mediated nitration of phenol.

\subsubsection{Examples of Free-radical Reactions}

Possible photochemical sources of ${ }^{\circ} \mathrm{NO}_{2}$ in the environment are by nitrate and nitrite UV photolysis. The unstable ${ }^{\circ} \mathrm{NO}_{2}$ in aqueous solution undergoes dimerization and hydrolysis, forming $\mathrm{N}_{2} \mathrm{O}_{4}$ (equation 3), nitrite and nitrate anions (equation 28, 29) and $\mathrm{H}^{+}$. Nitrite photolysis is a source of ${ }^{\circ} \mathrm{OH}$ (equation 59-60). Nitrite is also a sink for the same radical as shown in equation $58 .{ }^{[71]}$

$$
\begin{gathered}
{ }^{\circ} \mathrm{OH}+\mathrm{NO}_{2}^{-} \rightarrow{ }^{-\mathrm{NO}_{2}}+\mathrm{OH}^{-} \quad k_{58}=1.1 \times 10^{10} \mathrm{M}^{-1} \mathrm{~s}^{-1} \\
\mathrm{NO}_{2}^{-}+\mathrm{h} v \rightarrow{ }^{\circ} \mathrm{NO}+{ }^{\cdot} \mathrm{O}^{-}
\end{gathered}
$$




$$
\mathrm{O}^{-}+\mathrm{H}^{+} \leftrightarrow \cdot \mathrm{OH}
$$

The steady state values of ${ }^{\circ} \mathrm{NO}_{2}$ and ${ }^{\circ} \mathrm{OH}$ are an order of magnitude higher for fog and cloud water compared to sea water because of the photolysis of nitrite and nitrate in the atmosphere ${ }^{[72]}$ Accordingly, photonitration induced by nitrate and nitrite could account for over $10 \%$ of the 4-nitrophenol occurring in atmospheric waters. Additionally, the powerful phototoxic agent 2, 4-dinitrophenol would mainly arise on mononitrophenol photonitration by ${ }^{\circ} \mathrm{NO}_{2}$ in cloud water. ${ }^{[72]}$ Phenol nitration in acidic nitrite solutions is due to thermal processes involving $\mathrm{HNO}_{2}$. The thermal processes largely prevailed over the phenol nitration by photolysis of nitrous acid, the photolysis is shown in equation 61-62 and the thermal decomposition is shown in equation $63 .{ }^{[73]}$

$$
\begin{gathered}
\mathrm{HNO}_{2}+\mathrm{h} v \rightarrow{ }^{\circ} \mathrm{NO}+{ }^{\circ} \mathrm{OH} \\
\mathrm{HNO}_{2}+{ }^{\circ} \mathrm{OH} \rightarrow{ }^{\circ} \mathrm{NO}_{2}+\mathrm{H}_{2} \mathrm{O} \\
2 \mathrm{HNO}_{2} \rightarrow{ }^{\circ} \mathrm{NO}+{ }^{\circ} \mathrm{NO}_{2}+\mathrm{H}_{2} \mathrm{O}
\end{gathered}
$$

Thus, the thermal decomposition of $\mathrm{HNO}_{2}$ is a much more important source of nitrogen dioxide than photolysis, as illustrated by the enhancement of 4-nitrophenol (4NOP) formation rate at acidic $\mathrm{pH}$. The reaction happens between phenol and $\mathrm{N}_{2} \mathrm{O}_{3}$, and the latter forms from ${ }^{\mathrm{NO}}$ and $\mathrm{NO}_{2}$ as shown in equation 30 . Thus the thermal reaction enhances phenol nitrosation as it enhances production of $\mathrm{N}_{2} \mathrm{O}_{3}$. Another possible explanation of nitrophenol formation in an acidic medium is that $\mathrm{HNO}_{2}$ or $\mathrm{N}_{2} \mathrm{O}_{3}\left(\mathrm{~N}^{\mathrm{III}}\right.$ species) reacts with phenol without photolysis such as the nitrous acid-catalyzed nitration of phenol. Scheme 2 shows the effect $\mathrm{HNO}_{2}$ on phenol in photonitration. ${ }^{[73]}$ 

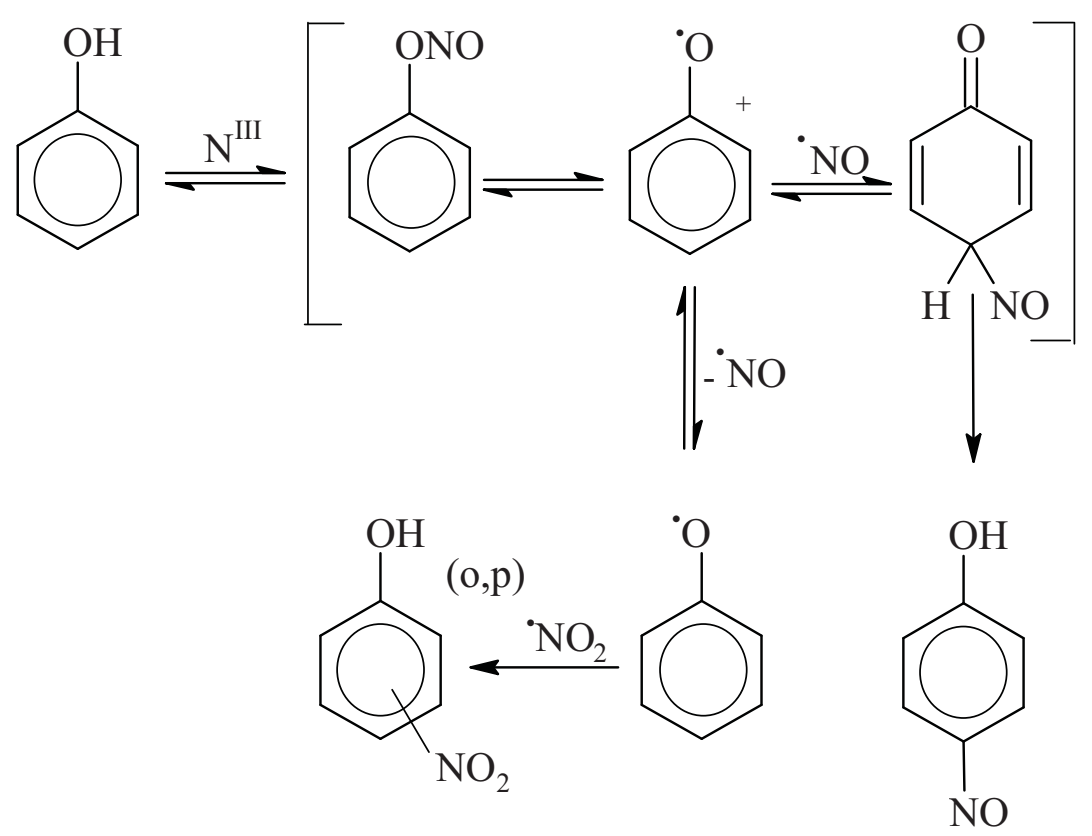

Scheme 2. Mechanism of the nitrous acid catalyzed nitration of phenol

Nitrate and nitrite have a role in the production of ${ }^{\circ} \mathrm{OH}$ in surface waters at different seasons and times of the day (equations 64 and 65). ${ }^{[74]}$

$$
\begin{aligned}
& \mathrm{NO}_{3}{ }^{-}+\mathrm{h} v+\mathrm{H}^{+} \rightarrow{ }^{\circ} \mathrm{NO}_{2}+{ }^{\circ} \mathrm{OH} \quad(\mathrm{h} v \text { indicates photolysis }) \\
& \mathrm{NO}_{2}{ }^{-}+\mathrm{h} v+\mathrm{H}^{+} \rightarrow{ }^{\circ} \mathrm{NO}+{ }^{\circ} \mathrm{OH}
\end{aligned}
$$

Pernitrous acid formed from nitrous acid and hydrogen peroxide undergoes homolytic fission and produces ${ }^{\circ} \mathrm{OH}$ and ${ }^{\circ} \mathrm{NO}_{2}$ radicals. ${ }^{[75]}$ The hydroxyl radical enters the aromatic nucleus in the ortho and para positions and the nitro-group in the meta position, ${ }^{[19]}$ relative to the original substituent as shown in equation 20 . When both hydroxylation and nitration occur, hydroxyl and nitro-groups will be adjacent to one another as shown in equation 66 and 67 . With benzene, these suggestions account satisfactorily for the major products nitrobenzene and o-nitrophenol. Of the toluene products, the 
nitrotoluenes, cresols (equation 66), and different nitrocresols (equation 67) may well result from such reactions. ${ }^{[19]}$<smiles>Cc1ccccc1</smiles><smiles>Cc1ccccc1O</smiles>

Anisole provides an example in which the original substituent is eliminated. It would produce phenol and 2-nitrophenol as shown in Scheme 3 below. ${ }^{[19]}$<smiles>COc1ccccc1OO</smiles>

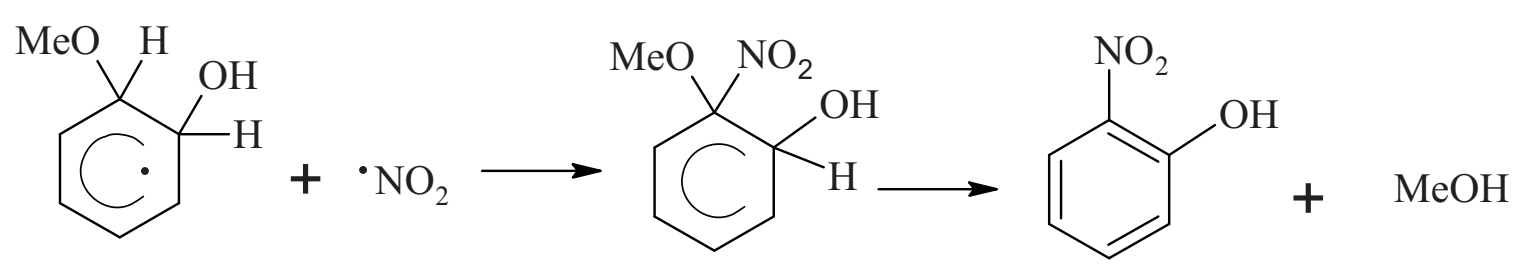

Scheme 3. Reactions of Anisole with ${ }^{\circ} \mathrm{OH}$ and ${ }^{\circ} \mathrm{NO}_{2}$ radicals

Free-radical nitration was discussed by Titov ${ }^{[20]}$ for different organic compounds, mainly toluene. When the nitration mechanism is initiated by ${ }^{\circ} \mathrm{NO}_{2}$, the reaction gives 
rise to a free alkyl radical, $\mathrm{C}_{6} \mathrm{H}_{5} \mathrm{CH}_{2}{ }^{\circ}$ and $\mathrm{HNO}_{2}$. In this case, the $\mathrm{H}$ atom abstraction occurs on the methyl group of toluene rather than the ring. As was shown in equation 63, the

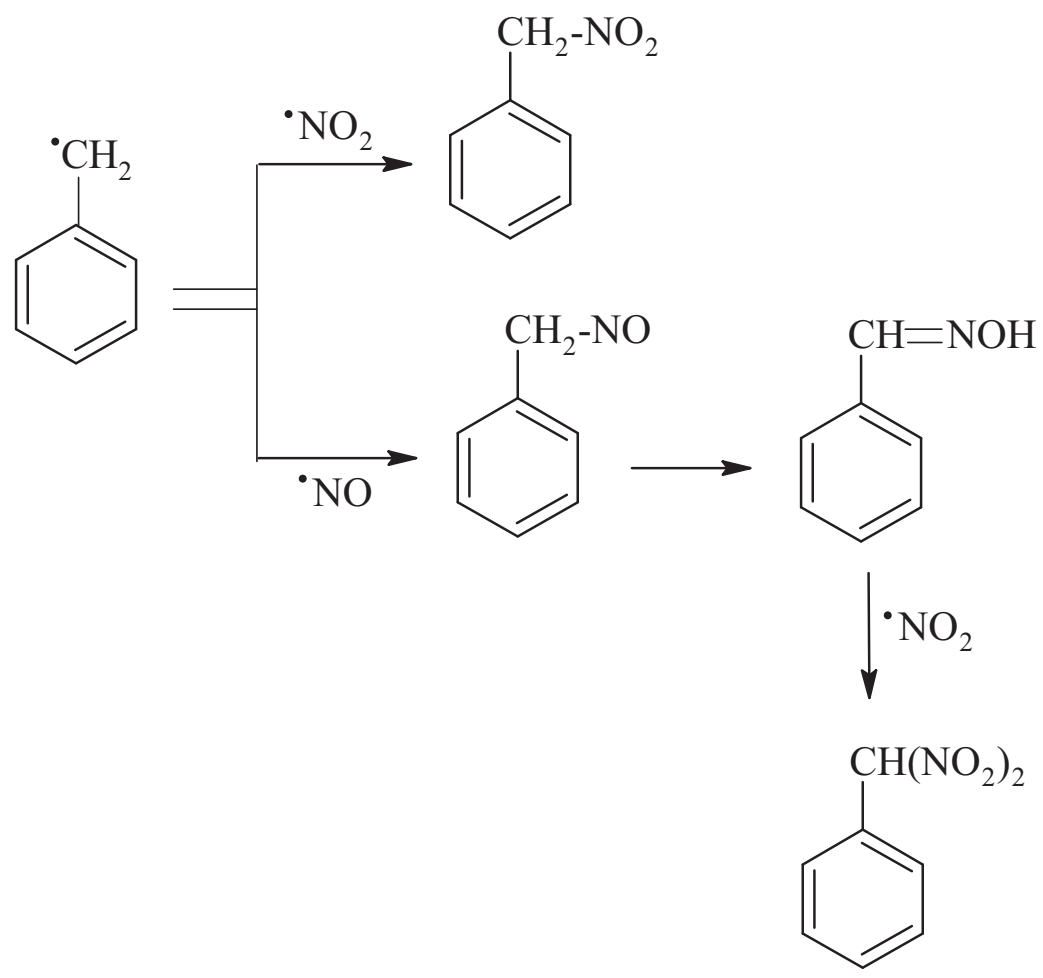

dissociation of $\mathrm{HNO}_{2}$ forms ${ }^{\circ} \mathrm{OH}$ and ${ }^{\circ} \mathrm{NO}$. The possible nitro products of reaction with $\mathrm{C}_{6} \mathrm{H}_{5^{-}}{ }^{\circ} \mathrm{CH}_{2}$ with ${ }^{\circ} \mathrm{NO}$ and ${ }^{\circ} \mathrm{NO}_{2}$ are shown in equation 68 and 69.

The possible products from toluene ring substitution are nitrotoluenes (similar to equation 13), nitrocresols (equation 67), and nitrophenols (similar to scheme 3 ). The possible products from side chain substitution are the products like phenyl nitromethanes (equation 68, and 70) and their oxidation products benzaldehyde, benzoic acid, pnitrobenzoic acid, esters of organic acids, ether, and oximes (equation 69) as described by Titov. ${ }^{[20]}$ Similarly, naphthalene in the presence of ${ }^{\circ} \mathrm{OH}$ and ${ }^{\circ} \mathrm{NO}_{\mathrm{x}}$ radicals produces 
nitronaphthalenes and naphthols. ${ }^{[3]}$ These are analogous to the major aromatic ring containing products observed from toluene.

The $\mathrm{NO}_{3}$ radical is a major atmospheric night time oxidant. It is produced through the reaction of $\mathrm{O}_{3}$ with $\mathrm{NO}_{2}$ as shown in equation 71 .

$$
\mathrm{O}_{3}+{ }^{\cdot} \mathrm{NO}_{2} \rightarrow{ }^{\cdot} \mathrm{NO}_{3}+\mathrm{O}_{2}
$$

The liquid phase reaction produces nitric acid (equation 72$).{ }^{[75]}$

$$
\mathrm{H}_{2} \mathrm{O}_{(\mathrm{liq})}+{ }^{\circ} \mathrm{NO}_{3}(\mathrm{aq}) \leftrightarrow \mathrm{HNO}_{3}(\mathrm{aq})+{ }^{\circ} \mathrm{OH}(\mathrm{aq})
$$

Photodissociation of nitroethane is shown in equation 73 and $74 .^{[76]}$

$$
\begin{gathered}
\mathrm{C}_{2} \mathrm{H}_{5} \mathrm{NO}_{2}+\mathrm{h} v \rightarrow \mathrm{C}_{2} \mathrm{H}_{4}+{ }^{\bullet} \mathrm{HONO} \\
\cdot \mathrm{HONO} \rightarrow{ }^{\cdot} \mathrm{OH}+{ }^{\cdot} \mathrm{NO}
\end{gathered}
$$

Consequently it can be concluded that the chemistry of nitrogen oxide species in the gas and condensed phases is complicated. In an irradiated solution, where conditions favor the production of free-radicals, a suite of radical and ionic nitrating agents compete to nitrate organic solutes.

The goal of this work was to elucidate which species were most important in the nitration reactions of aromatic compounds in irradiated acidic and neutral solutions. This information is not available in the literature, and the results of the work can be applied to nuclear fuel dissolutions, especially to the nitration mechanisms of the Cs-7SB modifier in the FPEX solutions. Furthermore, this information may be used to understand the nitration reactions in the condensed-phase aerosols in the atmosphere and advanced oxidation technology for water treatment. 


\section{Chapter 3}

\section{Experimental}

All experiments in this research were done at the Idaho National Laboratory (INL) except pulse radiolysis, which was done at the U. S. Department of Energy Radiation Laboratory, University of Notre Dame, South Bend, Indiana, and Liquid Chromatography-Mass Spectrometry (LC-MS), which was done at the University of Utah, Salt Lake City, Utah.

\subsection{Steady-State Radiolysis}

Saturated and known concentrations of the reagent-grade neat compounds of anisole and toluene were prepared in $6 \mathrm{M} \mathrm{HNO}_{3}, 6 \mathrm{M} \mathrm{NaNO}_{3}$, and $\mathrm{NaNO}_{2}(0.05,0.1,0.5$ and $1 \mathrm{M}$ ) solutions. The acid, neutral nitrate and neutral nitrite solutions were chosen to maximize production of the ${ }^{\circ} \mathrm{NO}_{3}$ radical or ${ }^{\circ} \mathrm{NO}_{2}$ radical. These solutions were then sparged with $\mathrm{N}_{2}$ to remove oxygen and to provide adequate mixing. Oxygen was eliminated to minimize peroxyl radical formation and subsequent loss of products to ringopening reactions which would lead to decreased concentrations of the nitroaromatic products that were the object of this study. Different concentrations of nitric acid (2 M, 4 $\mathrm{M}$, and $6 \mathrm{M}$ ) were also irradiated to evaluate the production of $\mathrm{HNO}_{2}$. Aliquots of these solutions were irradiated in 1-mL glass vials.

Irradiations were performed using a Nordion Gammacell 220E (Ottawa, Canada) at the INL shown in Fig 3.1, which contains a $20,000 \mathrm{Ci}^{60} \mathrm{Co} \gamma$-source, with a nominal dose rate of $12 \mathrm{kGy} \mathrm{h}^{-1}(1 \mathrm{~Gy}=1$ joule/kg). The samples were exposed in a series of absorbed doses, including an unirradiated control, by varying the duration of exposure to 
the $\gamma$-ray source. Dosimetry was performed using GafChromic (Goleta, CA, USA) radiochromic films, traceable to Fricke ${ }^{[77]}$ dosimetry. The temperature in the irradiator sample chamber was $50{ }^{\circ} \mathrm{C}$ due to gamma heating of the shielding. Sample vials had GafChromic films (2-3) attached to the outside before the irradiation. After irradiation, the optical density of the films was monitored using a UV-Vis absorption spectrophotometer at $510 \mathrm{~nm}$. The irradiation dose was calculated by comparing these optical density values against a calibration curve. The curve was prepared by exposing films for known periods of time at a position with a well-known dose rate based on the primary standard $\mathrm{FeSO}_{4}$ solution (Fricke) ${ }^{[77]}$. Fricke dosimetry is based upon the oxidation of colorless Fe (II) to colored Fe (III) during irradiation. The Fricke dosimeter solution contains $10^{-3} \mathrm{M} \mathrm{Fe}^{\mathrm{II}}$ in $0.4 \mathrm{M} \mathrm{H}_{2} \mathrm{SO}_{4}$. The concentration (c) of $\mathrm{Fe}$ (III) produced by irradiation was calculated using Beer's equation, $\mathrm{A}=\varepsilon \mathrm{cl}$, where $\mathrm{A}$ is the measured absorbance at $303 \mathrm{~nm}, \varepsilon=$ molar absorption coefficient $\left(2174 \mathrm{M}^{-1} \mathrm{~cm}^{-1}\right)$, and 1 is the cell path length, $1 \mathrm{~cm}$. With the known G-value $(\sim 1.62)$ of $\mathrm{Fe}^{\mathrm{III}}$, the dose rate was calculated, where $\mathrm{G}=\mu$ moles $\mathrm{J}^{-1}$. The film calibration curve was thus a plot of absorbed dose as determined by the dose-rate using the Fricke primary standard versus the optical density of the film. 


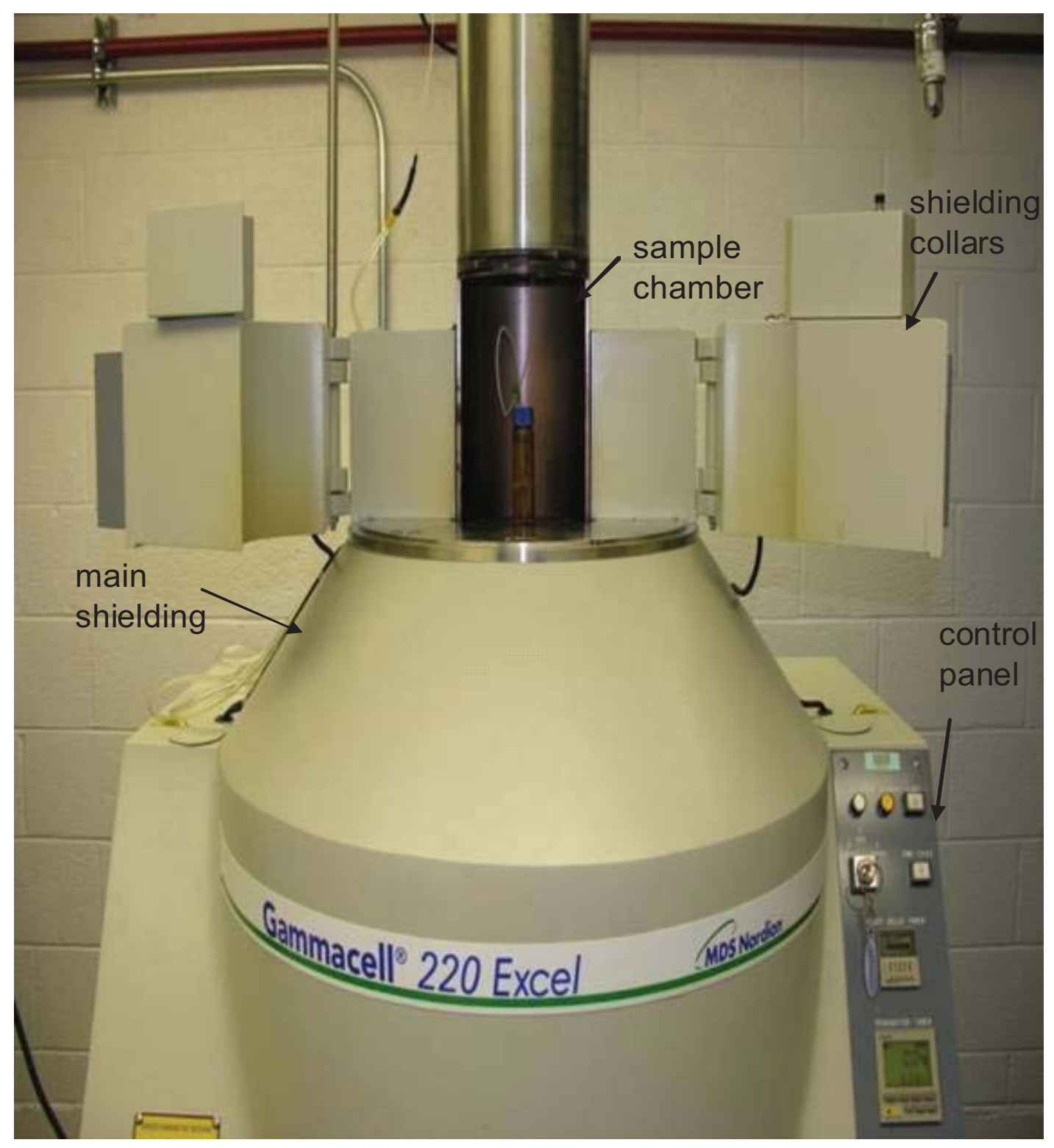

Figure 3.1 Nordion Gammacell 220E 


\subsection{Pulse Radiolysis}

The linear accelerator (LINAC) electron pulse radiolysis system ${ }^{[78]}$ at the Radiation Laboratory, University of Notre Dame, was used for the rate constant determinations. The schematic and photographs of this irradiation and transient absorption detection system are shown in Figure 3.2 (a, b, and c). The sample solution vessels were sparged with a minimum amount of $\mathrm{N}_{2} \mathrm{O}$ gas necessary to prevent air ingress during pulse radiolysis. The use of $\mathrm{N}_{2} \mathrm{O}$ removed oxygen and maximized production of ${ }^{\circ} \mathrm{NO}_{3}$ and ${ }^{\circ} \mathrm{NO}_{2}$ radicals in nitrate or nitrite solution, respectively. It reacts with both the solvated electron and hydrogen atom to give ${ }^{\circ} \mathrm{OH}$ radical, which, in turn, reacts with nitric acid or nitrite to give the appropriate $\mathrm{N}$ radical (equations $75-77)^{[79]}$

$$
\begin{array}{rlr}
\mathrm{N}_{2} \mathrm{O}+\mathrm{e}^{-}{ }_{(\mathrm{aq})}+\mathrm{H}_{2} \mathrm{O} & \rightarrow \mathrm{N}_{2}+\mathrm{OH}^{-}+{ }^{\circ} \mathrm{OH} & k_{75}=9.1 \times 10^{9} \mathrm{M}^{-1} \mathrm{~s}^{-1} \\
\mathrm{H}^{+} \mathrm{N}_{2} \mathrm{O} \rightarrow{ }^{\circ} \mathrm{OH}+\mathrm{N}_{2} & k_{76}=2.1 \times 10^{6} \mathrm{M}^{-1} \mathrm{~s}^{-1} \\
\cdot \mathrm{OH}+\mathrm{NO}_{3}{ }^{-} \rightarrow \mathrm{OH}^{-}+{ }^{-} \mathrm{NO}_{3} & &
\end{array}
$$

Similarly, $\mathrm{NO}_{2}{ }^{-}$forms ${ }^{\circ} \mathrm{NO}_{2}$ by an analogous ${ }^{\circ} \mathrm{OH}$ reaction (equation 58 ).

As shown in Figure 3.2, the $\mathrm{N}_{2} \mathrm{O}$-sparged sample solution flows through the optical cell continuously at a constant flow rate to expose fresh solution to the radiation. The UV-Vis analytical light beam from the xenon lamp and the e-beam from the LINAC are directed into the optical cell in a perpendicular fashion. The light beam from the cell is then directed to the optical spectrophotometer in a different room using proper mirror arrangements. A filter wheel is used for appropriate wavelength selection. The e-beam is pulsed to deliver radiation at 2-5 Gy in several nanoseconds. Following the pulse, the sample is interrogated spectroscopically to follow the decay of transient species absorption. The setup in the LINAC room is observed remotely and the sample flow rate 
and spectrophotometer parameters are controlled remotely. The resultant absorbance spectra of the species of interest from the sample and the rate of product formation/decay at a selected wavelength are monitored on a computer screen in the control room. All data are stored in the computer for the calculation of the rate constants.

Dosimetry was performed using $\mathrm{N}_{2} \mathrm{O}$-saturated, $1.00 \times 10^{-2} \mathrm{M}$ KSCN solutions at $\lambda=$ $475 \mathrm{~nm}^{[77]}$ using average doses of 3-5 Gy per 2-3 ns pulse. Absorbance due to $(\mathrm{SCN})_{2}{ }^{-}$ $(475 \mathrm{~nm})$ was measured at the end of the pulse. $(\mathrm{SCN})_{2}{ }^{-}$has a strong absorption band with $\lambda_{\max }=475 \mathrm{~nm}$ and was produced by:

$$
{ }^{\circ} \mathrm{OH}+\mathrm{SCN}^{-}+\left(\mathrm{SCN}^{-}\right) \rightarrow{ }^{\cdot}(\mathrm{SCN})_{2}^{-}+\mathrm{OH}^{-} \quad k_{78}=1.05 \times 10^{10} \mathrm{M}^{-1} \mathrm{~s}^{-1}
$$

with the known value of $\mathrm{G} \varepsilon{ }^{\circ}(\mathrm{SCN})_{2}{ }^{-}=(2.59 \pm 0.05) \times 10^{-4} \mathrm{~m}^{2} \mathrm{~J}^{-1}$ at $475 \mathrm{~nm}(\mathrm{G} \varepsilon=$ product of $\mathrm{G}$ value and molar absorption coefficient). A calibration curve was built by measuring the absorbance values at different pulse widths. Since the yield of ${ }^{\circ} \mathrm{OH}$ under these conditions is known, the dose may be calculated since $\mathrm{G} \varepsilon{ }^{\circ}(\mathrm{SCN})_{2}{ }^{-}=\mathrm{G}\left({ }^{\circ} \mathrm{OH}\right)$. The thiocyanate dosimetry was performed every day at the beginning and at the end of the experiments. All kinetics measurements were conducted at a room temperature of $18 \pm 1$ ${ }^{\mathrm{o}} \mathrm{C}$. 


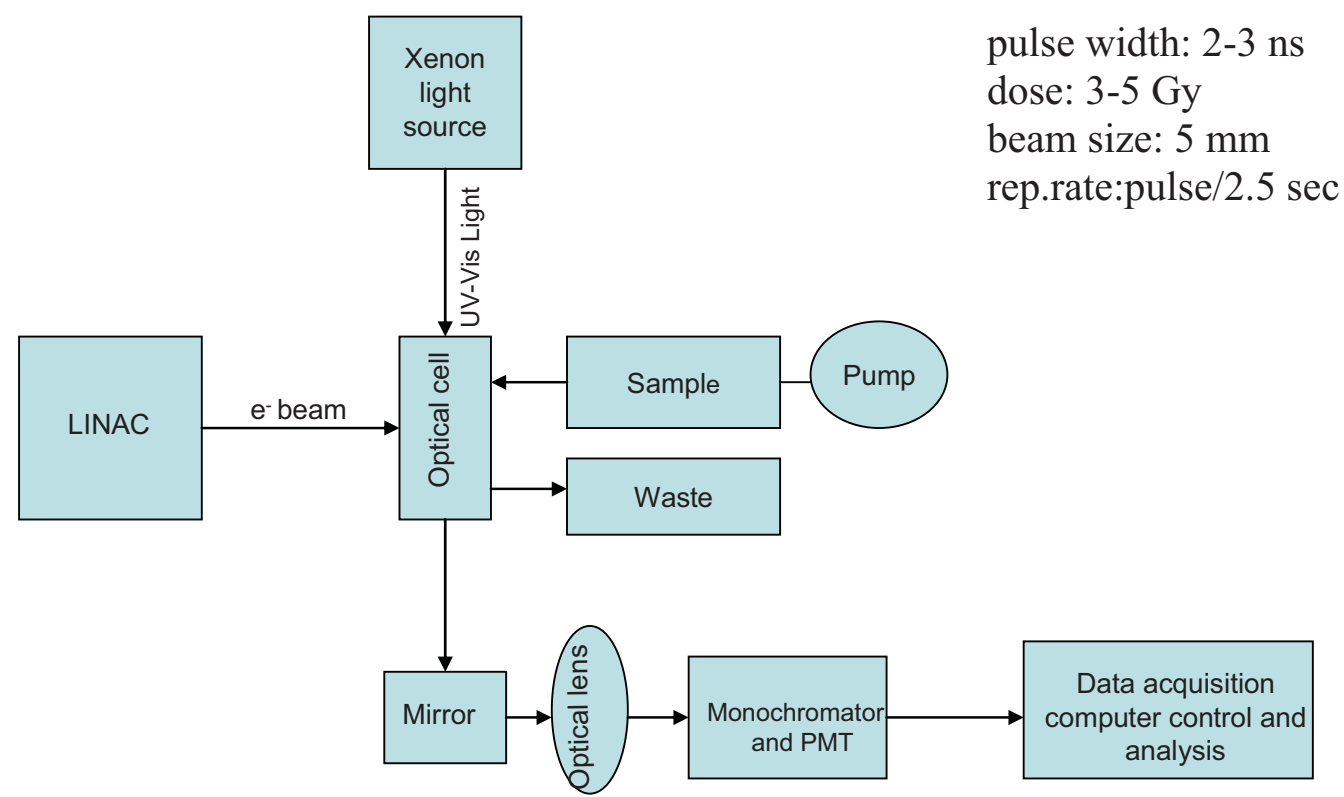

Figure 3.2.a Schematic of the pulse radiolysis set-up-University of Notre Dame

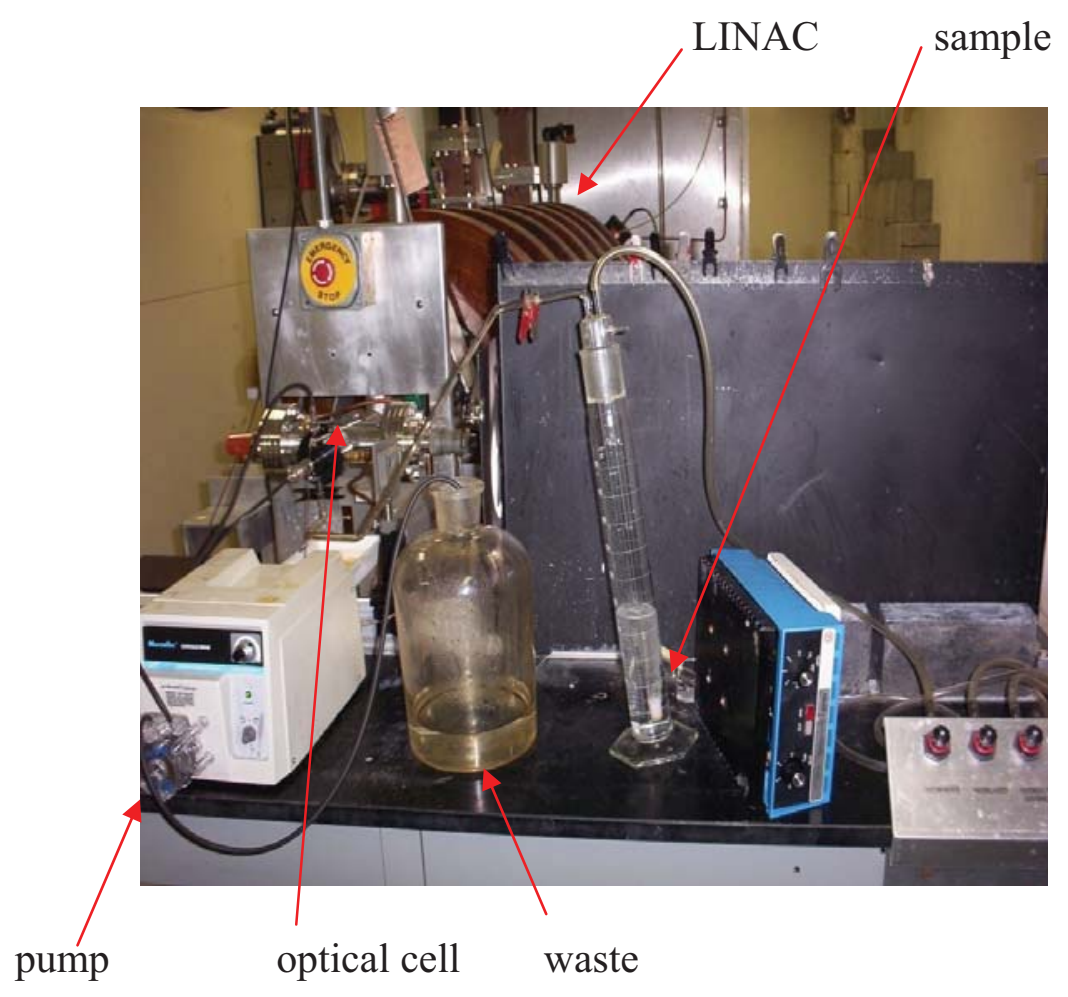

Figure 3.2.b LINAC - Electron Pulse Radiolysis, University of Notre Dame 


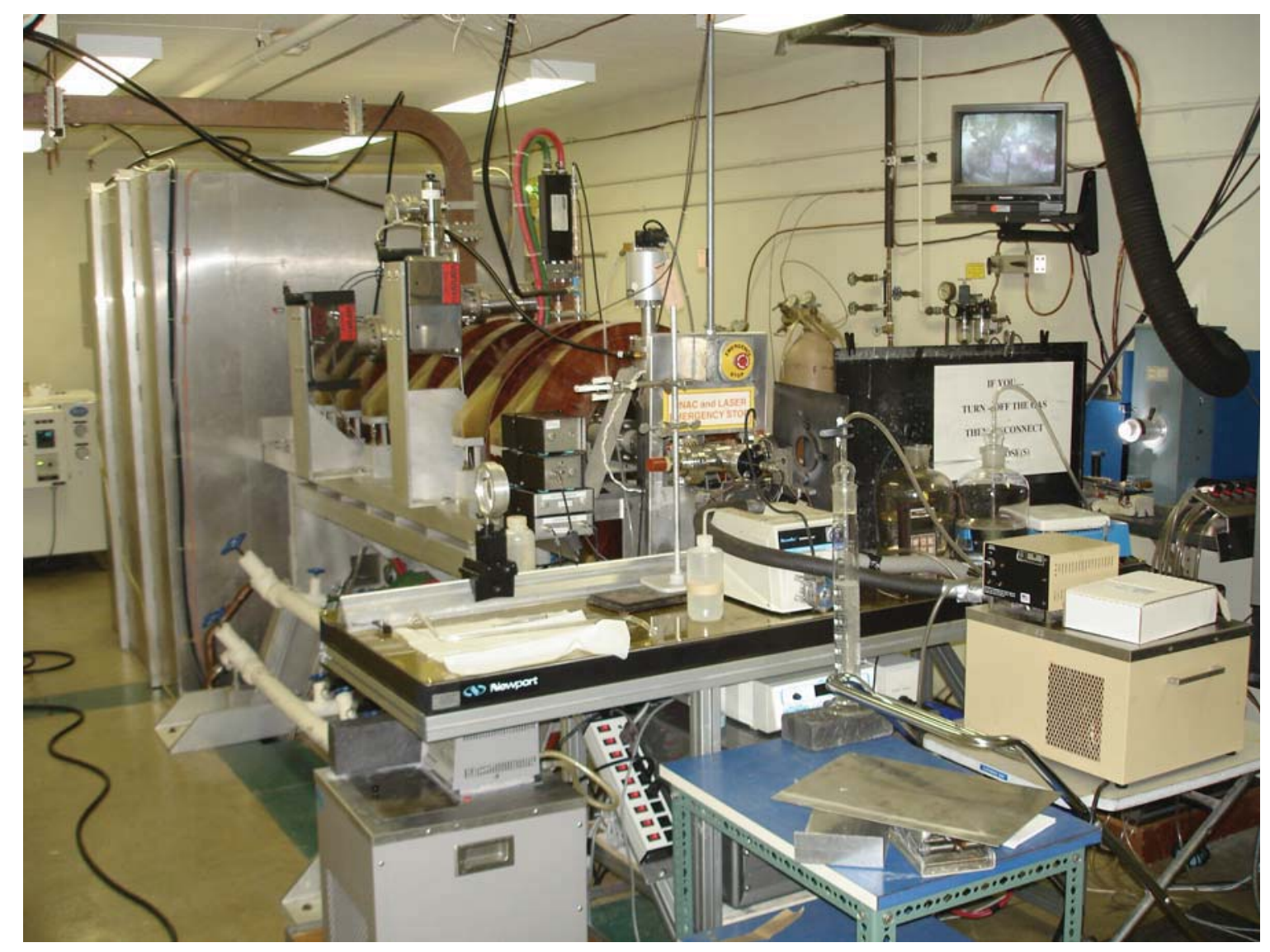

Figure 3.2.b LINAC - Electron Pulse Radiolysis (Another view) 


\subsection{Chemicals and Reagents}

The chemicals used for these experiments came from the following USA companies: anisole - Aldrich Chemical Co.(Milwaukee, WI); 2-nitroanisole, 3nitroanisole, 4-nitroanisole, 2-nitrophenol, 3-nitrophenol, 4-nitrophenol, and 2,6dinitrophenol, benzaldehyde, benzaldehyde oxime, nitrobenzene - Aldrich Chemical Co. (St. Louis, MO); 4-nitrophenol - Chem Service (West Chester, PA); toluene, hydrazine, and HPLC-grade methanol - Fisher Scientific (Fair Lawn, NJ); nitrotoluenes (2-nitro, 3nitro, and 4-nitro) - Supelco (Bellefonte, PA) and Accustandard, New Haven, CT; 2,6dinitrotoluene, nitrobenzene - Accustandard (New Haven, CT); 2,4,6-trinitrotoluene and 1,3,5-trinitrobenzene - Cerilliant (Round Rock, TX).

\subsection{Chromatography}

HPLC analyses used Shimadzu LC-10 AD VP pumps, a CTO-10 AC VP column oven, SIL-HTc autosampler and a SPD-M10A VP photo-diode array detector and Class VP software. A Supelco $25 \mathrm{~cm}$ x $4.6 \mathrm{~mm}, 5 \mu \mathrm{m} \mathrm{C}-18$ column at $55^{\circ} \mathrm{C}$ was used with a direct $10 \mu \mathrm{L}$ injection volume for all acidic and neutral toluene and anisole samples. A schematic of the system and the instrument are shown in Figures 3.3 and Figure 3.4, respectively. Anisole in the acidic medium was diluted to 1:100 to see well-resolved peaks. Nitric acid at concentrations of $2 \mathrm{M}, 4 \mathrm{M}$, and $6 \mathrm{M}$ were irradiated at different absorbed doses and were analyzed on HPLC to estimate the $\mathrm{HNO}_{2}$ concentration. A calibration curve for $\mathrm{HNO}_{2}$ was constructed with $\mathrm{NaNO}_{2}$ solutions of known concentrations. Methanol and water (55:45) at a flow rate of $0.5 \mathrm{~mL} \mathrm{~min}^{-1}$ was used isocratically at $254 \mathrm{~nm}$ detection wavelength and a run time of 30 minutes for all samples. For Cs-7SB , 2-propanol and water $(60: 40)$ at a flow rate of $0.5 \mathrm{~mL} \mathrm{~min}^{-1}$ was 
also used isocratically at $280 \mathrm{~nm}$ detection wavelength with a run time of 30 minutes. The column temperature was maintained at $30^{\circ} \mathrm{C}$. Products were identified by comparison of the retention times and UV spectra to standard compounds. Analytes detected at $254 \mathrm{~nm}$ were used for quantitation of anisole and toluene and their stable products. 


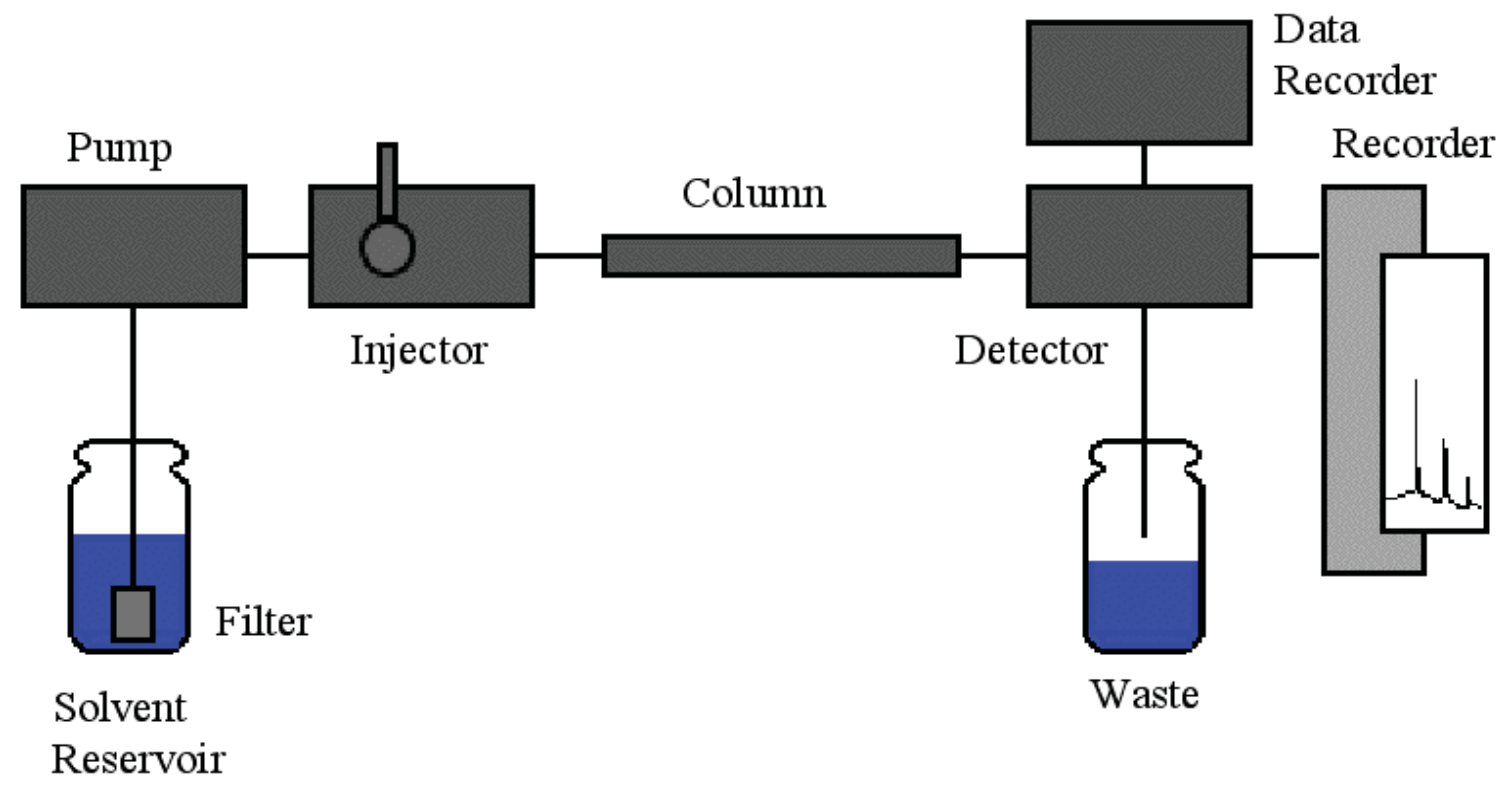

Figure 3.3 Schematic of an HPLC system

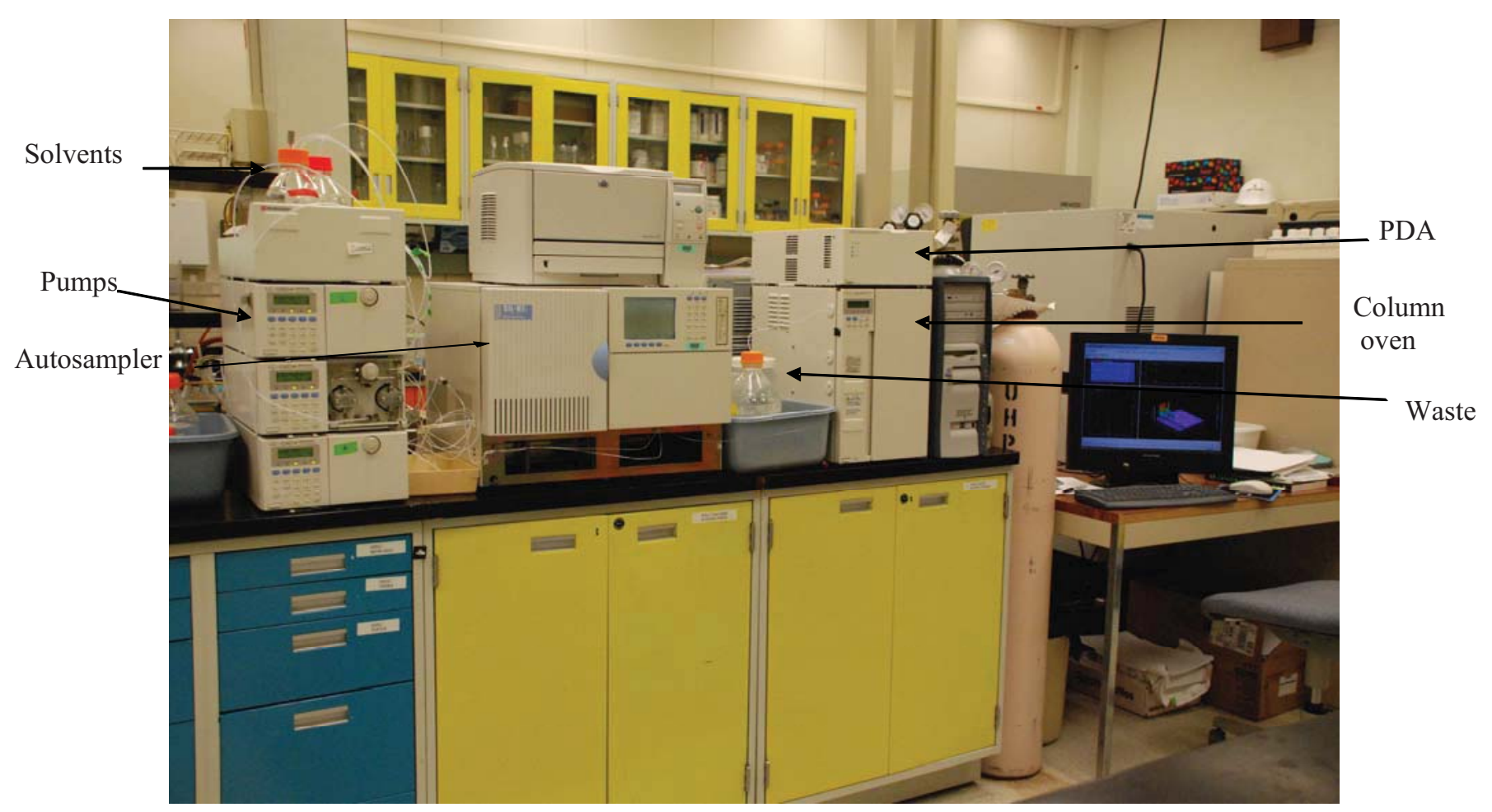

Figure 3.4 Shimadzu HPLC system 
For GC-ECD, an HP 5890 Series II gas chromatograph was used with a $30 \mathrm{~m} \mathrm{x}$ $0.25 \mathrm{~mm}$ id and a film thickness of $0.25 \mu \mathrm{m}$ Restek XTI- 5 column, He carrier gas, and $\mathrm{N}_{2}$ auxiliary gas. The injector temperature was $350{ }^{\circ} \mathrm{C}$ with a temperature program of 2-min hold time at $40{ }^{\circ} \mathrm{C}, 8{ }^{\circ} \mathrm{C} \min ^{-1}$ ramp to $350{ }^{\circ} \mathrm{C}$ with a 5-minute hold time, and detector temperature of $360{ }^{\circ} \mathrm{C}$. An Agilent HP/7673 autosampler was used to perform triplicate analyses of each sample.

For GC-MS analyses, a Shimadzu GC system (GC-MS QP 2010, AOC-5000 auto injector, and GCMS solution software) coupled to a quadrupole mass spectrometer operating in electron impact ionization (EI) mode was used. Schematic of the system and the instrument are shown in Figure 3.5 and Figure 3.6, respectively. The GC separation was performed using a Restek XTI-5 capillary column with a length of $30 \mathrm{~m} \times 0.25 \mathrm{~mm}$ id and a film thickness of $0.25 \mu \mathrm{m}$. The oven temperature was programmed as follows: $40{ }^{\circ} \mathrm{C}\left(3 \mathrm{~min}\right.$.); $5{ }^{\circ} \mathrm{C} / \mathrm{min}$ to $100{ }^{\circ} \mathrm{C} ; 50{ }^{\circ} \mathrm{C} / \mathrm{min}$ to $250^{\circ} \mathrm{C}(2 \mathrm{~min}$.); $1 \mu \mathrm{L}$ injection of sample with a split ratio of 15.0 was used for anisole products analysis in the extracted methylene chloride solution. The $\mathrm{pH}$ of selected irradiated acidic toluene samples was adjusted to $\sim 2$ and the toluene products were collected in methanol using Strata (Phenomenox) SPE cartridges. The methanol solution was introduced to the GC-MS using a solid phase micro extraction (SPME) device from Supelco $(75 \mu \mathrm{m}$ Carboxen PDMS (polydimethylsiloxane)) in a splitless mode. Helium was used as carrier gas at a constant flow of $1 \mathrm{~mL} / \mathrm{min}$. The interface temperature was set at $280{ }^{\circ} \mathrm{C}$. The EI source temperature was set at $260^{\circ} \mathrm{C}$ and a solvent delay of $3 \mathrm{~min}$. was selected. 


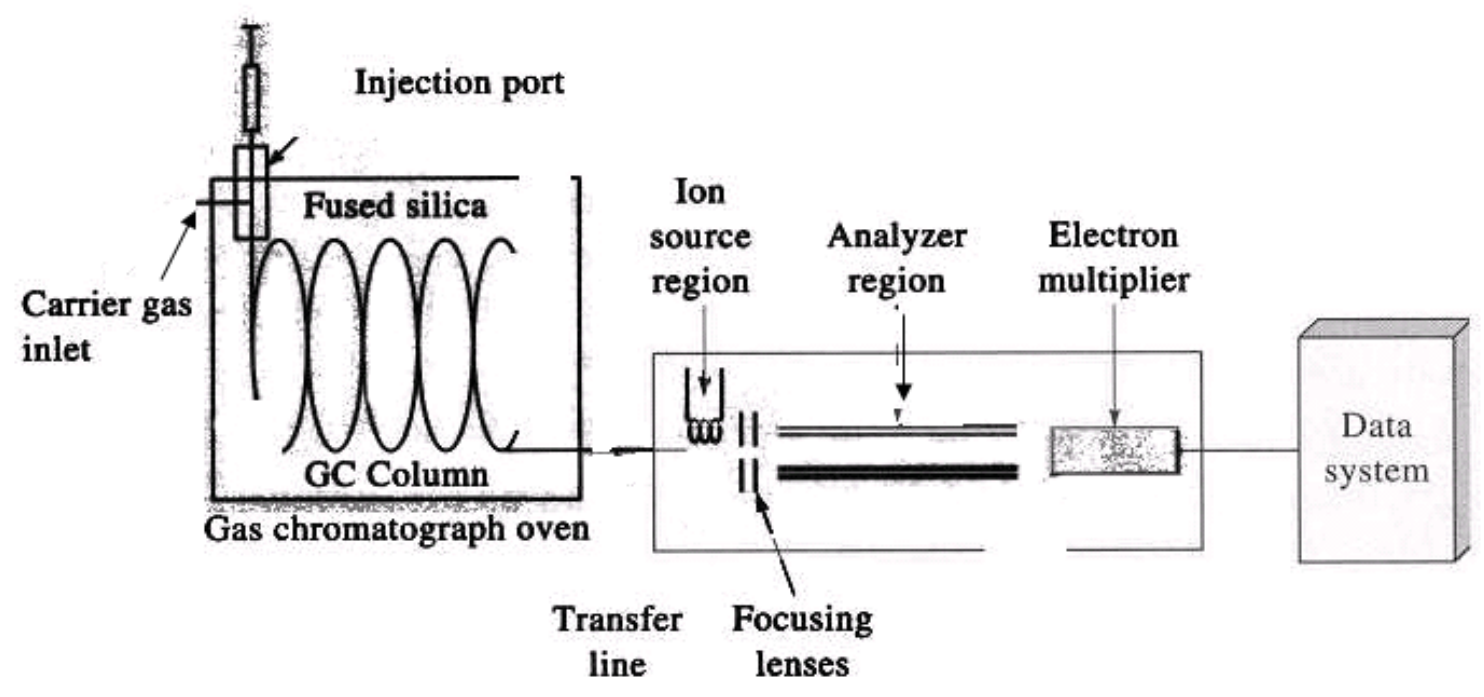

Figure 3.5 Schematic of a GC-MS system

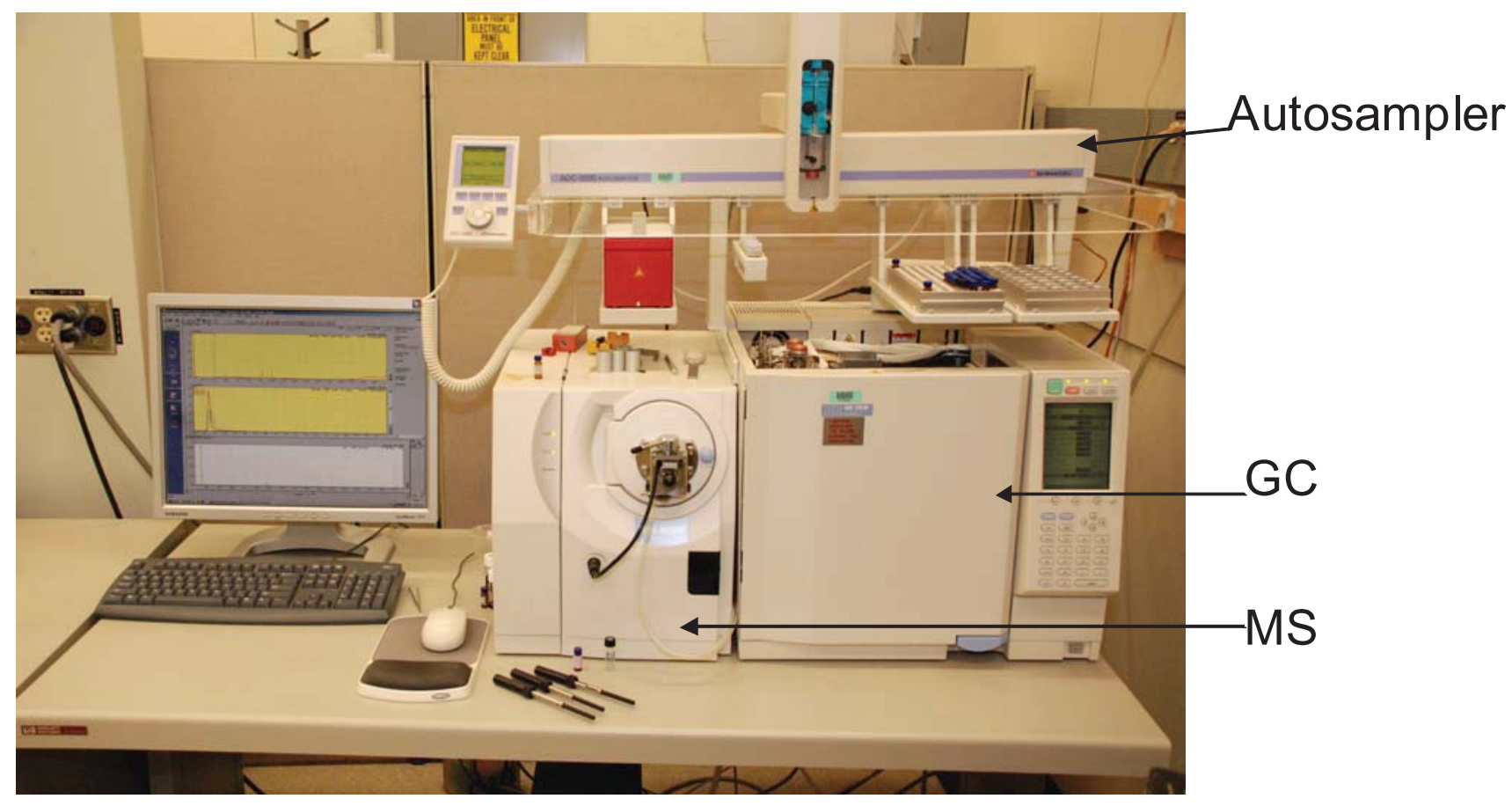

Figure 3.6 Shimadzu GC-MS system 
For LC-MS analyses, a Waters Acquity Ultra Performance LC (UPLC) system coupled to a Waters LCT Premier XTE mass spectrometer operating in electrosprayatmospheric pressure chemical ionization (ESI/APCI) mode with a time of flight (TOF) mass analyzer and photodiode-array detector (PDA) was used (University of Utah). Schematic of the system and the instrument are shown in Figure 3.7 and Figure 3.8, respectively. The LC separation was performed using an Acquity BEH C-18 column (2.1 x $100 \mathrm{~mm} \times 1.7 \mu \mathrm{m})$ Methanol and water were used in a gradient program. The gradient programs used for toluene samples and Cs-7SB are shown in Table 3.1 and Table 3.2 respectively.

The $\mathrm{pH}$ of selected irradiated acidic toluene and Cs-7SB samples was adjusted to $\sim 1$ 2 with $\mathrm{NaOH}$ to analyze on LC-MS.

Table 3.1 Toluene gradient program

\begin{tabular}{|c|c|c|c|}
\hline Time (min.) & $\begin{array}{c}\text { Flow Rate } \\
(\mathrm{mL} / \mathrm{min} .)\end{array}$ & $\%$ A (Water) & $\%$ B (Methanol) \\
\hline Initial & 0.400 & 60 & 40 \\
\hline 0.50 & 0.400 & 60 & 60 \\
\hline 6.00 & 0.400 & 40 & 60 \\
\hline 7.00 & 0.400 & 40 & 40 \\
\hline 7.50 & 0.400 & 60 & \\
\hline
\end{tabular}


Table 3.2 Cs-7SB gradient program

\begin{tabular}{|c|c|c|c|}
\hline Time (min.) & $\begin{array}{c}\text { Flow Rate } \\
(\mathrm{mL} / \mathrm{min} .)\end{array}$ & $\%$ A (Water) & $\%$ B (Methanol) \\
\hline Initial & 0.400 & 60 & 40 \\
\hline 0.50 & 0.400 & 60 & 40 \\
\hline 6.00 & 0.400 & 5 & 95 \\
\hline 7.00 & 0.400 & 5 & 40 \\
\hline 7.50 & 0.400 & 60 & 95 \\
\hline
\end{tabular}




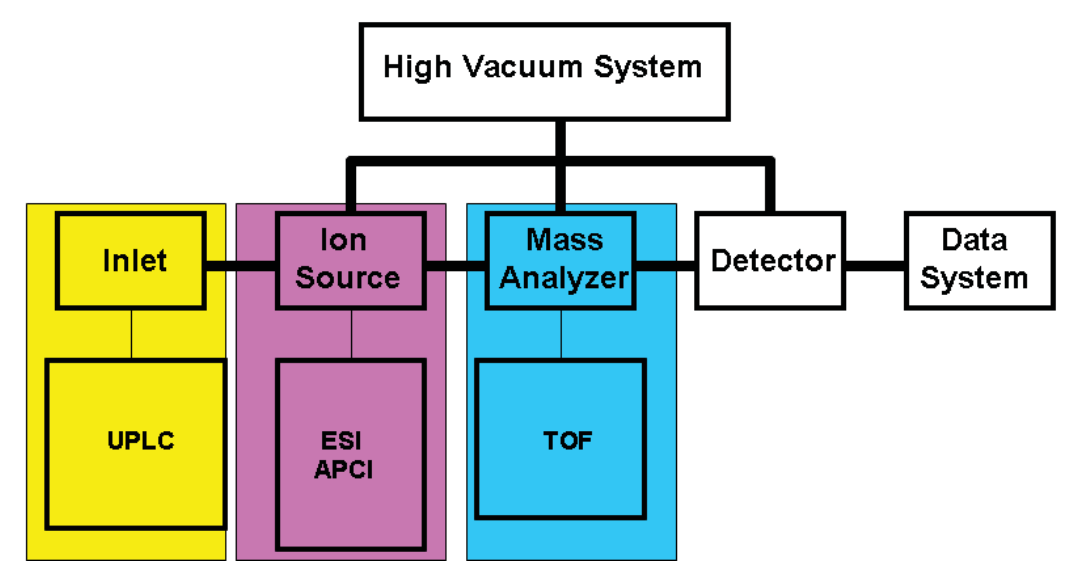

Figure 3.7 Schematic of an LC (UPLC)-MS (ESI/APCI /TOF) system

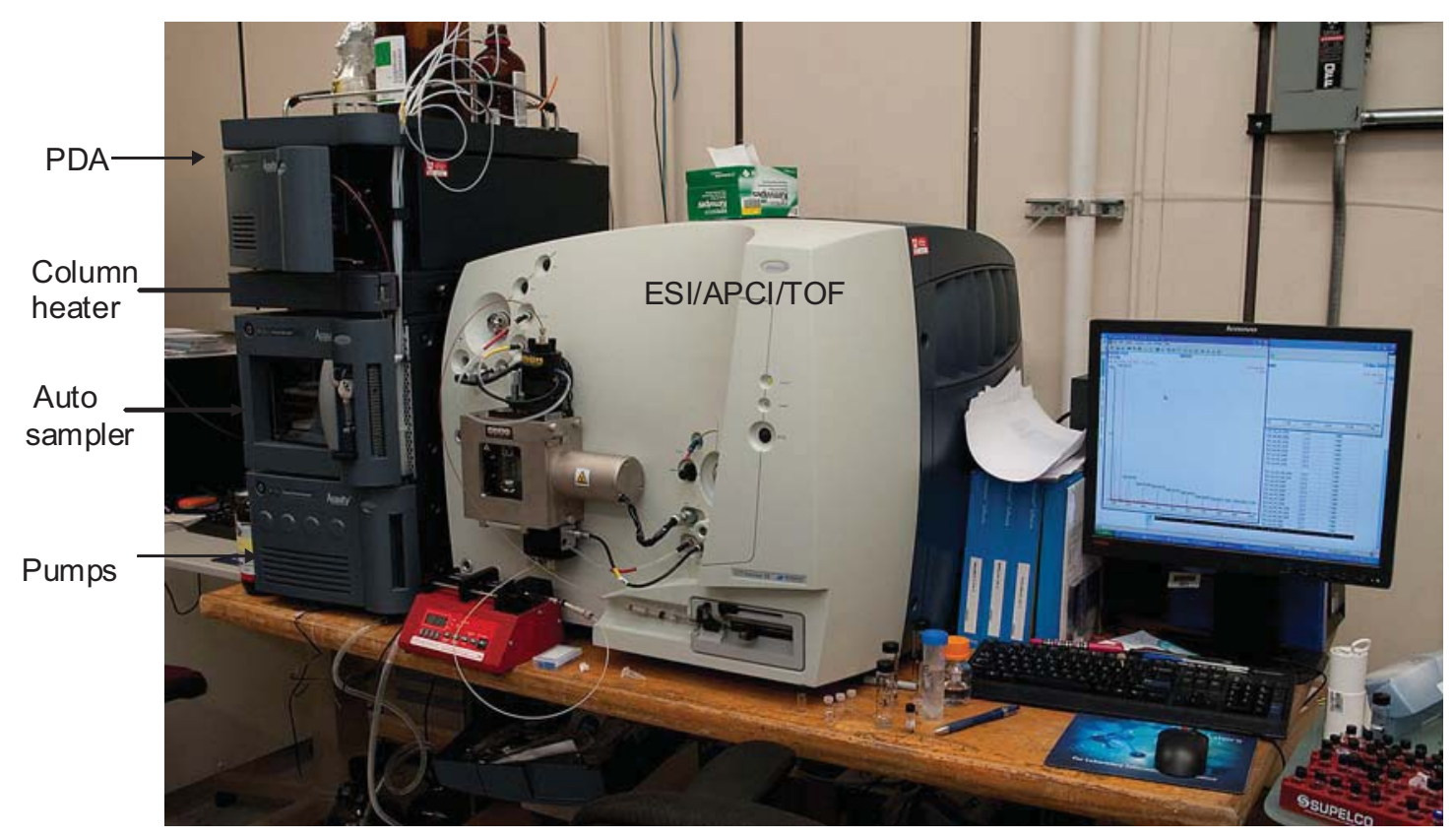

Figure 3.8 Waters LC (UPLC)-MS (ESI/APCI /TOF) system, University of Utah 


\subsection{Fourier Transform Infrared Spectroscopy (FTIR)}

A Brunker Equinox 55 FTIR with attenuated total reflectance (ATR) was used to analyze Cs-7SB and the orange layer, as well as the anisole and the yellow layer. The data was scanned from $4000-400 \mathrm{~cm}^{-1}$.

\subsection{Procedure}

The solubilities of anisole and toluene in neutral aqueous media are low. The water solubility of anisole $\left(15 \mathrm{mM}\right.$ at $\left.20^{\circ} \mathrm{C}\right)$ is comparatively higher than that of toluene $\left(6 \mathrm{mM}\right.$ at $\left.25^{\circ} \mathrm{C}\right)$. Higher solute concentrations $(23 \mathrm{mM}$ anisole and $19 \mathrm{mM}$ toluene $)$ dissolved in $6.0 \mathrm{M} \mathrm{HNO}_{3}$ solution were used for these experiments. These optimal values were achieved by trial and error. Lower values in neutral solution were possible. In the saturated solution of $6 \mathrm{M}$ sodium nitrate, $1.1 \mathrm{mM}$ anisole and in $1 \mathrm{M}$ sodium nitrite, $5.1 \mathrm{mM}$ anisole were achieved. In $0.5 \mathrm{M}$ sodium nitrite, $1.2 \mathrm{mM}$ toluene was achieved. Commercially available standards of each analyte and their nitro derivatives, in addition to hydroxylated and hydroxylated nitro derivatives, were dissolved in methanol as standards. Different concentrations of sodium nitrite solution were added to samples of anisole and toluene in $6 \mathrm{M} \mathrm{HNO}_{3}$ at $50{ }^{\circ} \mathrm{C}$ to verify the production of nitro aromatic compounds in the presence of increased concentrations of $\mathrm{HNO}_{2}$. Hydrazine, an $\mathrm{HNO}_{2}$ scavenger, was also added to the acidic solutions of anisole, toluene, and Cs-7SB. The concentration of their nitro products and the color formation in the solutions were monitored to understand the role of $\mathrm{HNO}_{2}$ in the reactions.

Anisole and toluene samples in the nitric acid medium were analyzed using HPLC, with conditions as described above, to assess the initial analyte concentrations and the nitro products produced in the samples both at room temperature and for thermal 
reactions occurring at $50{ }^{\circ} \mathrm{C}$. The samples were later irradiated in a Nordion Gamma Cell (Ottawa, Canada) ${ }^{60} \mathrm{Co}$-irradiator. The sample cell ambient temperature was $50{ }^{\circ} \mathrm{C}$. The samples were irradiated to different absorbed doses to simulate the conditions in a nuclear waste reprocessing stream. The irradiated samples were analyzed on the HPLC under the same conditions as unirradiated samples. Selected irradiated samples of anisole, toluene, and Cs-7SB were analyzed on GC-MS. Selected irradiated samples of toluene and selected irradiated and thermal samples of Cs-7SB were analyzed on LC-MS. Cs-7SB samples, with and without nitric acid were analyzed on GC-ECD before and after irradiation. 


\section{Chapter 4}

\section{Reactions of Radiolytically-Produced Nitrogen Oxide Radicals with Anisole and Toluene}

\subsection{Anisole and Toluene Model Compounds}

Anisole $\left(\mathrm{C}_{6} \mathrm{H}_{5}-\mathrm{OCH}_{3}\right)$, an aryl alkyl ether, was used as a model compound in this study as a surrogate for Cs-7SB which is also an aryl ether (Figure 1.1 and Figure 1.3). Anisole $\left(\mathrm{C}_{6} \mathrm{H}_{5}-\mathrm{OCH}_{3}\right)$ was used in this study as a surrogate for $\mathrm{Cs}-7 \mathrm{SB}$, since both are aryl ethers. Toluene was used as a surrogate for Cs-7SB because of the alkyl group on the benzene ring in both molecules. Anisole and toluene are small molecules compared to $\mathrm{Cs}-7 \mathrm{SB}$ and the nitration products were easier to identify compared to the larger Cs7SB molecule. Different kinds of organic molecules under acidic conditions are found in the environment, in industrial applications, and in nuclear fuel reprocessing and many of these are subjected to free-radical reactions by photolysis, or radiolysis. Therefore, a highly reactive molecule like anisole and a less reactive molecule like toluene were considered in this study as model compounds to compare the reaction mechanisms and the nitrated products in acidic media under irradiation.

\subsubsection{Anisole and Toluene - Kinetic Investigations}

The bimolecular reaction rates for anisole, toluene, and related compounds with both ${ }^{\circ} \mathrm{NO}_{2}$ and ${ }^{\circ} \mathrm{NO}_{3}$ radicals were measured in this study. The reactions of ${ }^{\circ} \mathrm{NO}_{3}$ radical were measured in $\mathrm{N}_{2} \mathrm{O}$-sparged $6 \mathrm{M} \mathrm{HNO}_{3}$ solution, where production of ${ }^{\circ} \mathrm{NO}_{3}$ is favored over ${ }^{\circ} \mathrm{NO}_{2}$ by direct radiolysis of the high concentration of nitric acid and nitrate anion (equations 37,38$).^{[53,80]}$ 
The measured transient spectrum of the $\mathrm{NO}_{3}$ radical is given in Figure 4.1.a.

Absorbance values were converted into absorption coefficients using the ${ }^{\mathrm{N}} \mathrm{NO}_{3}$ radical yield of $0.46 \mu \mathrm{mol} \mathrm{J}^{-1}$ (G value), reported by Katsamura et al. ${ }^{[53]}$ From the known $\mathrm{G}$ value and the known dose, the absorption coefficient was calculated, since $\mathrm{A}=\varepsilon \mathrm{bc}$. The spectrum shape and intensity are in very good agreement with Katsumura et al ${ }^{[53]}$ and Neta and Huie. ${ }^{[7]}$
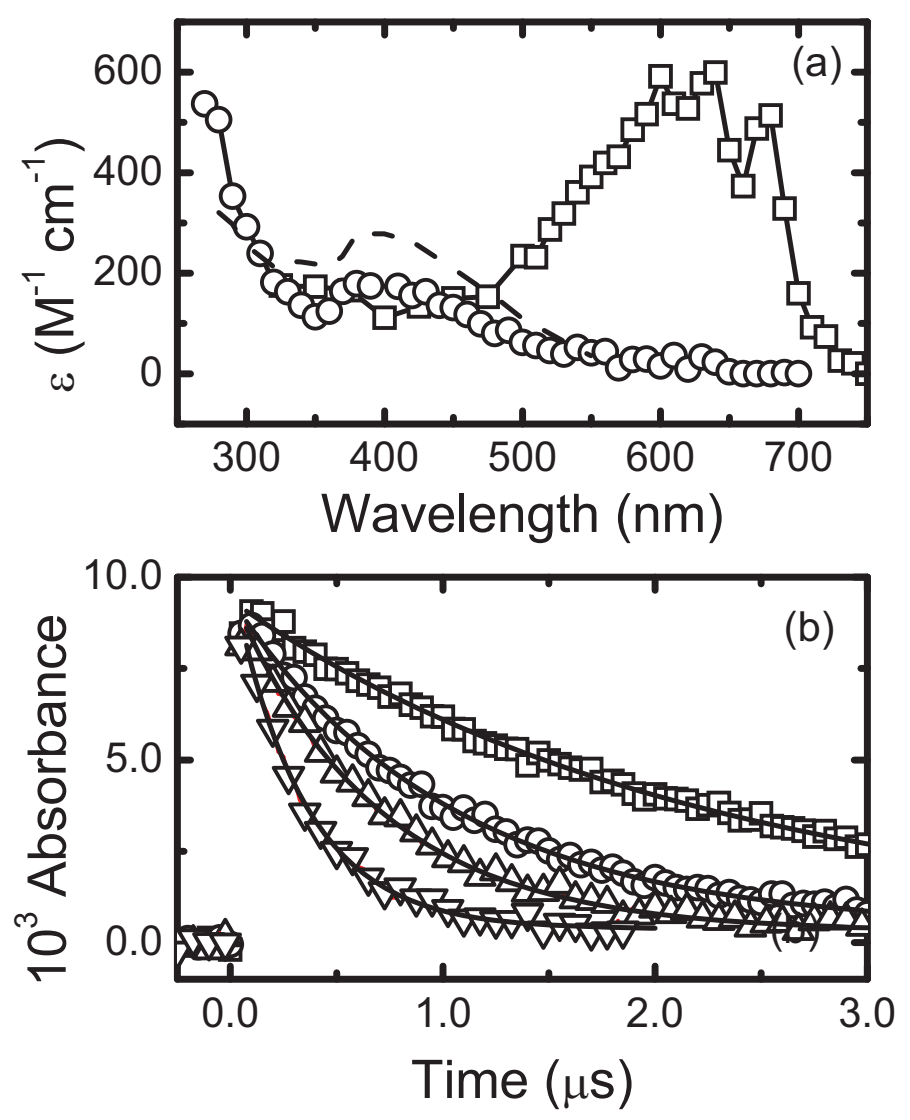

Figure 4.1.a Room temperature transient absorption spectra for ${ }^{\circ} \mathrm{NO}_{3}\left(\square, \mathrm{N}_{2} \mathrm{O}\right.$-saturated $\left.6 \mathrm{M} \mathrm{HNO}_{3}\right)$ and ${ }^{\circ} \mathrm{NO}_{2}\left(\mathrm{O}, \mathrm{N}_{2} \mathrm{O}\right.$-saturated $0.10 \mathrm{M} \mathrm{NaNO}_{2}, \mathrm{pH}$ 7) radicals in aqueous solution. Absorption coefficient values calculated as described in text. Dashed line corresponds to literature $\mathrm{NO}_{2}$ radical spectrum from Hug. ${ }^{[26]}$

4.1.b Transient decay kinetics of ${ }^{\circ} \mathrm{NO}_{3}$ radical with $93(\square)$, 203(O), $328(\Delta)$, and 661 ( $\nabla) \mu \mathrm{M}$ anisole added. 
(c)

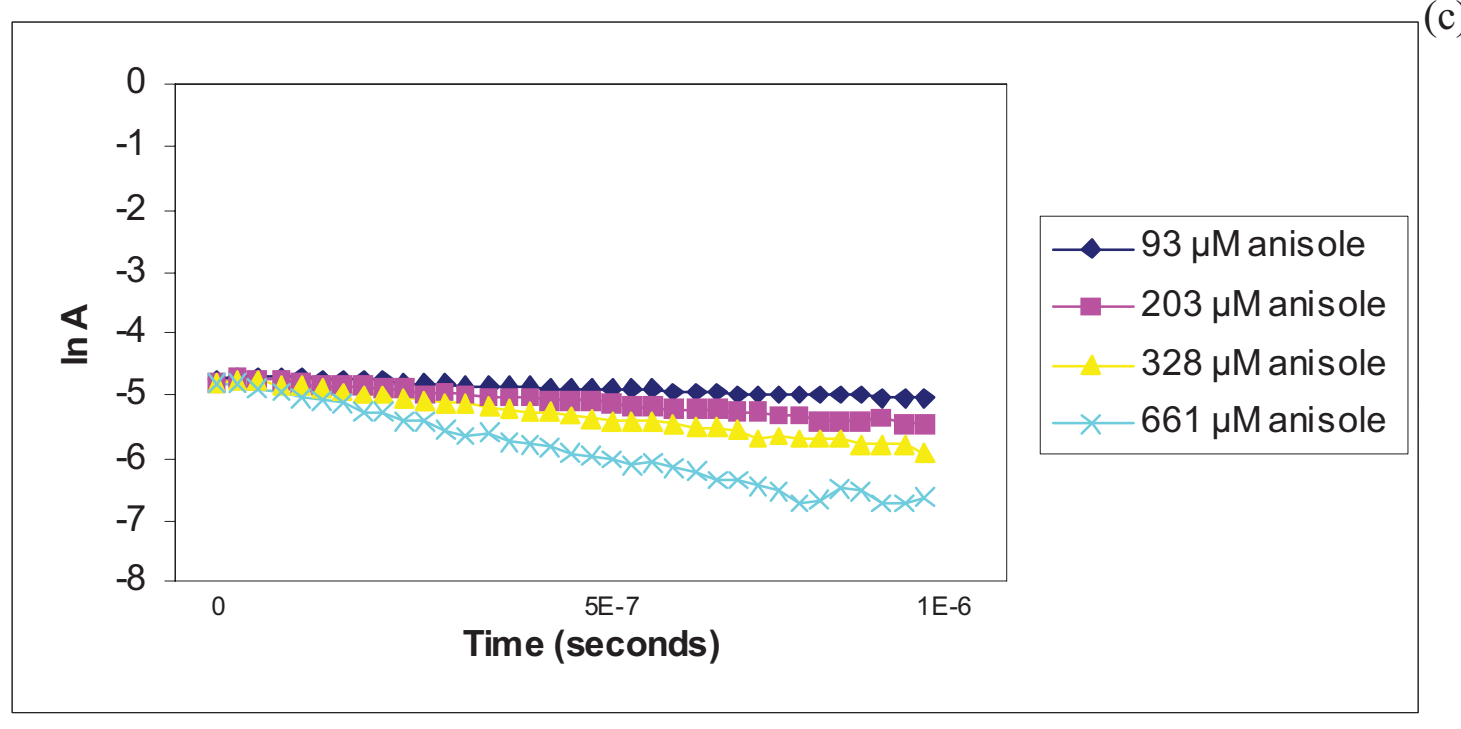

(d)

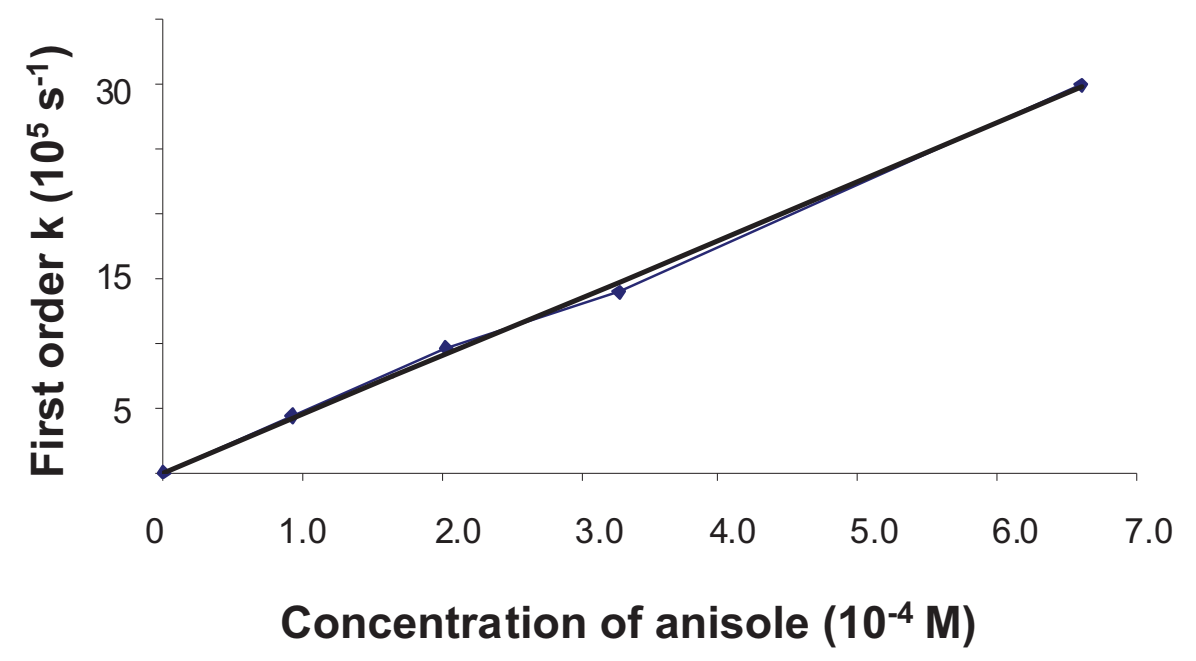

Figure 4.1.c ln A vs. time to find the first order rate constant. Slope of the line is the first order rate constant.

Figure 4.1.d Concentration of anisole vs. first order $\mathrm{k}$ to find the second order rate constant. Slope of the line is the second order rate constant.

The transient absorption spectrum of the ${ }^{\circ} \mathrm{NO}_{2}$ radical was measured in $\mathrm{N}_{2} \mathrm{O}$ sparged 0.10 M sodium nitrite solution, and is also shown in Figure 4.1.a. Under these 
conditions, ${ }^{\circ} \mathrm{NO}_{2}$ radicals are produced through the reaction of ${ }^{\circ} \mathrm{OH}$ radicals with nitrite ion (equation 58). The relatively high concentration of nitrite in this system means that reactions with the formed $\mathrm{e}_{\mathrm{aq}}{ }^{-}$and ${ }^{\circ} \mathrm{H}$ atoms also occur. ${ }^{[49]}$ The reaction of the hydrated electron with nitrite, with the $\mathrm{k}_{79}$ in equation 79 , is known to give the ${ }^{\circ} \mathrm{NO}_{2}{ }^{2-}$ radical. However, its subsequent fate in aqueous solution is not known. By analogy with the electron reduction of nitrate, ${ }^{[49]}$ it is expected that the $\mathrm{NO}_{2}{ }^{2-}$ radical will quickly react with water to give hydroxide ion and ${ }^{\circ} \mathrm{NO}$ radical (equation 80 ).

$$
\begin{array}{ll}
\mathrm{e}_{\mathrm{aq}}{ }^{-}+\mathrm{NO}_{2}{ }^{-} \rightarrow \mathrm{NO}_{2}{ }^{2-} & k_{79}=3.8 \times 10^{9} \mathrm{M}^{-1} \mathrm{~s}^{-1} \\
\mathrm{NO}_{2}{ }^{2-}+\mathrm{H}_{2} \mathrm{O} \rightarrow 2 \mathrm{OH}^{-}+{ }^{-} \mathrm{NO} & \\
\mathrm{H}^{\cdot}+\mathrm{NO}_{2}{ }^{-} \rightarrow{ }^{\circ} \mathrm{OH}+\mathrm{NO}^{-} / \mathrm{OH}^{-}+{ }^{\circ} \mathrm{NO} & k_{81}=1.6 \times 10^{9} \mathrm{M}^{-1} \mathrm{~s}^{-1}
\end{array}
$$

For the ${ }^{\cdot} \mathrm{H}$ atom reaction, there are two sets of products possible,${ }^{[81]}$ as listed in equation 81. Production of the hydroxide ion and nitric oxide products is more thermodynamically stable. Therefore, it is assumed that neither the $\mathrm{e}_{\mathrm{aq}}{ }^{-}$nor ${ }^{\circ} \mathrm{H}$ atom reactions with nitrite resulted in $\mathrm{NO}_{2}$ radical production. Therefore, a total hydroxyl radical yield (G-value) of $0.53 \mu \mathrm{mol} \mathrm{J}{ }^{-1[82]}$ was used to determine the absorption coefficients of the ${ }^{\circ} \mathrm{NO}_{2}$ transient spectrum shown in Figure 4.1a. This spectrum is similar to the one previously published by $\operatorname{Hug}^{[83]}$ showing a maximum at about $400 \mathrm{~nm}$.

For rate constant determinations, the rate of change of the decay kinetics at the peak absorption maximum ( $\left.{ }^{\circ} \mathrm{NO}_{3}, 640 \mathrm{~nm} ;{ }^{\circ} \mathrm{NO}_{2}, 400 \mathrm{~nm}\right)$ was observed. Typical kinetic data are shown for the $\mathrm{NO}_{3}$ radical reaction with anisole in Figure 4.1.b. Figure 4.1.b shows decrease of concentrations of the $\mathrm{NO}_{3}$ radical for different anisole concentrations (The concentration is directly proportional to the absorbance (A) according to Beer's Law). Since the change in concentration of anisole is negligible compared to that of the 
$\mathrm{NO}_{3}$ radical, the reaction is a pseudo first order reaction. Rate $=\mathrm{k}^{\prime}\left[\mathrm{NO}_{3}\right]$. Since absorbance is proportional to concentration, plotting ln A vs. time gives a straight line and the slope of the line gives $\mathrm{k}^{\prime}$, the pseudo first order rate constant. Figure 4.1.c, shows a plot of $\ln \mathrm{A}$ vs. time for different anisole concentrations (The plot in Figure 4.1.c for the highest anisole concentration $(661 \mu \mathrm{M})$ shows some baseline noise as the time increases). The values of k' for the four concentrations shown in Figure 4.1.c are 4.46 x 10 $0^{5}, 9.53 \mathrm{x}$ $10^{5}, 1.40 \times 10^{6}$, and $3.00 \times 10^{6} \mathrm{~s}^{-1}$.

The pseudo-first-order rate constant is plotted against anisole concentration in Figure 4.1.d. The second-order rate constant $\mathrm{k}$ (the slope of the plot) was calculated to be $(4.42 \pm 0.05) \times 10^{9} \mathrm{M}^{-1} \mathrm{~s}^{-1}$ (The second order rate equation in this case is rate $=$ $\mathrm{k}[$ anisole $\left.]\left[\mathrm{NO}_{3}\right]\right)$. This approach was used for all the species in this study, and the rate constant values are summarized in Table 4.1. The reaction of the ${ }^{\circ} \mathrm{NO}_{3}$ radical with benzene is very slow, $k \sim 1 \times 10^{6} \mathrm{M}^{-1} \mathrm{~s}^{-1[83]}$ indicating that the predominant reaction is not by addition to the phenyl ring. The rate constant measured in this work for the $\mathrm{NO}_{3}$ radical reaction with toluene is $k=(1.71 \pm 0.06) \times 10^{9} \mathrm{M}^{-1} \mathrm{~s}^{-1}$, while that for 4methylanisole is faster, $k=(4.92 \pm 0.05) \times 10^{9} \mathrm{M}^{-1} \mathrm{~s}^{-1}$, suggesting that the reactions proceed by hydrogen atom abstraction from ring substituents. For the nitrated toluene species, the rate is seen to decrease by approximately two orders-of-magnitude for each subsequent nitro group. The nitro group reduces the electron density of the ring by resonance and induction, therefore, the molecule becomes less reactive than toluene (equation 20). However, this effect is not as large for mono-substituted anisole. For the $\mathrm{NO}_{2}$ radical measurements, no significant change in the rate of decay of this transient absorbance was determined, even at the highest solute concentrations used. Therefore, 
only upper limits for these direct radical reactions are reported, $k<2 \times 10^{5} \mathrm{M}^{-1} \mathrm{~s}^{-1}$.

Therefore, this study shows that ${ }^{\circ} \mathrm{NO}_{2}$ is not very reactive, and ${ }^{\circ} \mathrm{NO}_{3}$ does not add to the phenyl rings.

Table 4.1 Second-order rate constants $(k)\left(\mathrm{M}^{-1} \mathrm{~s}^{-1}\right)$ for the reactions of ${ }^{\circ} \mathrm{NO}_{2}$ and ${ }^{\circ} \mathrm{NO}_{3}$ radicals with anisole, toluene and analogous compounds

\begin{tabular}{|c|c|c|}
\hline Compound & $\mathrm{NO}_{2}$ & $\mathbf{N O}_{3}$ \\
\hline anisole & $<2 \times 10^{5}$ & $(4.42 \pm 0.05) \times 10^{9}$ \\
\hline 2-nitroanisole & $<2 \times 10^{5}$ & $(1.89 \pm 0.19) \times 10^{9}$ \\
\hline 4-methylanisole & $<2 \times 10^{5}$ & $(4.92 \pm 0.05) \times 10^{9}$ \\
\hline toluene & $<2 \times 10^{5}$ & $(1.71 \pm 0.06) \times 10^{9}$ \\
\hline 3-nitrotoluene & $<2 \times 10^{5}$ & $(2.80 \pm 0.05) \times 10^{7}$ \\
\hline 2,4- dinitrotoluene & $<2 \times 10^{5}$ & $(3.07 \pm 1.45) \times 10^{5}$ \\
\hline 3,4- dinitrotoluene & $<2 \times 10^{5}$ & $(9.63 \pm 1.39) \times 10^{5}$ \\
\hline benzene & $<2 \times 10^{5}$ & $<1 \times 10^{6}$ \\
\hline
\end{tabular}

\subsubsection{Steady-state anisole irradiation in acidic nitrate $\left(6 \mathrm{M} \mathrm{HNO}_{3}\right)$ solution}

The irradiation of dilute nitric acid produces the $\mathrm{NO}_{3}$ radical, as shown in equations 40 and 46 . It should also produce ${ }^{\circ} \mathrm{NO}_{2}$ radical via direct radiolysis of the nitrate ion (equation 82 ), ${ }^{[84,85]}$ and by hydrolysis of the $\mathrm{NO}_{3}{ }^{2-}$ radical product of nitrate ion electron capture, ${ }^{[59]}$ shown in equations $41-42:{ }^{[55]}$

$$
\mathrm{NO}_{3}^{-}-\mathrm{W} \rightarrow \mathrm{NO}_{2}+{ }^{\circ} \mathrm{O}+\mathrm{e}^{-}
$$

In acidic solution, the ${ }^{\circ} \mathrm{NO}_{3}{ }^{2-}$ radical anion is protonated to produce ${ }^{\circ} \mathrm{H}_{2} \mathrm{NO}_{3}$, however this species also decomposes to produce $\mathrm{NO}_{2}$ radical and water. ${ }^{[62]}$ Anisole was irradiated in $6 \mathrm{M}$ nitric acid because this solution favors undissociated nitric acid. This isolated the 
$\mathrm{NO}_{3}$ radical via equations 38 and 44, while minimizing production of the $\mathrm{NO}_{2}$ radical. The absorption spectrum of pulse-irradiated $6 \mathrm{M}$ nitric acid (Figure 4.1.a) confirmed that any ${ }^{\circ} \mathrm{NO}_{2}$ radical produced was below detection limit. The lack of ${ }^{\circ} \mathrm{NO}_{2}$ radical formation suggests that under highly acidic conditions, an alternate decay pathway of the $\mathrm{NO}_{3}{ }^{2-}$ radical occurs, possibly through the formation of ${ }^{\circ} \mathrm{H}_{2} \mathrm{NO}_{3}$ (equation 83) instead of the hydrolysis pathway to produce $\mathrm{NO}_{2}$ (equation 42 ):

$$
{ }^{\bullet} \mathrm{NO}_{3}{ }^{2-}+2 \mathrm{H}^{+} \rightarrow{ }^{\bullet} \mathrm{H}_{2} \mathrm{NO}_{3}
$$

This might be a more stable species than the intermediate monoprotonated radical formed by single proton addition to ${ }^{\circ} \mathrm{NO}_{3}{ }^{2-\left[{ }^{[85]}\right.}$ Daniels ${ }^{[55]}$ also reported that ${ }^{\circ} \mathrm{NO}_{2}$ radical was not found in irradiated, strongly acidic solution. Thus this solution isolated the ${ }^{\circ} \mathrm{NO}_{3}$ radical for study.

Anisole and $6 \mathrm{M}$ nitric acid showed nitro products in the unirradiated solution (Figure 4.2.a) and in the irradiated solution (Figure 4.2.b). The trend of nitroproduct formation - the nitroanisoles and nitrophenols, are shown in Figure 4.2.c. The product information in Figure 4.2.a, b, and c are from samples analyzed two days after preparation. The ingrowth of nitroanisole products and decomposition of anisole are shown in Figure 4.2.d (analyzed six hours after preparation). When $6 \mathrm{M}$ nitric acid containing $\sim 23 \mathrm{mM}$ anisole was $\gamma$-irradiated, the anisole was quickly decomposed, with less than $1 \mathrm{mM}$ detectable after an absorbed dose of only $8.9 \mathrm{kGy}$ (Figure 4.2.d). For nitroanisole products, the ortho-, and para-nitroanisoles were produced at an ortho/para ratio of about $\sim 0.35$. The absence of meta-nitroanisole suggests that nitration occurred via electrophilic aromatic substitution. 


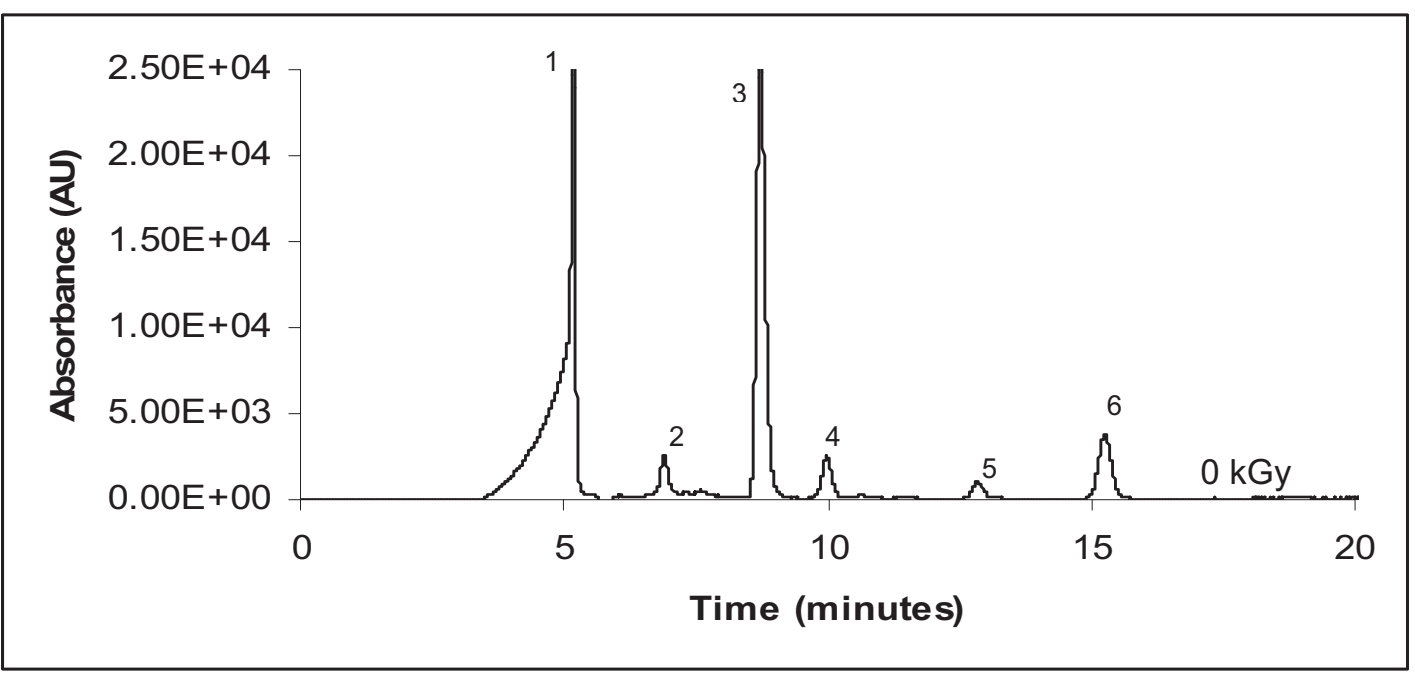

Figure 4.2.a HPLC chromatogram of $1 / 100$ diluted solution of anisole and $6 \mathrm{M}$ nitric acid at $0 \mathrm{kGy}$ (not irradiated) irradiation dose. Peaks: (1) Mixture of nitric acid and dinitrophenol (2) unknown, possibly impurity in the solvent (3) 4-nitrophenol (4) 2nitroanisole (5) 4-nitroanisole (6) anisole. HPLC conditions: reverse-phase C-18 column, 55:45 methanol/water, column temperature: $55^{\circ} \mathrm{C}$, Flow rate: $0.5 \mathrm{~mL} /$ minute, isocratic elution and UV detection at $254 \mathrm{~nm}$

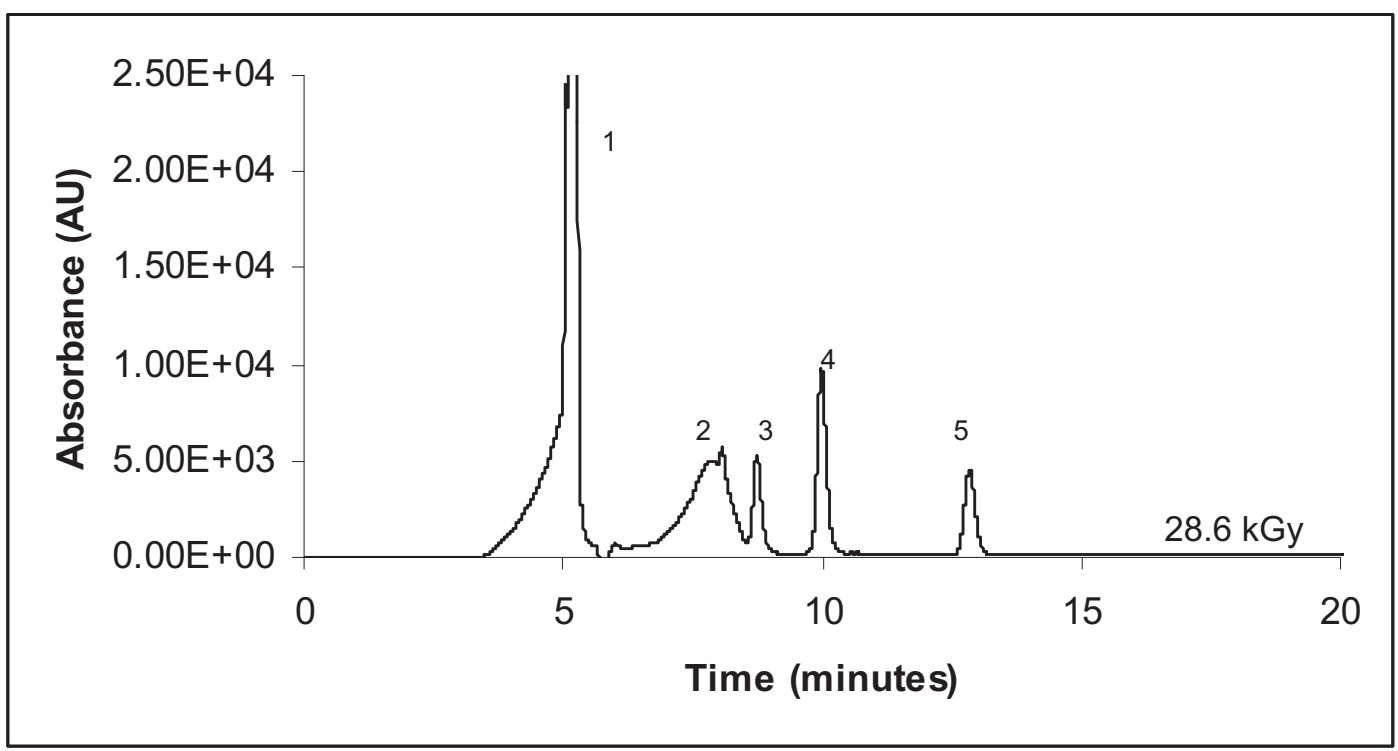

Figure 4.2.b HPLC chromatogram of 1/100 diluted solution of anisole and $6 \mathrm{M}$ nitric acid after irradiation at $28.6 \mathrm{kGy}$ dose. Peaks: (1) Mixture of nitric acid and dinitrophenol (2) nitrous acid (3) 4-nitrophenol (4) 2-nitroanisole (5) 4-nitroanisole. HPLC conditions are same as in Figure 4.2.a 


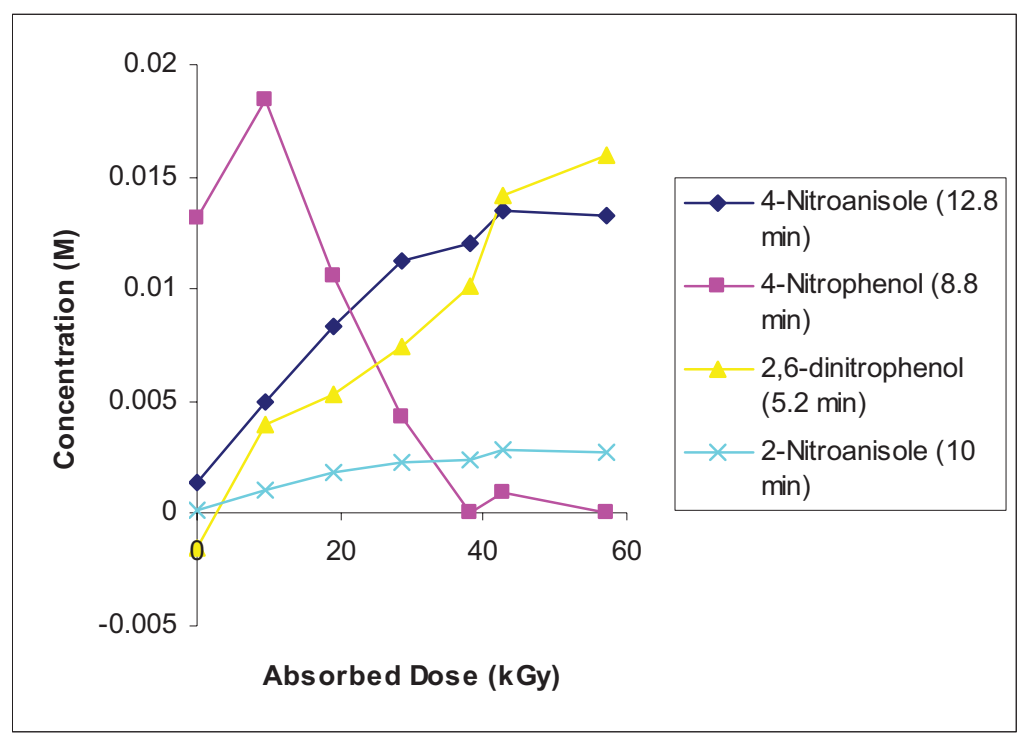

Figure 4.2.c HPLC results of irradiated anisole and $6 \mathrm{M} \mathrm{HNO}_{3}$ : The trend of ingrowth of 2- and 4-nitroanisoles, 4-nitrophenol and dinitrophenol

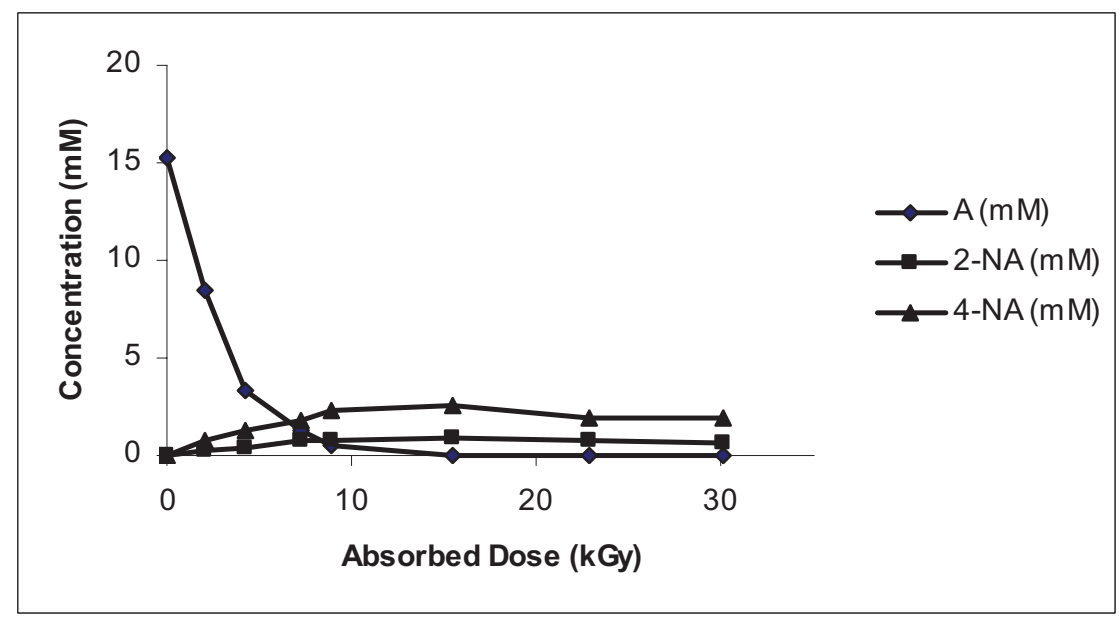

Figure 4.2.d The loss of anisole (A) and production of 2-nitroanisole (2-NA) and 4nitroanisole (4-NA) for irradiated anisole in $6 \mathrm{M}$ nitric acid solution

However, nitroanisoles and nitrophenols were also formed in anisole solutions of unirradiated nitric acid (Figure 4.2.a). When unirradiated samples were maintained at the ambient irradiator temperature of $50^{\circ} \mathrm{C}$, or even at room temperature, lesser but still 
significant amounts of the same products were created. For the $50{ }^{\circ} \mathrm{C}$ samples with similar anisole concentrations, $0.016 \mathrm{mM}$ 4-nitroanisole was produced in 2 hours reaction time. This same reaction time in the irradiator results in an absorbed dose of $\sim 24 \mathrm{kGy}$ and $\sim 3 \mathrm{mM}$ 4-nitroanisole.

The overall ortho/para ratio in the irradiated and unirradiated samples is $\sim 0.35$. The 4-nitrophenol concentration of $4.6 \mathrm{mM}$ at $2.1 \mathrm{kGy}$, is equivalent to that produced after 69 hours at room temperature in the unirradiated sample. Thus, the ratio of ortho/para isomers and the production of 4-nitrophenol in both irradiated and unirradiated solutions are consistent with a nitration mechanism resulting from nitrous acid catalyzed nitration (equations 6-9 and Scheme 1). The higher concentration of products in irradiated solution suggests that the mechanism is enhanced by radiolysis, probably due to the radiolytic generation of additional nitrous acid. Nitrous acid is produced in nitric acid radiolysis, ${ }^{[86,87]}$ as well as by nitric acid oxidation of solution components. The nitrosonium ion $\left(\mathrm{NO}^{+}\right)$, shown to nitrate aromatic compounds in equations 6-9, is also a

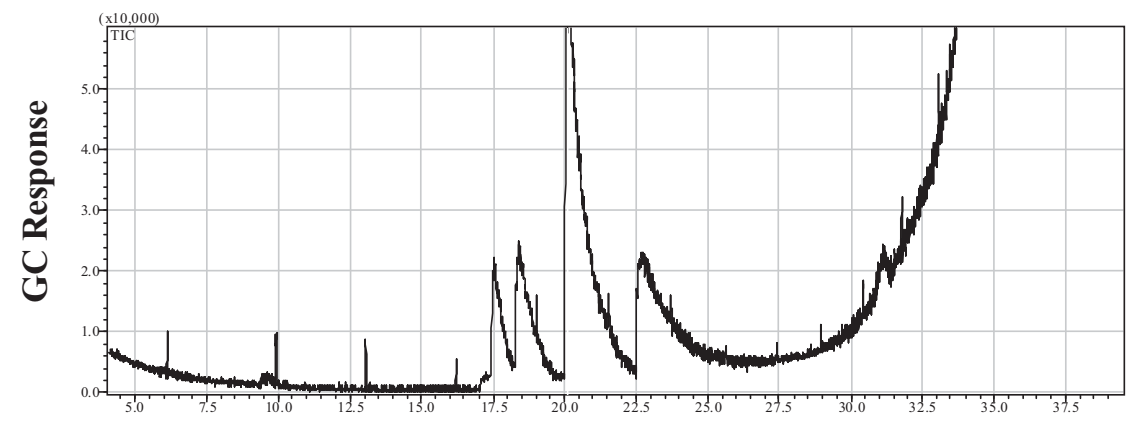

Time (Minutes)

Figure 4.3.a Chromatogram (GC-MS) of anisole and $6 \mathrm{M} \mathrm{HNO}_{3}$ (methylene chloride extract) at $4.07 \mathrm{kGy}$ irradiation dose. Peak information with mass spectra in Figure 4.3.b 


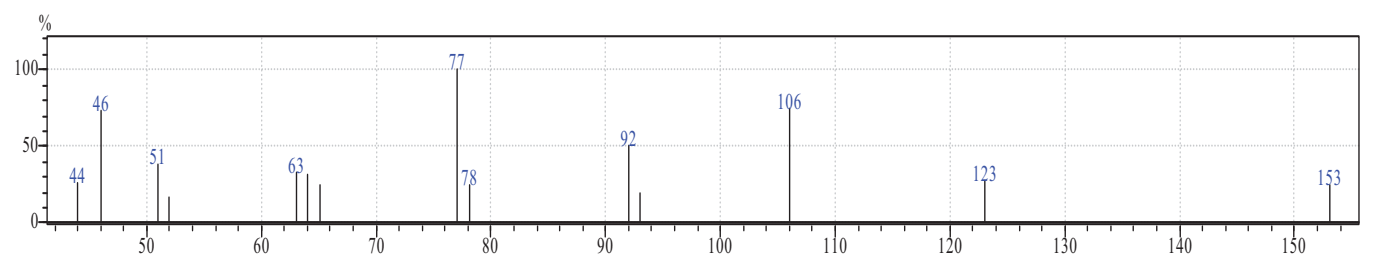

(1) Ret.Time : $17.626 \quad$ 2-nitroanisole
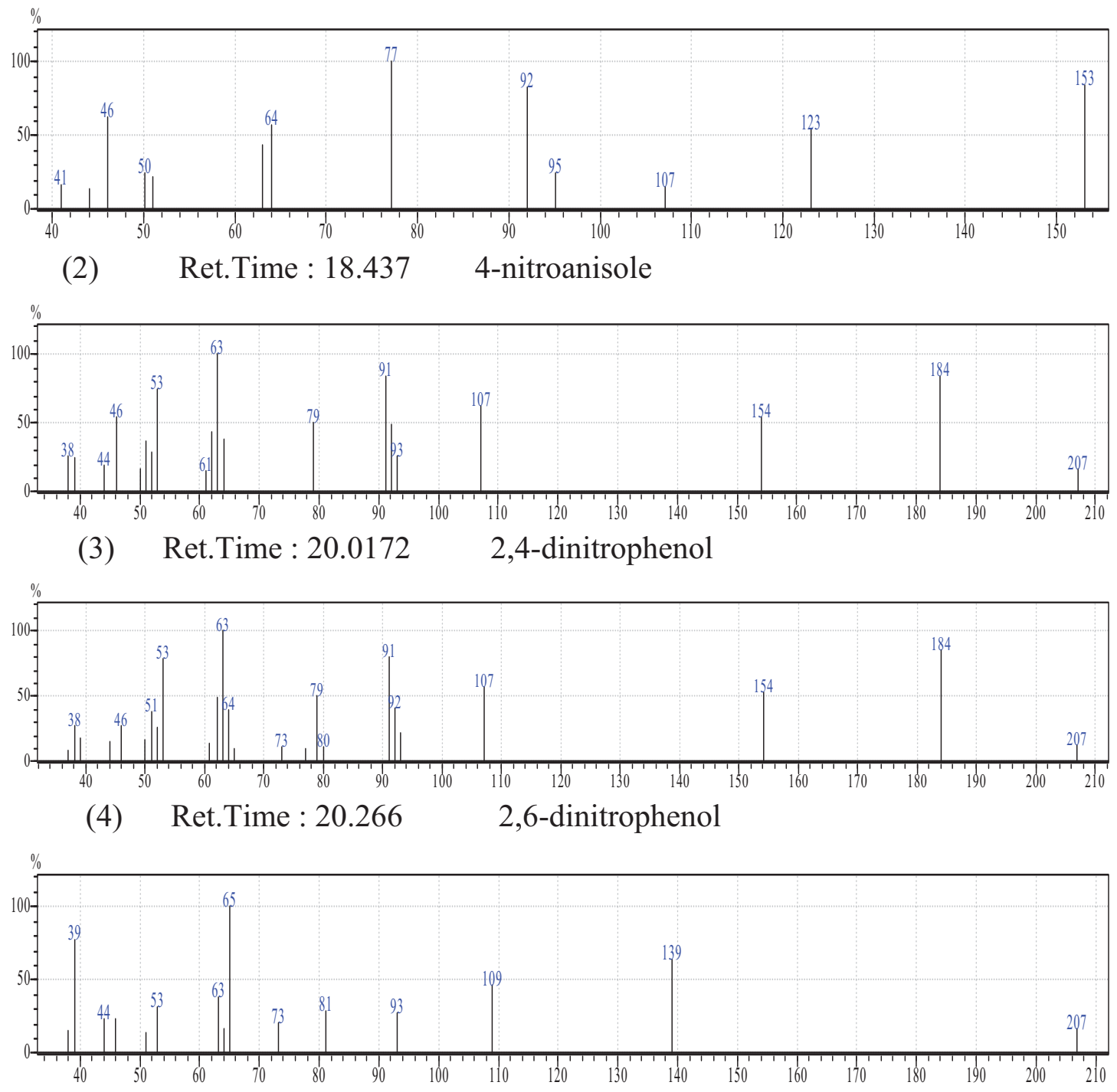

(5) Ret.Time : $22.811 \quad$ 4-nitrophenol

Figure 4.3.b Mass spectra of nitro compounds (2-nitroanisole (1), 4-nitroanisole (2), 2,4dinitrophenol (3), 2,6-dinitrophenol (4), and 4-nitrophenol (5)) produced with anisole and $6 \mathrm{M} \mathrm{HNO}_{3}$ shown in Figure 4.3.a identified from NIST library 
product of nitrous acid protonation (equation 9). This suggests that radiolyticallyenhanced concentrations of nitrous acid may be responsible for enhanced anisole nitration under $\gamma$-irradiation. The main nitration products, nitroanisoles and nitrophenols, were also confirmed using GC-MS (Figure 4.3.a and b).

The yield of nitro-products during thermal nitration was increased further when sodium nitrite was added to the $6 \mathrm{M}$ nitric acid solution showing the effect of the $\mathrm{HNO}_{2}$ catalyzed reaction of anisole. The same experiment of unirradiated anisole in $6 \mathrm{M} \mathrm{HNO}_{3}$ with added hydrazine, a nitrous acid scavenger, ${ }^{[10]}$ produced less concentrated nitroanisoles as shown Figure 4.4 (sometimes two orders of magnitudes less), and did not produce any p-nitrophenol or dinitrophenols. Also, solutions containing hydrazine did not show any color (yellow/ red orange) development which is mainly found to be due to the presence of nitrophenols formed by the $\mathrm{NO}^{+}$interactions. This further confirms the predominant activity of nitrous acid catalyzed nitration reactions in anisole and $6 \mathrm{M}$ $\mathrm{HNO}_{3} \cdot[23,29,30,31]$

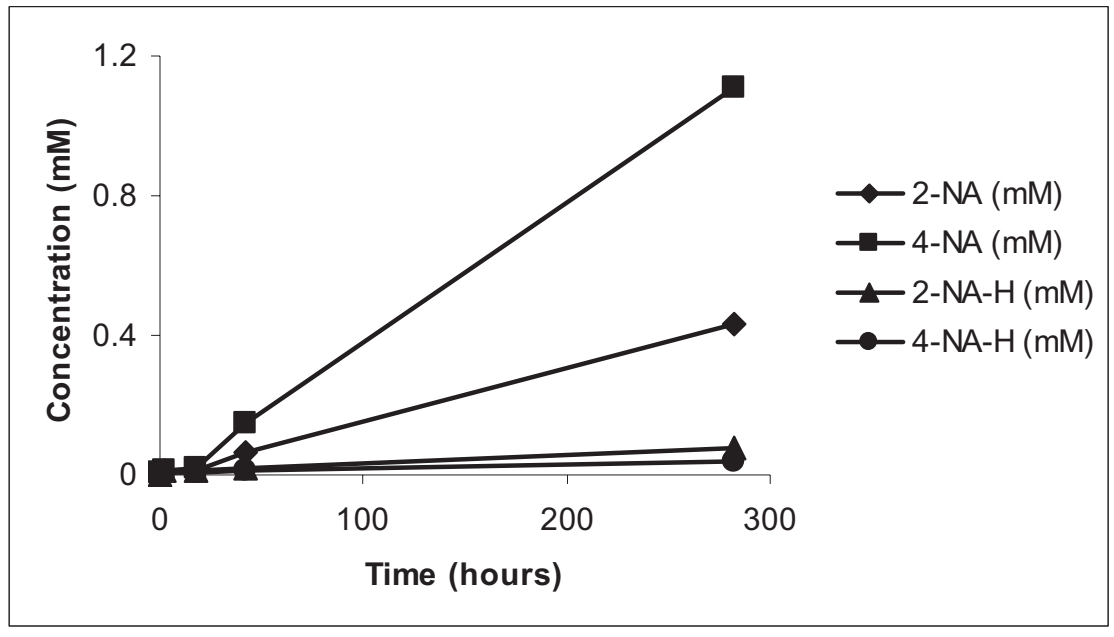

Figure 4.4 The ingrowth of 2-nitroanisole (2-NA) and 4-nitroanisole (4-NA) for thermal anisole reaction with $6 \mathrm{M} \mathrm{HNO}_{3}$ in the presence and absence of the nitrous acid scavenger hydrazine $(\mathrm{H})$ 
The ortho/para nitroanisole ratio found in Figure 4.2 and Figure 4.4 for irradiated solution, and for unirradiated solution without hydrazine of $\sim 0.25-0.35$, is close to that reported ${ }^{[30]}$ for $\mathrm{HNO}_{2}$ catalyzed nitration. Thus, the nitro-anisole products created in irradiated nitric acid may be sufficiently explained via electrophilic aromatic substitution resulting from radiolytically enhanced concentrations of $\mathrm{NO}^{+}$.

However, radiolysis may also increase production of the nitronium ion. At high nitric acid concentrations, the direct radiolysis of undissociated nitric acid produces the primary cation, which can decay to produce nitronium ion, as shown in equation $84 .^{[88]}$

$$
\mathrm{HNO}_{3}^{+} \rightarrow \mathrm{NO}_{2}^{+}+{ }^{\circ} \mathrm{OH}
$$

The scavenging of radiolytically produced $\mathrm{NO}_{2}$ radicals by ${ }^{\circ} \mathrm{NO}_{3}$ radicals is another source of $\mathrm{NO}_{2}{ }^{+}$ion as shown in equation 43. The $\mathrm{N}_{2} \mathrm{O}_{4}$ addition product of the ${ }^{\mathrm{N}} \mathrm{NO}_{2}$ radical will hydrolyze to produce $\mathrm{NO}_{2}{ }^{+[10,59]}$ although this will not be significant here because little $\mathrm{NO}_{2}$ radical was found in the irradiated $6 \mathrm{M} \mathrm{HNO}_{3}$

Despite the possibility of produced $\mathrm{NO}_{2}{ }^{+}$, the ortho/para ratios of the nitroanisole products are more consistent with the nitrous acid catalyzed reaction than with nitronium ion nitration. Nitrous acid produced from nitric acid during radiolysis as shown in equations 85 and $86^{[86]}$ is shown in Figure 4.5.

$$
\begin{gathered}
\mathrm{HNO}_{3} \rightarrow \mathrm{HNO}_{2}+{ }^{\circ} \mathrm{O} \\
\mathrm{HNO}_{3}+{ }^{\circ} \mathrm{O} \rightarrow \mathrm{HNO}_{2}+\mathrm{O}_{2}
\end{gathered}
$$

Given the fast rate constants found for the $\mathrm{NO}_{3}$ radical (Tables 4.1), this electrophilic species was at first expected to be a potential source of anisole nitration in irradiated nitric acid. However, rate constants as high as those measured here for ${ }^{\circ} \mathrm{NO}_{3}$ 
reactions with aromatic compounds have previously been attributed to electron transfer reactions with addition reactions being slower by two-orders of magnitude. ${ }^{[5,21]}$ Further, the rate was slow with benzene, suggesting the reaction is not occurring with the aromatic

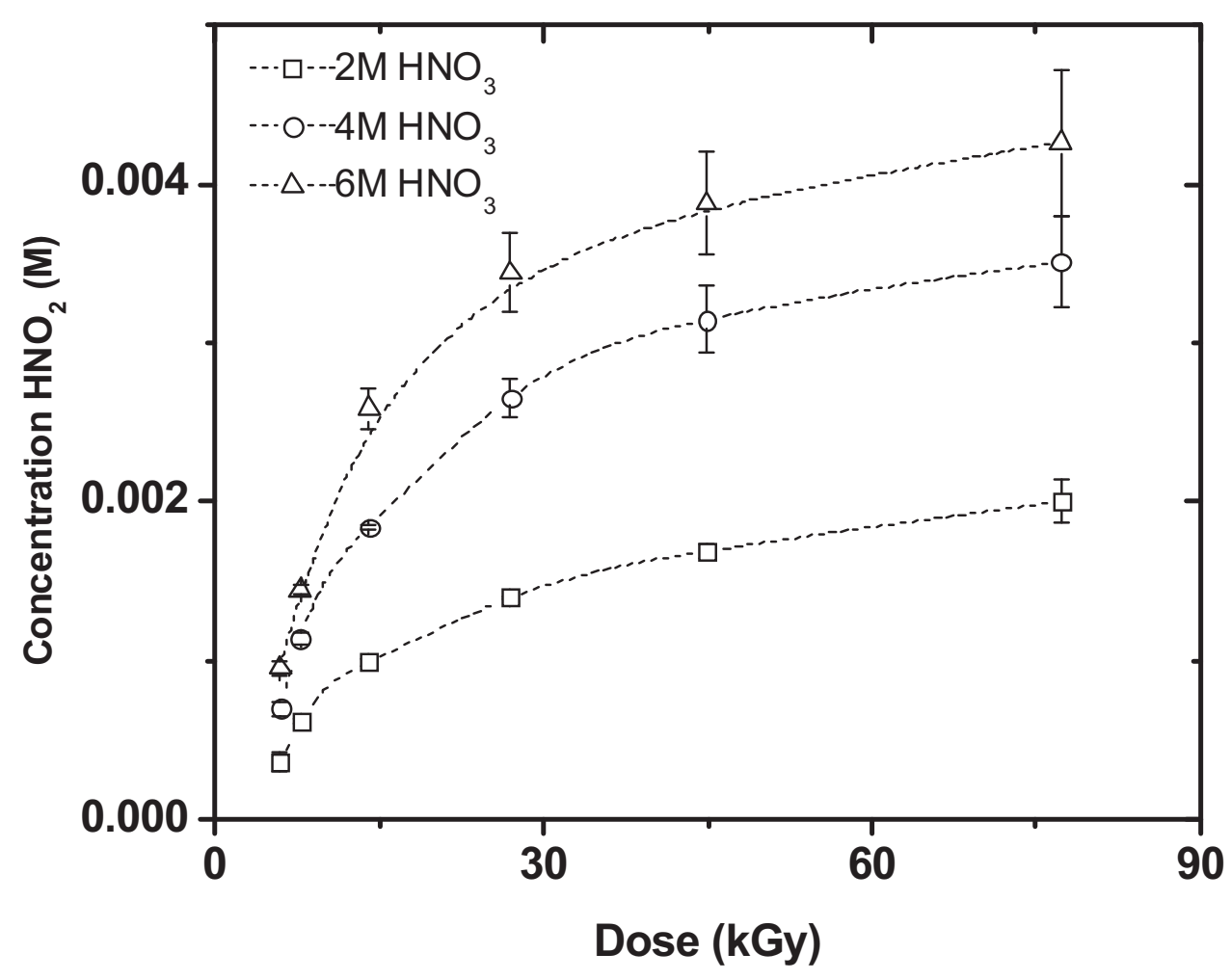

Figure 4.5 The production of nitrous acid with irradiation of nitric acid of different concentrations. Reported errors are the standard deviation of triplicate measurements

ring. Thus, because of the low expected yield of $\mathrm{NO}_{2}{ }^{+}$ion, the fast reaction rates in excess of those for $\mathrm{NO}_{3}$ radical addition, and the consistency of the nitroanisole product yields with $\mathrm{NO}^{+}$ion nitration, it is concluded that anisole nitration under $\gamma$-irradiation is due to radiolytically-enhanced concentrations of nitrous acid in acidic solution.

Despite the formation of nitrophenols, phenol was not detected in the irradiated samples (scheme 3). However, since phenol is even more reactive than anisole, it 
probably produces para nitrophenol immediately. The phenol reaction was investigated with experiments in unirradiated $6 \mathrm{M}$ nitric acid without irradiation at room temperature. Added phenol reacted immediately producing equal amounts of ortho and para nitrophenols within 2 hours. Phenol was no longer detectable. At 23 hours, the para nitrophenol concentration was reduced by half and the ortho nitrophenol to $1 / 10$ of the 2 hour concentration, the result of dinitrophenol formation from both isomers.

Dinitrophenols were also found in the irradiated and unirradiated solutions of anisole.

\subsubsection{Steady-state toluene irradiation in acidic nitrate $\left(6 \mathrm{M} \mathrm{HNO}_{3}\right)$ solution}

Toluene thermal reaction in $6 \mathrm{M}$ nitric acid at room temperature did not show any detectable products using HPLC. However, when this toluene solution was heated at 50 ${ }^{\circ} \mathrm{C}$ for a few hours, it produced detectable levels of ortho- and para-nitro toluenes. Experiments were also conducted by adding sodium nitrite to the nitric acid solution to produce a nitrous acid concentration between 0.01-0.1 M. In all samples the thermal nitration of toluene produced comparably the same amount of 2- and 4-nitrotoluenes and ortho:para ratios of $>1$ indicating that the nitronium ion electrophilic substitution reaction, rather than nitrosonium ion reaction, was the main mechanism of nitration. The nitrosonium ion nitration of anisole was possible in the unirradiated solution only because of the strongly electron-donating methoxy group.

Unlike the anisole experiments, where the same nitration reaction was merely enhanced by irradiation, the HPLC analysis of irradiated toluene samples showed several peaks representing new compounds not produced in the thermal samples (Figure 4.6). Nitrotoluenes, nitrophenols, and nitrobenzene were positively identified. However, several additional peaks could not be assigned by HPLC-UV analyses; these peaks are 
suspected to correspond to compounds produced by side-chain substitution and oxidation $^{[20]}$ reactions. Ortho- and para-nitrotoluenes were produced only in minor quantities (Figure 4.7). Analyses of the irradiated samples by UPLC-MS with electrospray and atmospheric pressure chemical ionization (ESI/APCI) and time of flight mass analyzer (TOF) showed 2,4- and 2,6-dinitrophenol, dinitrocresol, benzaldehyde with traces of benzaldehyde oxime, nitrobenzene, trinitrotoluene, and $N$-methyl- $N-2,4,6-$ tetranitroaniline (tetryl) (Figure 4.8). Detection of several of these compounds is in agreement with the GC-MS results where 2,6-dinitrophenol, 3,5-dinitro o-cresol, diphenyl ether, benzaldehyde, benzoic acid and benzaldehyde oxime were detected. All these products are in agreement with Halfpenny ${ }^{[19]}$ and Titov ${ }^{[20]}$ as resulting from freeradical reaction mechanisms. Some of these products are shown in equations 66,67 and 69.

The ortho:para ratio of nitrotoluenes was only $\sim 0.05$ and trace amounts of meta nitrotoluene were detected in some higher dose samples. The detection of traces of the meta product and the very low ortho/para ratio of these products, as well as the low product yields suggests that the nitronium $\left(\mathrm{NO}_{2}^{+}\right)$or nitrosonium $\left(\mathrm{NO}^{+}\right)$electrophilic substitution reactions are not an important source of nitration in the irradiated acidic toluene system. 


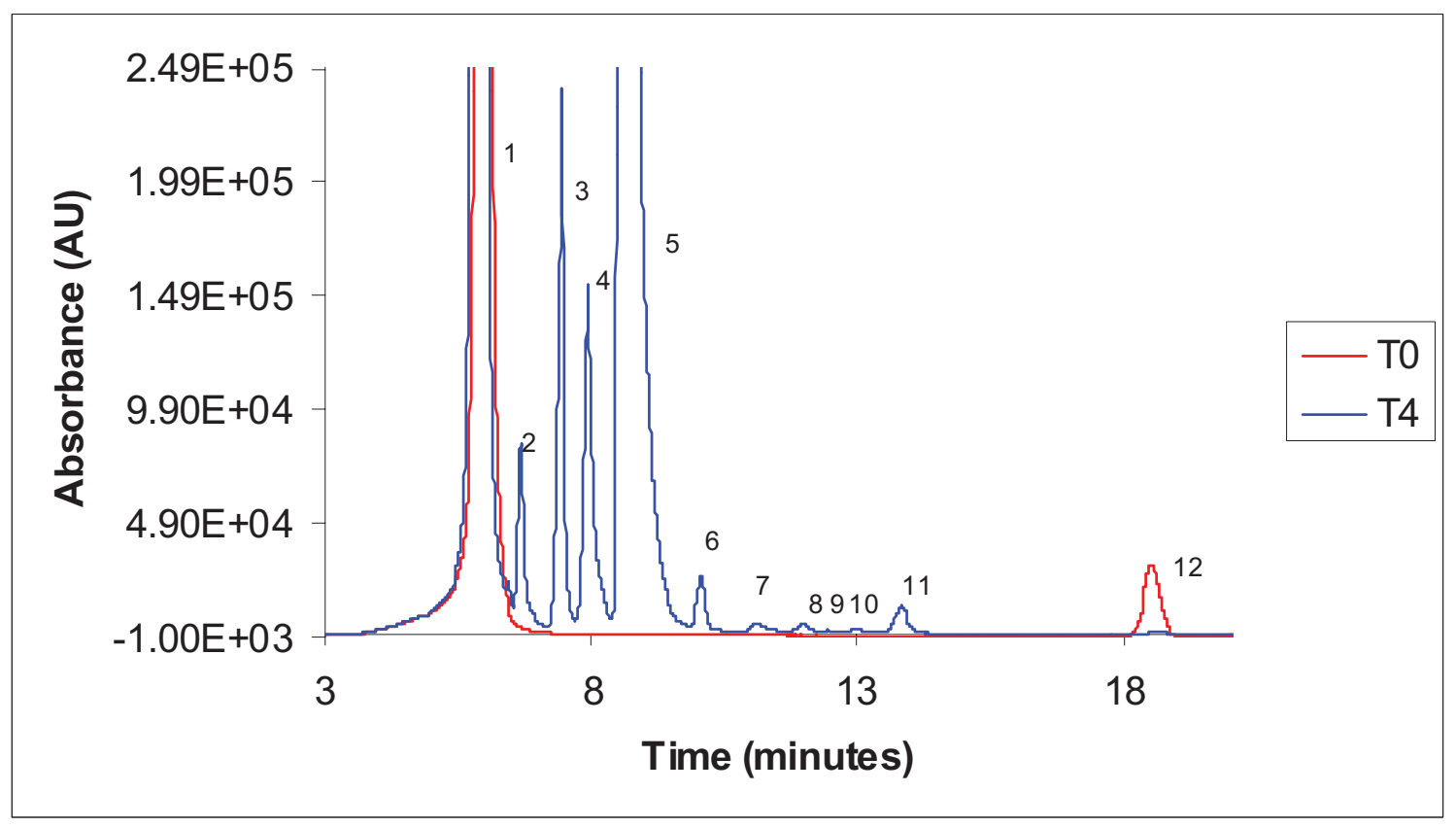

Figure 4.6 HPLC-UV chromatogram of toluene and $6 \mathrm{M}$ nitric acid before (T0, $0 \mathrm{kGy}$ irradiation dose) and after irradiation (T4, $8.45 \mathrm{kGy}$ ). Peaks: (1) Mixture of nitric acid and dinitrophenol (2), (3), and (5) nitrophenol like UV spectra (4) nitrous acid (6) nitrobenzene (7) and (8) 2-nitrotoluene-like UV spectra (9) 2-nitrotoluene (10) 4nitrotoluene (11) unknown (12) toluene. HPLC conditions: reverse-phase C-18 column, 55:45 methanol/water, column temperature: $55^{\circ} \mathrm{C}$, Flow rate: $0.5 \mathrm{~mL} /$ minute, isocratic elution and UV detection at $254 \mathrm{~nm}$

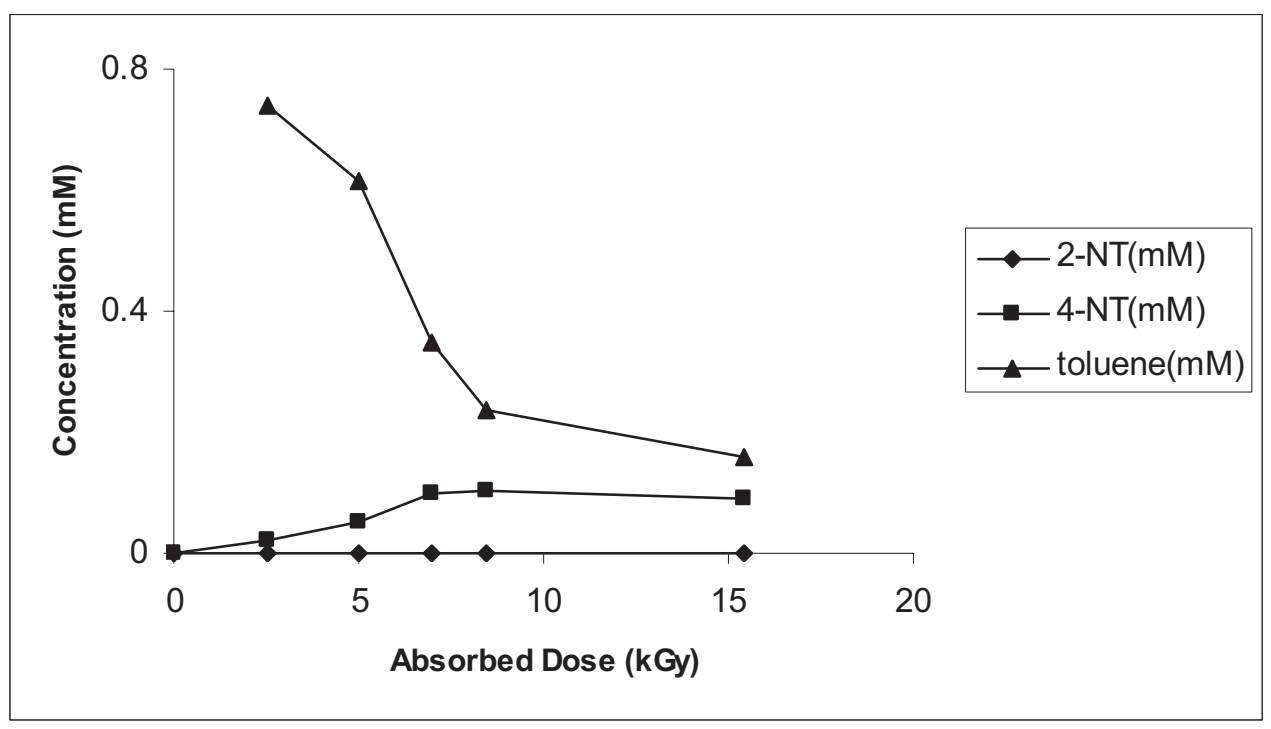

Figure 4.7 The loss of toluene (T) and production of 2-nitrotoluene (2-NT) and 4nitrotoluene (4-NT) for irradiated toluene in $6 \mathrm{M}$ nitric acid solution 
The ${ }^{\circ} \mathrm{NO},{ }^{\circ} \mathrm{NO}_{3}$ and ${ }^{\circ} \mathrm{NO}_{2}$ radicals from nitric acid radiolysis ${ }^{[89]}$ might create opportunities for free-radical nitration reaction mechanisms in the irradiated toluenenitric acid medium. The nitration mechanisms may be initiated by an ${ }^{\circ} \mathrm{H}$ atom abstraction reaction from the toluene alkyl group, by radiolytically-produced ${ }^{\circ} \mathrm{OH},{ }^{\circ} \mathrm{H},{ }^{\circ} \mathrm{NO}_{3},{ }^{\circ} \mathrm{NO}_{2}$, or NO. The reaction gives rise to a free alkyl radical, shown in equation 68 for the ${ }^{\circ} \mathrm{NO}_{2}$ reaction.

A subsequent addition reaction between the alkyl carbon-centered radical with an additional $\mathrm{NO}_{2}$ or $\mathrm{NO}$ or even an $\mathrm{NO}_{3}$ radical would result in a derivative with nitro substitution on the alkyl chain, as shown in equations 68-70.

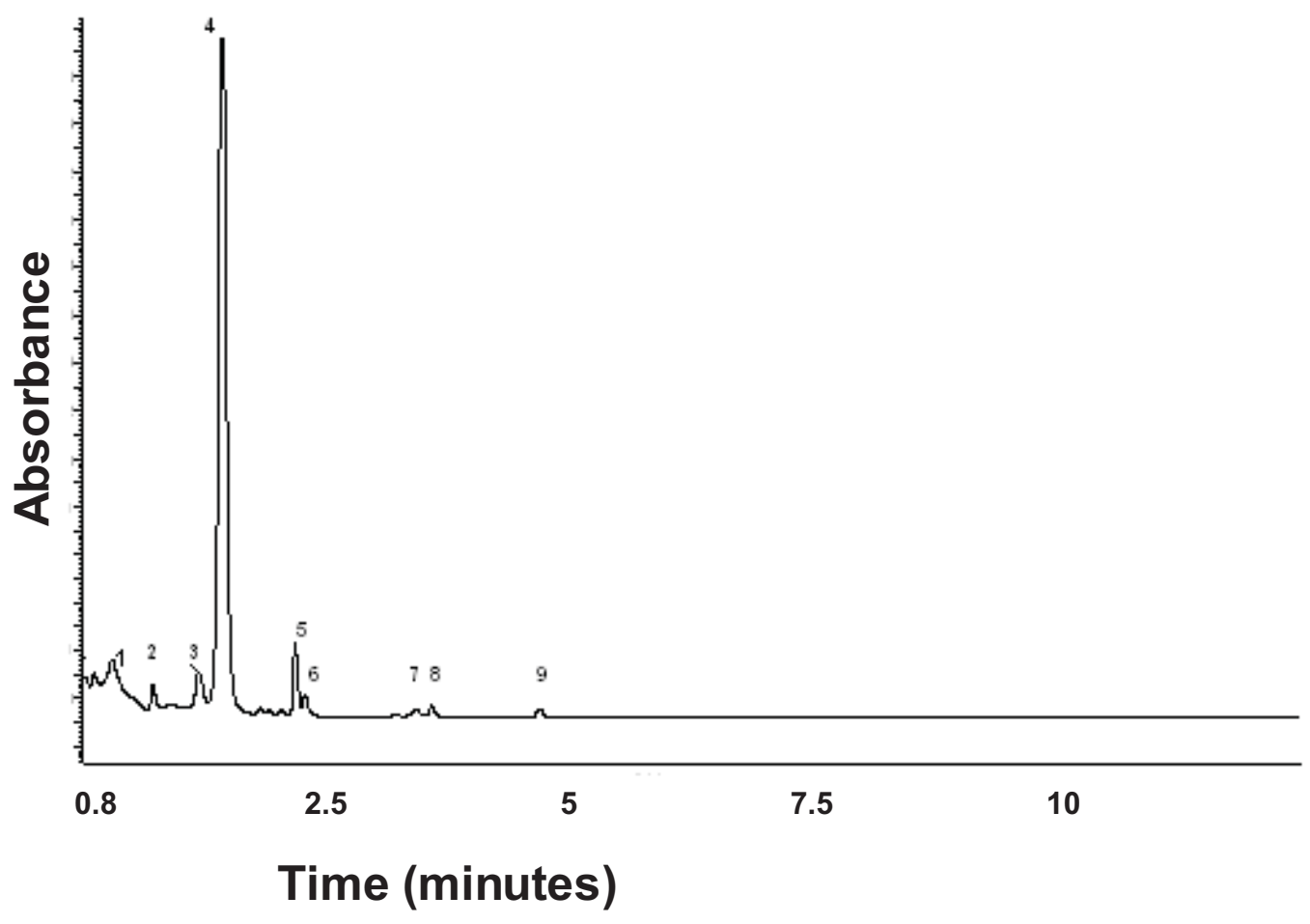

Figure 4.8 UPLC- ESI/APCI ( + and - ion mode) with UV and TOF. Chromatogram of toluene and nitric acid with 43.8 kGy absorbed dose. Peaks: (1) 2,4- and 2,6dinitrophenol, (2), and (3) dinitrocresol, (4) benzaldehyde with trace of benzaldehyde oxime, (5) trinitrotoluene, (6) nitrobenzene, (7), (8) and (9) tetryl. UPLC conditions: reverse-phase $\mathrm{C}$ - 18 column, methanol/water-gradient elution, column temperature: $50^{\circ} \mathrm{C}$, Flow rate: $0.4 \mathrm{~mL} /$ minute, $\mathrm{UV}$ detection at $254 \mathrm{~nm}$ 
Reactions such as these on the toluene methyl group account for some of the unidentified species reported for toluene irradiation in the HPLC chromatogram. The LC-MS and GC-MS identified nitrophenols, nitrocresols and side chain oxidation products. However, the reaction of the $\mathrm{NO}_{2}$ radical with various analytes is typically slower than that of ${ }^{\circ} \mathrm{NO}_{3}$ and ${ }^{\circ} \mathrm{OH},{ }^{[53]}$ while the reaction kinetics of ${ }^{\circ} \mathrm{NO}$ radical are not well characterized. Thus the initial ${ }^{\circ} \mathrm{H}$ atom abstraction is probably due to reaction with $\mathrm{OH}$ or ${ }^{\circ} \mathrm{NO}_{3}$.

Alternately, direct addition of ${ }^{\circ} \mathrm{NO}_{2}$ radical to the ring is possible. According to Titov's concept, ${ }^{[20]} \mathrm{NO}_{2}$ adds to the aromatic $\pi$-sextet to form a nitrocyclohexadienyl radical followed by dehydrogenation to form nitro substitution on the ring as shown in equations $10-11$. The formation of nitrotoluenes, nitrocresols, nitrophenols, phenylnitromethanes, benzaldehyde, benzoic acid, p-nitrobenzoic acid, esters of organic acids, ether, and oximes have all been discussed by Titov based on radical reaction mechanisms. ${ }^{[20]}$ Products such as phenylnitromethane can be transformed into benzaldehyde in an acid-catalyzed reaction. ${ }^{[10]}$ However, alternate reaction mechanisms with ${ }^{\circ} \mathrm{NO}_{2}$ and ${ }^{\circ} \mathrm{OH}$ with toluene to give similar products are also available. ${ }^{[19]}$ Direct addition reactions of ${ }^{\circ} \mathrm{NO}_{2}$ radical are expected to be kinetically slow, however, the yields of nitro products in irradiated toluene were also very low. The production of detectable amounts of ring substitution compounds like nitrophenols, nitrocresols, nitrobenzene, and nitrotoluenes with irradiation showed that the ${ }^{\circ} \mathrm{OH}$ mediated hydrogen abstraction mechanism (equation 1) followed by ${ }^{\circ} \mathrm{NO}$ or ${ }^{*} \mathrm{NO}_{2}$ radical addition is the most likely route to nitration. From the evaluation of all these products, a conclusion is reached that the reaction mechanism of toluene nitration under irradiation in acidic solution is mainly a 
free-radical mechanism. This is in contrast to the results for anisole, where free-radical reactions did not compete with ionic nitration mechanisms.

\subsubsection{Anisole irradiation in neutral nitrate solution}

If nitrous acid is the principal radiolytically-generated nitrating species in irradiated acidic nitrate solution, the concentrations of nitroanisole products should be significantly reduced in neutral nitrate solution. Radiolytic production of $\mathrm{HNO}_{2}$ from $\mathrm{HNO}_{3}$ is shown in equations 85 and 86 and the decrease in $\mathrm{HNO}_{2}$ production in dilute $\mathrm{HNO}_{3}$ is shown in Figure 4.5. When $1.1 \mathrm{mM}$ anisole in $6 \mathrm{M}$ sodium nitrate was $\gamma$ irradiated, fewer nitrated products were generated. The anisole concentration decreased but was still detectable at a concentration of about $0.1 \mathrm{mM}$ after $64 \mathrm{kGy}$, and was only below the detection limit at the highest absorbed dose of $220 \mathrm{kGy}$. The major nitrated product was again 4-nitroanisole. Its maximum concentration, which occurred at 18.2 kGy (See Figure 4.9; change in retention times of the compounds were accounted for using standards), was a factor of 100 less than that produced at a similar dose in nitric acid. Some 3-nitroanisole was also produced, but at concentrations too low to accurately quantify. However, this appearance of meta-nitroanisole suggests the participation of $\mathrm{NO}_{2}$ radical reactions, although with low prevalence.

The production of 4-nitrophenol also occurs in these samples, and at $18.2 \mathrm{kGy}$ it is about a factor of 20 less than that produced at a similar dose in nitric acid. The overwhelming production of the 4-nitroanisole, and the production of 4-nitrophenol again suggests that an ionic electrophilic aromatic substitution mechanism still occurs in the initially neutral nitrate solution. However, for these solutions the nitro-products were observed only after irradiation. This suggests the radiolytic formation of small amounts 
of nitrous acid in the initially neutral solution. Some acid is radiolytically produced in neutral water as was shown in equation 36. The nitroanisole product ortho/para ratio ranged from $0.7-2.5$ over the absorbed dose range 18.2 to $220 \mathrm{kGy}$. However, onitrophenol and p-nitrophenol were detected at $18.2 \mathrm{kGy}$ and only p-nitrophenol by 220 kGy. 2-nitrophenol formation is characteristic of free-radical reactions (scheme 3) ${ }^{[19]}$ and 4-nitrophenol formation is characteristic of nitrous acid catalyzed electrophilic reaction (scheme 1). ${ }^{[29]}$ This product distribution suggests that a combination of electrophilic nitration with $\mathrm{NO}^{+}, \mathrm{NO}_{2}{ }^{+}$, and free-radical reactions with ${ }^{\circ} \mathrm{OH}$ and ${ }^{\circ} \mathrm{NO}_{2}$ occur in irradiated neutral sodium nitrate solution.

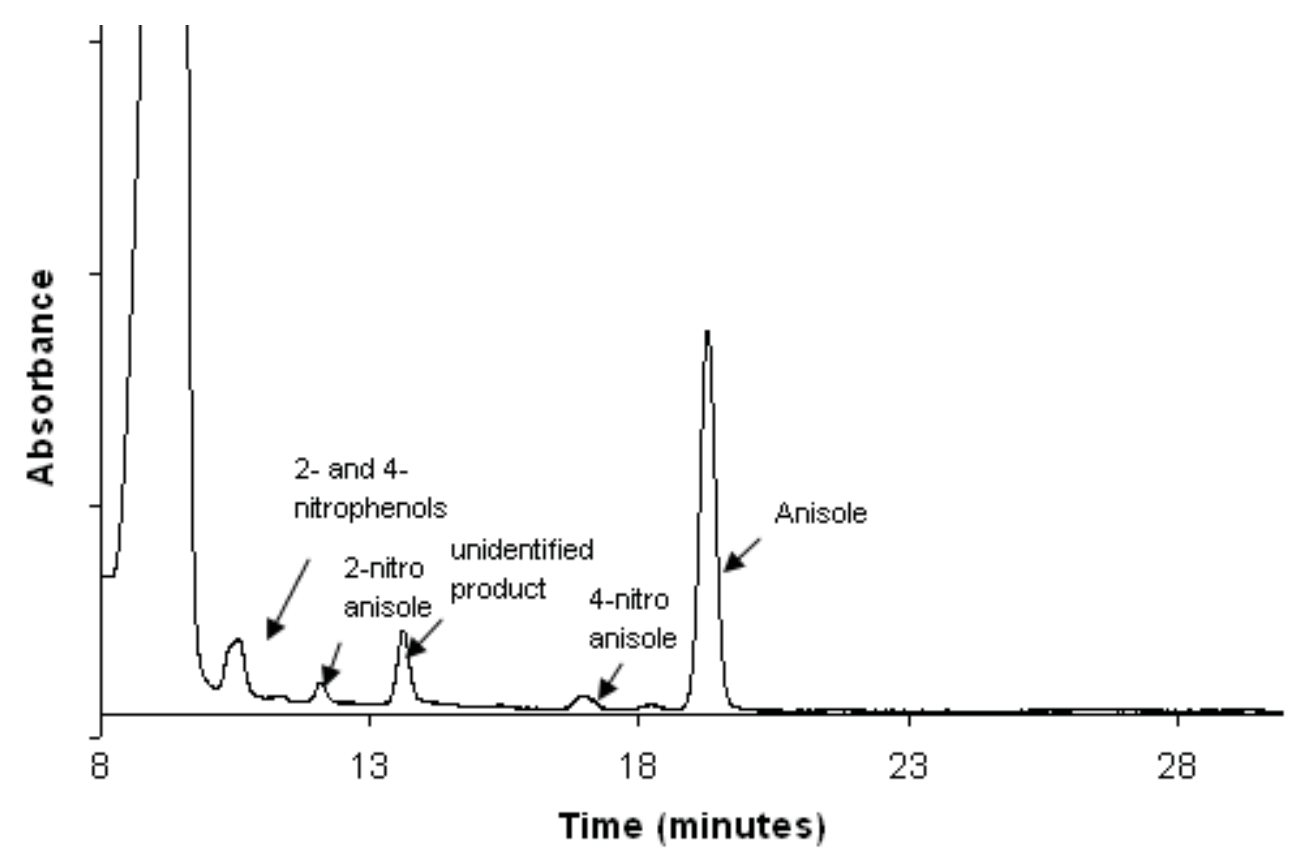

Figure 4.9 HPLC chromatogram (same HPLC conditions as Figure 4.2.a) of anisole and $6 \mathrm{M}$ sodium nitrate solution at $18.2 \mathrm{kGy}$ absorbed dose

\subsubsection{Toluene in irradiated neutral nitrate solution}

The irradiation of toluene in neutral nitrate solution resulted in very low concentrations of 4-nitrotoluene and 3-nitrotoluene. Toluene and 2-nitrotoluene were not 
detected after irradiation in any samples. The presence of the meta isomer suggests that radical addition reactions to the phenyl ring also occur here, as found for anisole under the same conditions. This may be due to the addition of ${ }^{\circ} \mathrm{NO}_{2}$ radical either directly to the phenyl ring, or to aryl carbon-centered radicals. The concentrations of the nitroproducts are very low, precluding mechanistic conclusions aside from the appearance of the meta isomer.

\subsubsection{Anisole in irradiated neutral nitrite solution}

In an effort to investigate only the free-radical addition nitration of anisole, irradiation experiments were also performed in 0.05 - $1 \mathrm{M}$ sodium nitrite. This was necessary because the reaction rate constants for the ${ }^{\circ} \mathrm{NO}_{2}$ radical measured here (Table 4.1) were too low to compete with the faster reactions encountered in the presence of nitrate ion. In this solution, only the ${ }^{\circ} \mathrm{NO}_{2}$ radical was present, according to equation 58 . The spectrum of irradiated neutral nitrite solution, shown for $0.1 \mathrm{M} \mathrm{NO}_{2}$ in Figure 4.1.a, confirmed that ${ }^{\circ} \mathrm{NO}_{2}$ radical is the dominant $\mathrm{N}$-centered radical in this solution.

The decomposition rate of anisole irradiated in neutral nitrite solution was slow. All three nitroanisole isomers were produced in irradiated 0.5 and $1 \mathrm{M}$ sodium nitrite containing 5.1 $\mathrm{mM}$ anisole, and they do not appear to have reached maximum concentrations at the highest absorbed dose of more than $460 \mathrm{kGy}$ (Figure 4.10). It can be seen that the concentrations of ortho- and meta-nitro isomers were high compared to those of the para-nitro isomer. The nitroanisole distribution was 30-50\% for 2- and 3nitroanisoles and 20\% for 4-nitroanisole. This is in qualitative agreement with the statistically random distribution resulting from ${ }^{\circ} \mathrm{NO}_{2}$ radical reactions with toluene, reported by Olah et al. ${ }^{[18]}$ The product 2-nitrophenol was also detected in $0.1 \mathrm{M}$ sodium 
nitrite solution at $346.9 \mathrm{kGy}$, characteristic of free-radical reaction mechanisms in the presence of ${ }^{\circ} \mathrm{OH}$ and ${ }^{\circ} \mathrm{NO}_{2} \cdot{ }^{[19]}$ However, at higher nitrite concentrations, all ${ }^{\circ} \mathrm{OH}$ is scavenged according to equation 58. Therefore, no nitrophenols were detected at higher nitrite concentrations.

\subsubsection{Toluene in neutral nitrite solution}

All three possible nitrotoluenes were produced in irradiated neutral nitrite media. For irradiation in $0.1 \mathrm{M}, 0.5 \mathrm{M}$, and $1 \mathrm{M}$ nitrite, the nitrotoluenes grew in and do not appear to have reached maximum concentrations at the highest absorbed dose of more than $240 \mathrm{kGy}$ except 4-nitrotoluene (Figure 4.11). The most abundant product was the meta isomer. The distribution of the three nitrotoluenes in the three nitrite concentrations were $50-80 \%$ meta, $10-40 \%$ para and $\sim 10 \%$ ortho in the absorbed dose range. Figure 4.11 shows the distribution in $0.5 \mathrm{M}$ sodium nitrite solution. The products 2-nitrophenol

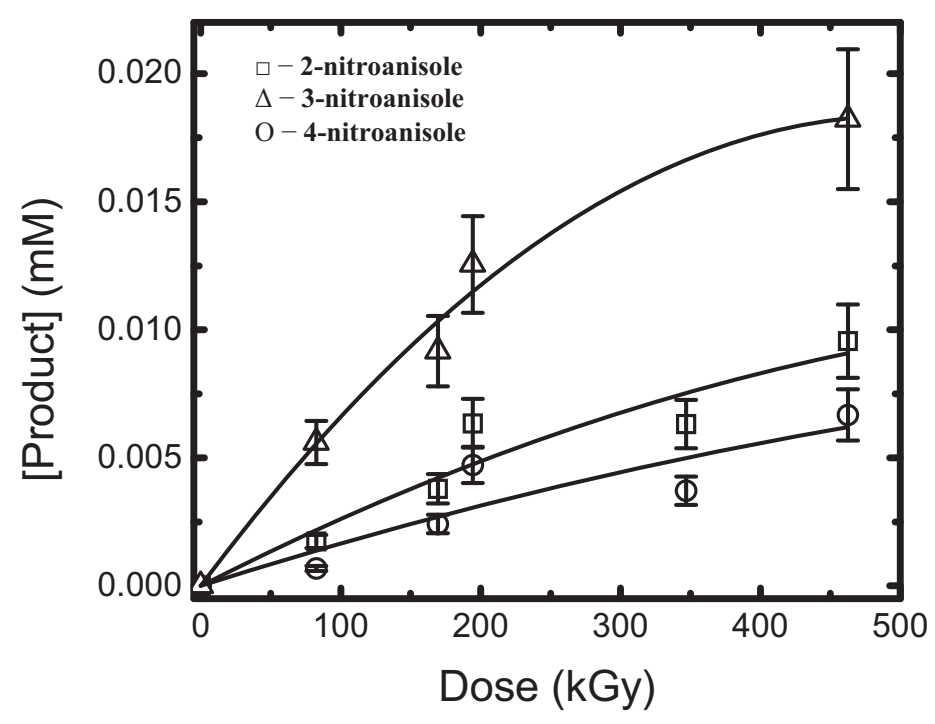

Figure 4.10 The production of 2-nitroanisole (2-NA), 3-nitroanisole (3-NA), and 4nitroanisole (4-NA) as a function of absorbed dose in irradiated anisole in $1.0 \mathrm{M}$ sodium nitrite solution. Reported errors are the standard deviation of triplicate measurements 
and nitrocresols were also detected in $0.5 \mathrm{M}$ sodium nitrite solution, characteristic of free-radical reaction mechanisms in the presence of ${ }^{\circ} \mathrm{OH}$ and ${ }^{\circ} \mathrm{NO}_{2} \cdot{ }^{[19]}$

The absence of evidence for the nitronium and nitrosonium ion reactions in the o:p ratio and the abundance of the meta isomer suggest that ${ }^{\circ} \mathrm{NO}_{2}$ radical reactions are also responsible for the nitration of toluene in neutral irradiated nitrite solution.

These results at a single nitrite concentration do not definitively identify the mechanism as ${ }^{\circ} \mathrm{NO}_{2}$ radical addition (equations $10-11$ ), due to the possibility of reaction with radiolytically produced ${ }^{\circ} \mathrm{OH}$ radical, since this species has a much higher rate constant for reactions with anisole and toluene than ${ }^{\circ} \mathrm{NO}_{2}$ radical (Table 4.1). The ${ }^{\circ} \mathrm{OH}$ radical could react by hydrogen atom abstraction (equation 52). The resulting

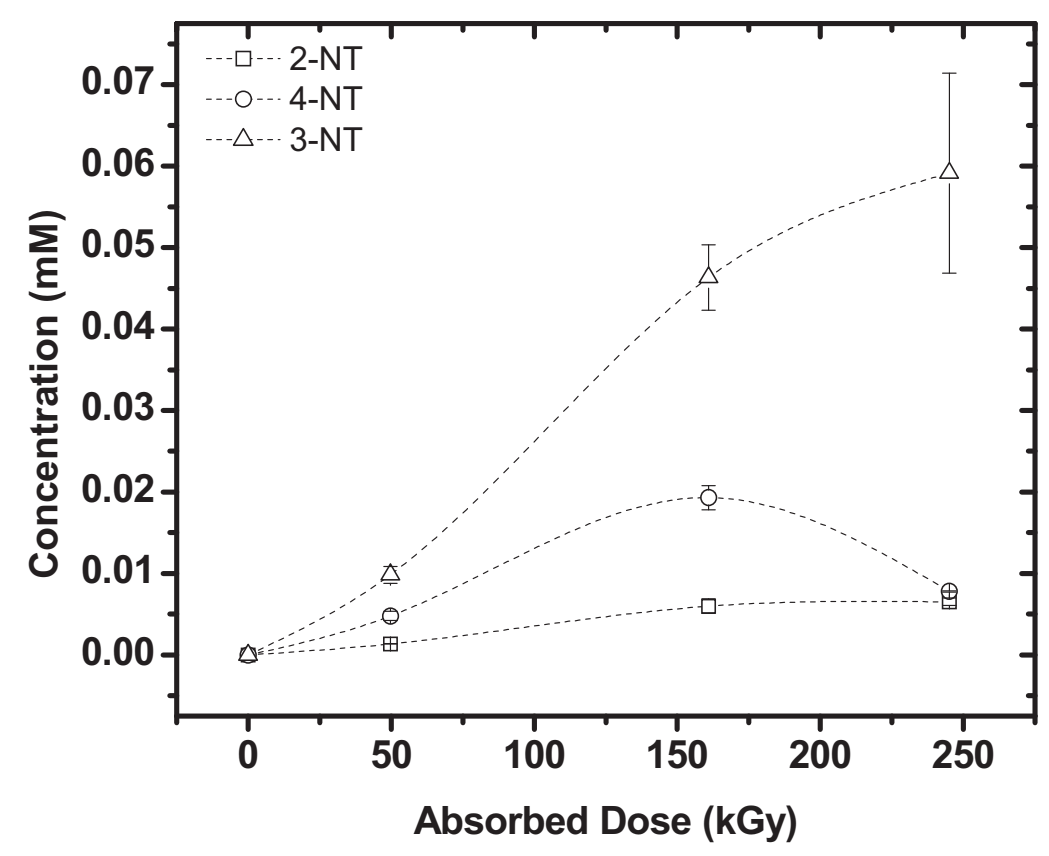

Figure 4.11 The production of 2-nitrotoluene (2-NT), 3-nitrotoluene (3-NT), and 4nitrotoluene (4-NT) as a function of absorbed dose in irradiated toluene in $0.5 \mathrm{M}$ sodium nitrite solution. Reported errors are the standard deviation of triplicate measurements 
carbon-centered radicals might then add ${ }^{\circ} \mathrm{NO}_{2}$ radical to produce the nitrated species (equation 13). Therefore, irradiations at varying nitrate concentrations were used to completely scavenge the ${ }^{\circ} \mathrm{OH}$ radical according to equation 58. Figure 4.12.a shows a plot of meta-nitroanisole and Figure $4.12 \mathrm{~b}$ shows a plot of meta- nitrotoluene production versus nitrite concentration at $460 \mathrm{kGy}$ and $245 \mathrm{kGy}$ respectively in irradiated neutral nitrite solution. It can be seen that the yield of the nitroanisole and nitrotoluene increased with the increase in nitrite concentration. It may therefore be concluded that the reaction must be due to ${ }^{\circ} \mathrm{NO}_{2}$ radical addition, produced from nitrite anion (equation 58), rather than via addition of ${ }^{\circ} \mathrm{NO}_{2}$, by ${ }^{\circ} \mathrm{OH}$ radical initiation. These curves level off at the high nitrite concentrations, indicating that all produced ${ }^{\circ} \mathrm{OH}$ radical has been scavenged at that nitrite concentration.

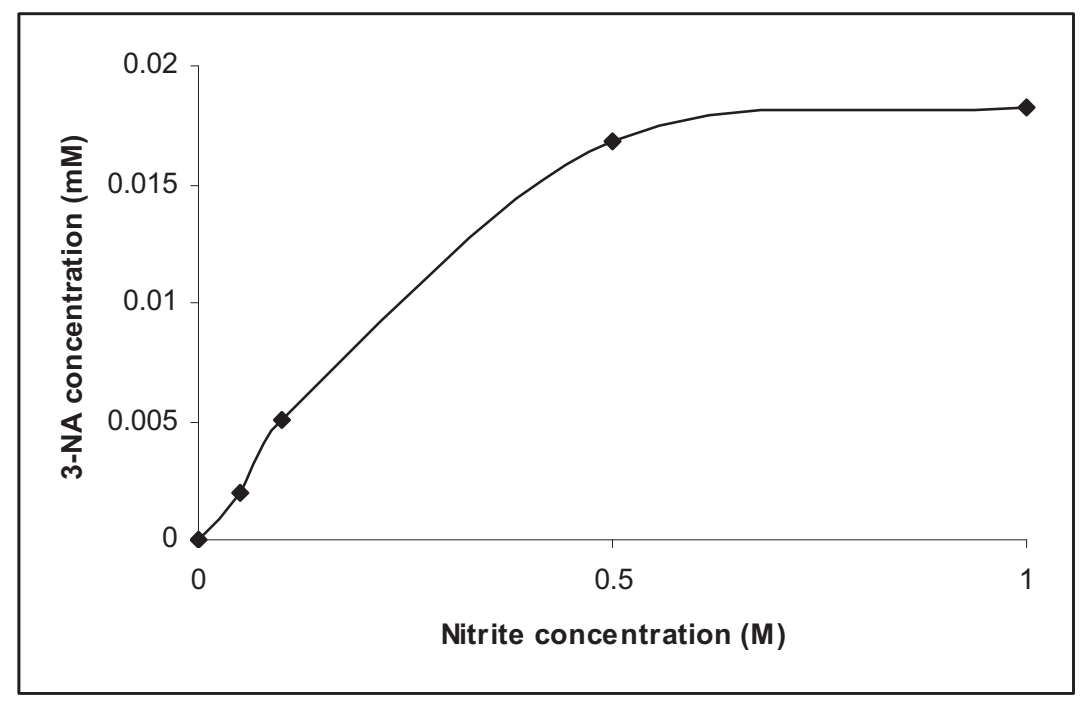

Figure 4.12.a Growth of meta nitroanisole as a function of nitrite concentration at an absorbed dose of $460 \mathrm{kGy}$ 


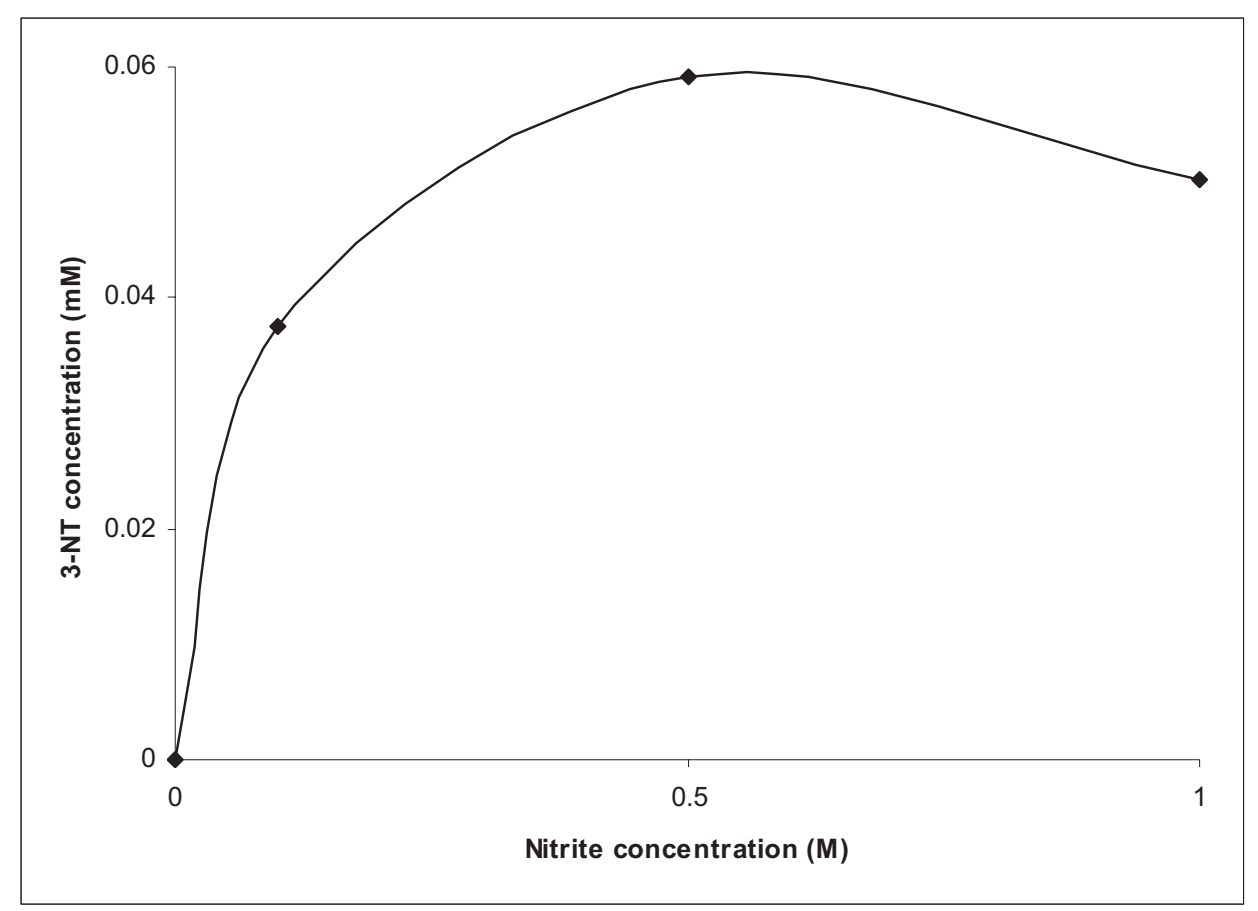

Figure 4.12.b Growth of meta nitrotoluene as a function of nitrite concentration at an absorbed dose of $245 \mathrm{kGy}$

\subsection{Cs-7SB}

\subsubsection{Cs-7SB Gamma-Irradiation}

The compound 1-(2,2,3,3,-tetrafluoropropoxy)-3-(4-sec-butylphenoxy)-2propanol (Cs-7SB) modifier, is used in the Fission Product Extraction (FPEX) solvent formulation for the extraction of Cs and $\mathrm{Sr}$ from dissolved nuclear fuel. The formulation also contains the ligands calix[4]arene-bis-(tert-octylbenzo-crown-6) (BOBCalixC6) for Cs extraction and 4,4',(5')-di-(t-butyldicyclohexano)-18-crown-6 (DtBuCH18C6) for Sr extraction all in Isopar L, a branched-chain alkane diluent. FPEX solvent has favorable extraction efficiency for $\mathrm{Cs}$ and $\mathrm{Sr}$ from acidic solution and was investigated at the INL for changes in extraction efficiency after $\gamma$-irradiation. ${ }^{[90]}$ Decreased extraction efficiency was found after irradiation, and this suppression of solvent extraction efficiency was 
identical for Cs and Sr despite that they are complexed by different ligands. This suggests that radiolysis of the modifier, which solvates both metal complexes, is responsible for this change. ${ }^{[13]}$

The products of Cs-7SB irradiation were investigated by gas chromatography with electron capture detection (GC-ECD). Figure 4.13 shows chromatograms for unirradiated Cs-7SB, Cs-7SB irradiated in the presence and absence of $1.5 \mathrm{M}$ nitric acid and FPEX solvent irradiated in the presence of $1.5 \mathrm{M}$ nitric acid, all to $400 \mathrm{kGy}$. Pure, unirradiated Cs-7SB has three ECD peaks, at approximately 25.2, 25.4 and the main peak at 25.7 minutes. For irradiated neat Cs-7SB, it can be seen that the main modifier peak at 25.7 minutes decreased, as did the 25.2-minute peak. The minor peak at 25.4 minutes grew in quickly. ${ }^{[13]}$

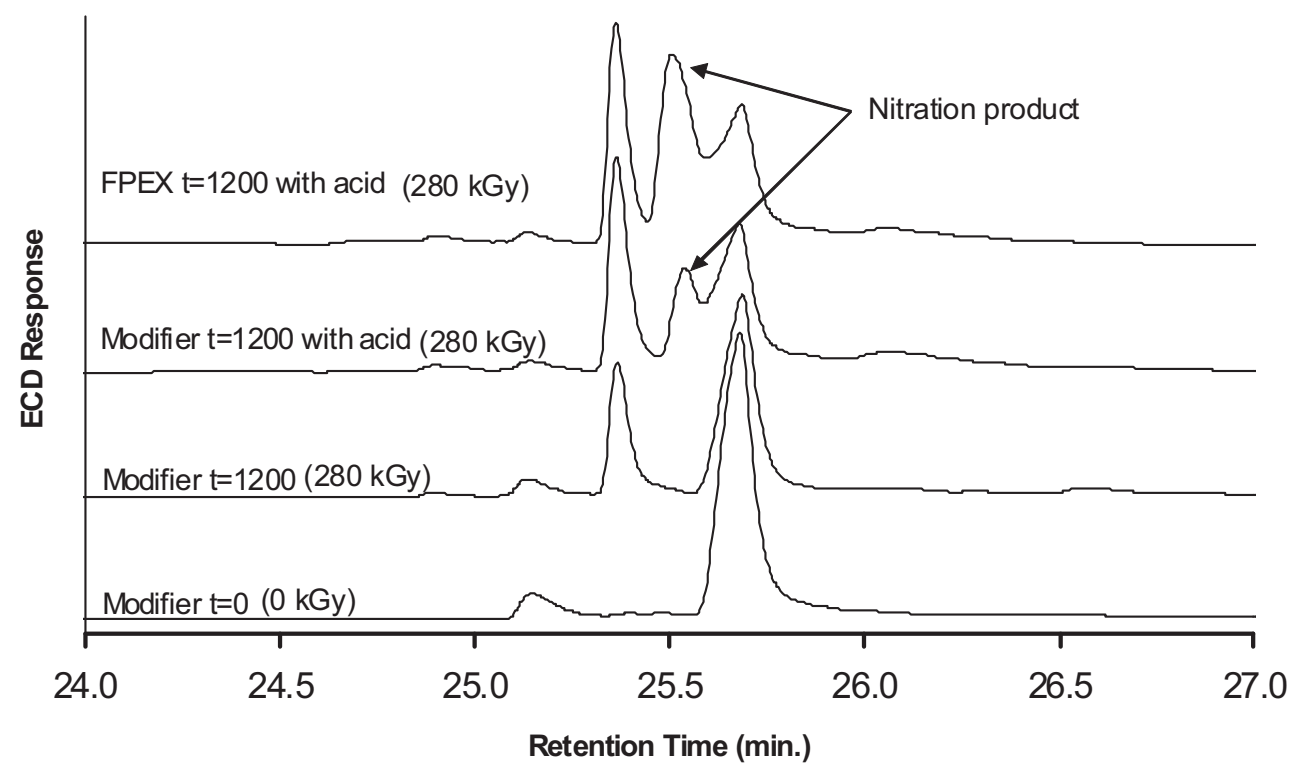

Figure 4.13 GC-ECD chromatograms for FPEX and Cs-7SB modifier samples irradiated to $400 \mathrm{kGy}$ in the presence and absence of $1.5 \mathrm{M}$ nitric acid

A new ECD peak at 25.5 minutes occurs only when Cs-7SB or FPEX was irradiated in the presence of the nitric acid. This was accompanied by a color change to yellow, and 
then to yellow-orange with increasing absorbed dose. The combination of color change to yellow-orange, and the generation of an ECD responsive peak that only occurs during irradiation in the presence of nitric acid suggest that Cs-7SB nitration is occurring.

\subsubsection{Cs-7SB Pulse Radiolysis- Kinetic Study}

To determine which of the reactive radical species is most important in Cs-7SB

reactions, pulse radiolytic kinetic investigations were performed on a series of samples ${ }^{[87]}$ containing varying concentrations of aqueous Cs-7SB. The solution conditions were adjusted to favor the radical of choice, for which the rate constant was to be determined. Second-order rate constants for the reaction between the radical and Cs-7SB were determined and are shown in Table 4.2. Unlike the ${ }^{\circ} \mathrm{NO}_{3}$ and ${ }^{\circ} \mathrm{NO}_{2}$ radicals, the ${ }^{\circ} \mathrm{OH}$ radical has no useful absorbance in the appropriate wavelength range, competition kinetic methods were used to determine the rate constant. The ${ }^{\circ} \mathrm{OH}$ radicals were produced in equation 75 and 76 with $\mathrm{N}_{2} \mathrm{O}$ for this reaction. The ${ }^{\circ} \mathrm{OH}$ radical reaction rate constants with $\mathrm{Cs}-7 \mathrm{SB}$, were determined using $\mathrm{SCN}^{-}$competition kinetics, monitoring the decrease in absorbance of the produced ${ }^{\circ}\left(\mathrm{SCN}_{2}\right)^{-}$transient at $475 \mathrm{~nm}$ upon increasing addition of Cs7SB (equation 78).

$$
\begin{gathered}
{ }^{\circ} \mathrm{OH}+\mathrm{SCN}^{-}\left(+\mathrm{SCN}^{-}\right) \rightarrow \mathrm{OH}^{-}+{ }^{\cdot}(\mathrm{SCN})_{2}^{-} \quad k_{78}=1.05 \times 10^{10} \mathrm{M}^{-1} \mathrm{~s}^{-1} \\
\cdot \mathrm{OH}+\mathrm{Cs}-7 \mathrm{SB} \rightarrow\left({ }^{\bullet} \mathrm{Cs}-7 \mathrm{SB}\right)+\mathrm{H}_{2} \mathrm{O} \quad k_{87}
\end{gathered}
$$

Since the rate constant $k_{78}$ is well-known, the unknown rate constant $k_{87}$ can be found from the following expression:

$$
\left[{ }^{\circ}(\mathrm{SCN})_{2}{ }^{-}\right]_{0} /\left[{ }^{\bullet}(\mathrm{SCN})_{2}{ }^{-}\right]=1+k_{87}[\mathrm{Cs}-7 \mathrm{SB}] / k_{78}\left[\mathrm{SCN}^{-}\right]
$$


Where $\left[{ }^{\circ}\left(\mathrm{SCN}_{2}\right)^{-}\right]_{\mathrm{o}}$ and $\left[{ }^{\circ}\left(\mathrm{SCN}_{2}\right)^{-}\right]$are the concentrations of ${ }^{\circ}\left(\mathrm{SCN}_{2}\right)^{-}$in the absence and presence of added Cs-7SB, respectively. From a plot of $\left[{ }^{\circ}\left(\mathrm{SCN}_{2}\right)^{-}\right]_{\mathrm{o}} /\left[^{\circ}\left(\mathrm{SCN}_{2}\right)^{-}\right]$versus $[\mathrm{Cs}-$ $7 \mathrm{SB}] /\left[\mathrm{SCN}^{-}\right]$a straight line was obtained with the slope corresponding to the ratio of $k_{87 /}$ $k_{78}$. Since the value of $k_{78}$ is known, ${ }^{[77]}$ the value of the Cs-7SB rate constant can be determined. The results for the reactions of the oxidizing radicals with Cs-7SB are shown in Table. 4.2.

Table 4.2 Aqueous bimolecular rate constants for reaction of the oxidizing radical products of aqueous nitric acid with Cs-7SB

\begin{tabular}{|c|c|}
\hline Radical & Rate Constant $\left(\mathrm{M}^{-1} \mathrm{~s}^{-1}\right)$ \\
\hline$\cdot \mathrm{OH}$ & $(2.19 \pm 0.21) \times 10^{9}$ \\
\hline$\cdot \mathrm{NO}_{3}$ & $(2.90 \pm 0.08) \times 10^{9}$ \\
\hline$\cdot \mathrm{NO}_{2}$ & $<10^{6}$ \\
\hline
\end{tabular}

The results in Table 4.2 indicate that the ${ }^{\circ} \mathrm{OH}$ radical and ${ }^{\circ} \mathrm{NO}_{3}$ radical reactions are major contributors to Cs-7SB radiolysis in contact with acidic solution. As for the model compounds, reactions with Cs-7SB involving the ${ }^{\circ} \mathrm{NO}_{2}$ radical are less important due to the low rate constant, which indicates that this radical does not successfully compete. The possible nitration mechanisms of Cs-7SB by comparison to the model compound anisole are discussed in the next chapter. 


\section{Chapter 5}

\section{Common Results of Anisole and Cs-7SB}

Anisole, the model compound, and Cs-7SB, the modifier used in the FPEX extractant, are aryl ethers. The irradiation results of both compounds in nitric acid solution are described in sections 4.1 and 4.2. Anisole is a small molecule and Cs-7SB is a large molecule with longer side chains embedded with several fluorine atoms (Figure 1.2 and Figure 1.3). For this reason, the results of anisole are easier to illustrate with better conclusive remarks than those of the modifier.

The main purpose of this research was to have a basic understanding of the nitration reaction mechanisms of aromatic compounds under irradiation in acidic media. In the irradiated acidic condensed phase, radiation-enhanced nitrous acid-catalyzed electrophilic aromatic substitution dominated over radical addition reactions for anisole. Similar results were expected for Cs-7SB. The dominant activity of the nitrous acid catalyzed reactions in acidic anisole solution was confirmed by the addition of the nitrous acid scavenger, hydrazine, in the acidic solution. The solutions of anisole in $6 \mathrm{M}$ nitric acid turned yellow at room temperature with time, at the irradiator temperature $\left(50{ }^{\circ} \mathrm{C}\right)$, and during irradiation at $50{ }^{\circ} \mathrm{C}$. However, when hydrazine was added to the same acidic solution, there was no color change. Figure 5.1.a shows these color changes in anisole. Figure 5.1.a shows anisole in $6 \mathrm{M} \mathrm{HNO}_{3}$ kept at $50{ }^{\circ} \mathrm{C}$ for a period of time with hydrazine (no color formation) and without hydrazine (yellow color). The same phenomenon was observed for Cs-7SB in the acid (Figure 5.1.b). Chromatographic peaks which represented some nitro products of anisole and the modifier in the acid solutions also failed to appear in hydrazine treated acidic samples (HPLC analysis for 
anisole, and HPLC and LC-MS analysis for the modifier). When saturated anisole in the acidic solution was left for a longer period of time, the solution became turbid with some yellow solid precipitating and finally turned into a yellow solid (Figure 5.1c). The modifier also showed similar yellow-orange color development in acidic saturated solution at $50{ }^{\circ} \mathrm{C}$ and under irradiation (Figure 5.2). Neither anisole nor the modifier showed any color formation in the presence of hydrazine. This shows that the nitrous acid-catalyzed reaction is responsible for the color formation for Cs7SB, in analogy with anisole. Experiments also showed formation of products of higher concentration (deep color) when the nitric acid concentration was higher, as illustrated in Figure 5.1.c. Analysis of the yellow solid produced in anisole solutions of $\mathrm{HNO}_{3}$ using $\mathrm{HPLC}$ and GC-MS showed nitrophenols, especially dinitrophenols. GC-MS analysis of irradiated samples of anisole with nitric acid showed 2- and 4-nitroanisoles, 4nitrophenol, and 2,4- and 2,6-dinitrophenols. FTIR analysis also showed the presence of nitro groups and hydroxyl groups in the yellow solid from anisole (Figure 5.3). The GCECD results of the modifier showed the formation of a new compound in the presence of nitric acid Figure 4.13 (section 4.2.1). Analysis was done on the yellow-orange material created by the $400 \mathrm{kGy}$ irradiation of the Cs-7SB modifier in contact with nitric acid by GC-MS. The Cs-7SB molecular ion mass, at 338 amu, was a relatively low intensity peak in this sample. Major peaks occurred at 121 and 309 amu. The compounds corresponding to these masses are not immediately obvious. Nitrated or defluorination derivatives of the modifier were not detected. The GC-MS could not satisfactorily identify the new compounds. However, LC - MS analysis of the orange layer of the 
modifier showed clearly a hydroxy, nitro-modifier compound which was verified with the mass spectrum (Figure 5.4.a and b).

FTIR analysis of anisole's orange solid (formed from yellow layer) and the modifier's yellow layer revealed the appearance of new absorbance peaks (Figure 5.3) in the irradiated material at approximately $1500-1700 \mathrm{~cm}^{-1}$, possibly corresponding to aldehydes and ketones and/or nitrated products (not easy to distinguish nitro groups); and $3000-3700 \mathrm{~cm}^{-1}$, possibly corresponding to phenols and alcohols. This indicates the formation of some nitrophenols in both the modifier and anisole. 

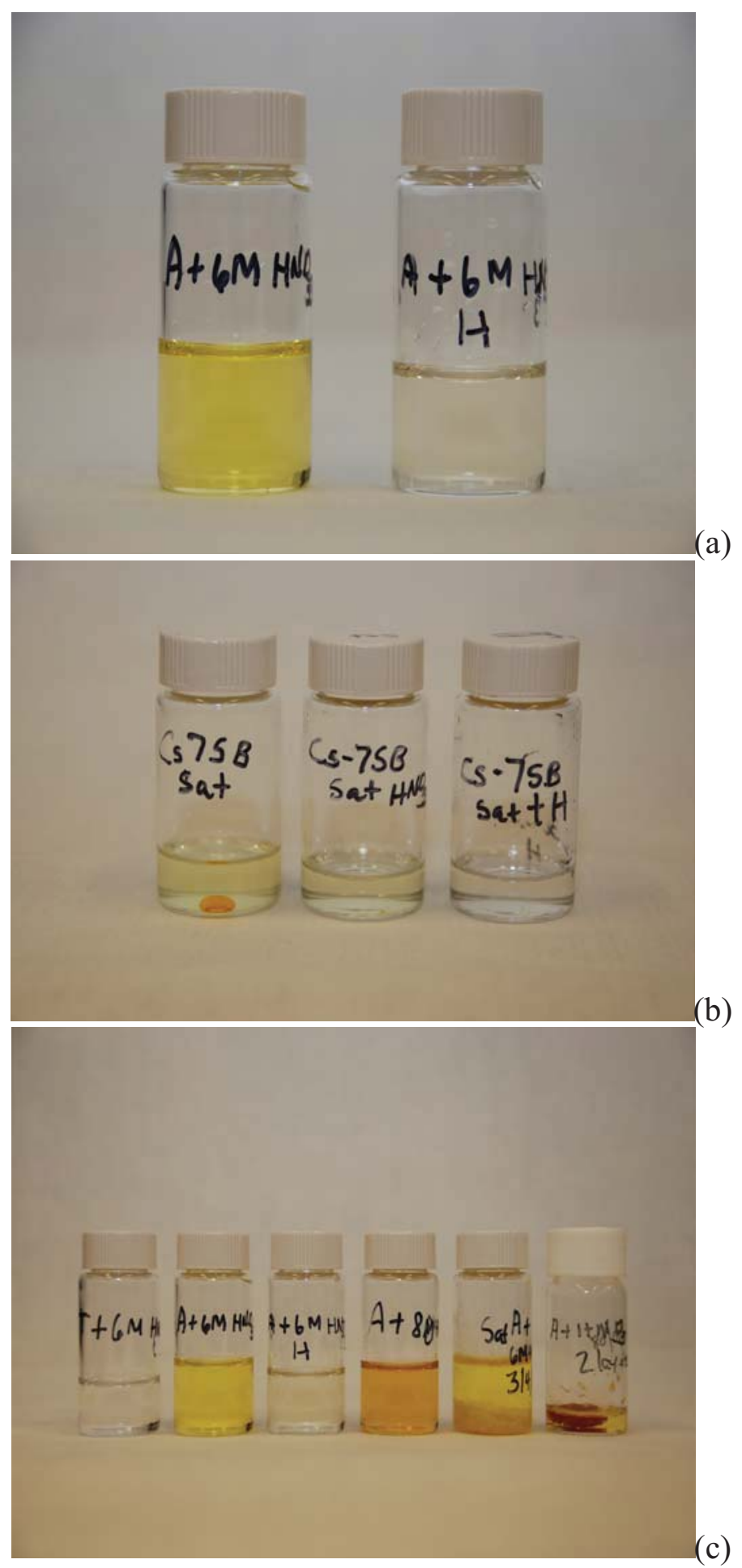

Figure 5.1 Thermal nitration

(a) anisole and $6 \mathrm{M} \mathrm{HNO}_{3}$ with (clear) and without hydrazine (yellow)

(b) Cs-7SB and $3 \mathrm{M} \mathrm{HNO}_{3}$ with (third bottle from the left - clear) and without hydrazine (first bottle from the left - higher concentration and orange/yellow; second bottle from the left - lower concentration and light yellow) 
(c) Far left-toluene $+6 \mathrm{M} \mathrm{HNO}_{3}$ (no color), anisole with $6 \mathrm{M} \mathrm{HNO}_{3}$ (second bottle from the left), anisole $+6 \mathrm{M} \mathrm{HNO}_{3} .+$ hydrazine (third bottle from the left), anisole $+8 \mathrm{M}$ $\mathrm{HNO}_{3}$ (fourth bottle from the left, deeper yellow-orange color), yellow solid formation in anisole and acid after several months (two bottles at the far right)

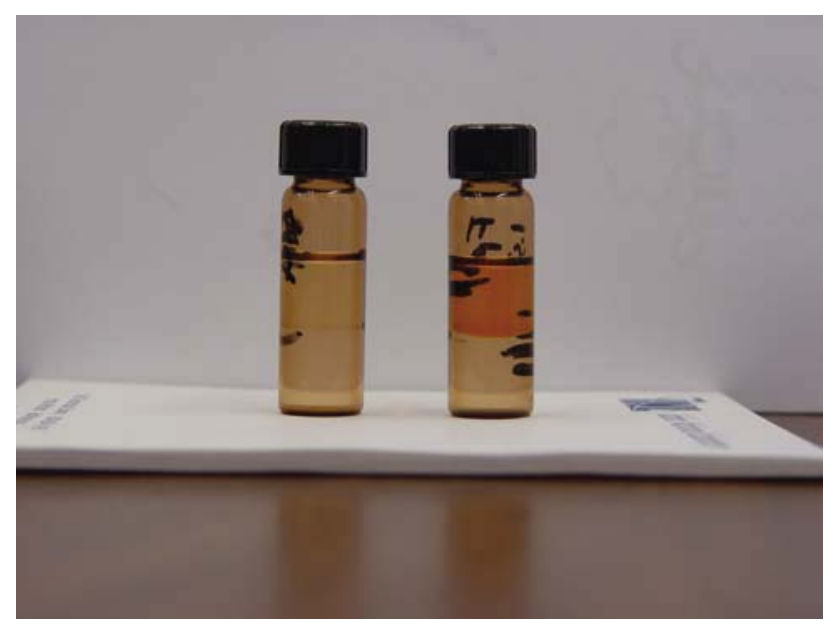

Figure 5.2 Unirradiated (left bottle) and irradiated (right bottle) FPEX solution with Cs$7 \mathrm{SB}$ in $1.5 \mathrm{M} \mathrm{HNO}_{3}$

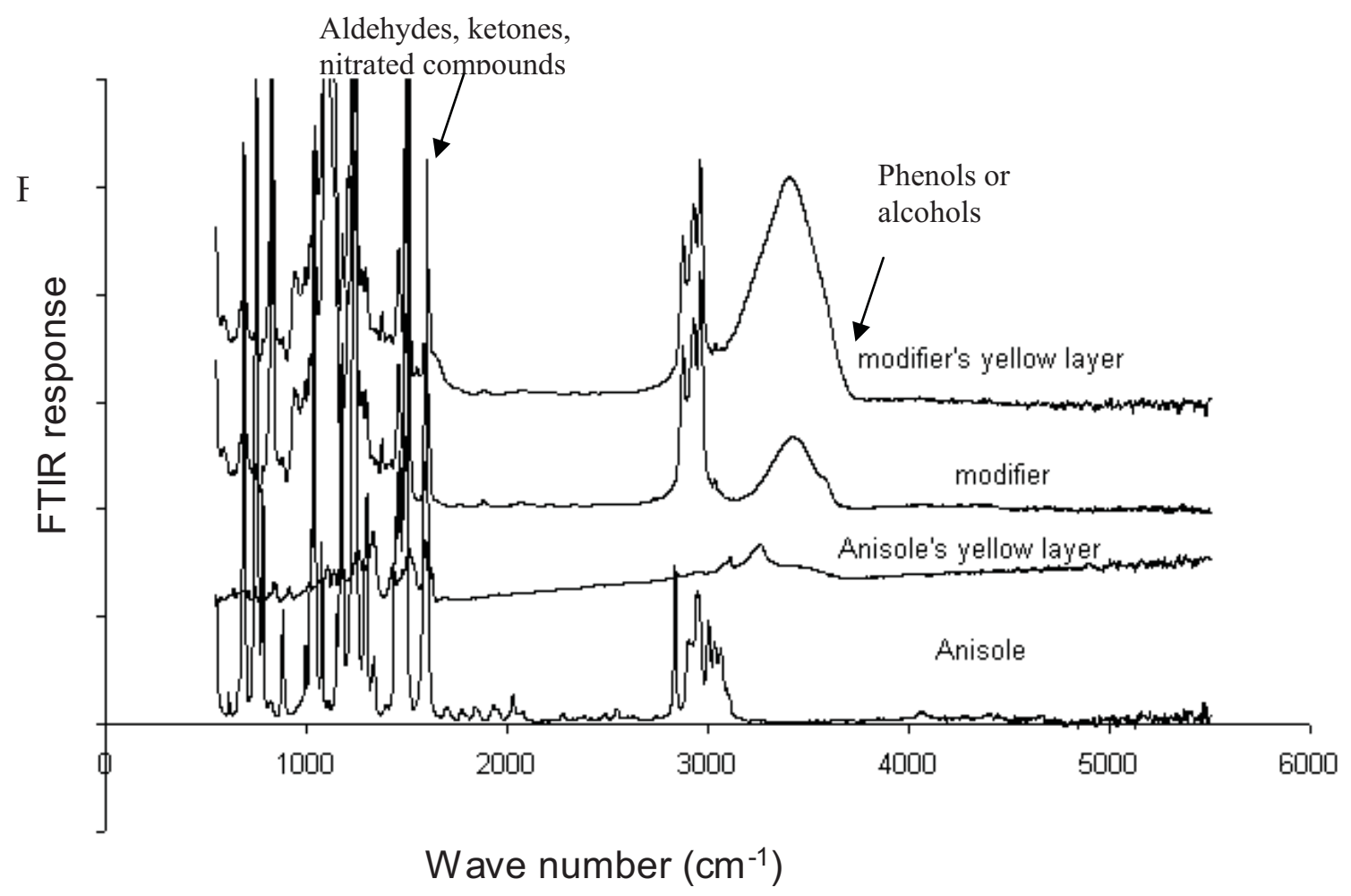

Figure 5.3 FTIR spectra of modifier, yellow-orange modifier layer, anisole, and yellow solid from anisole 


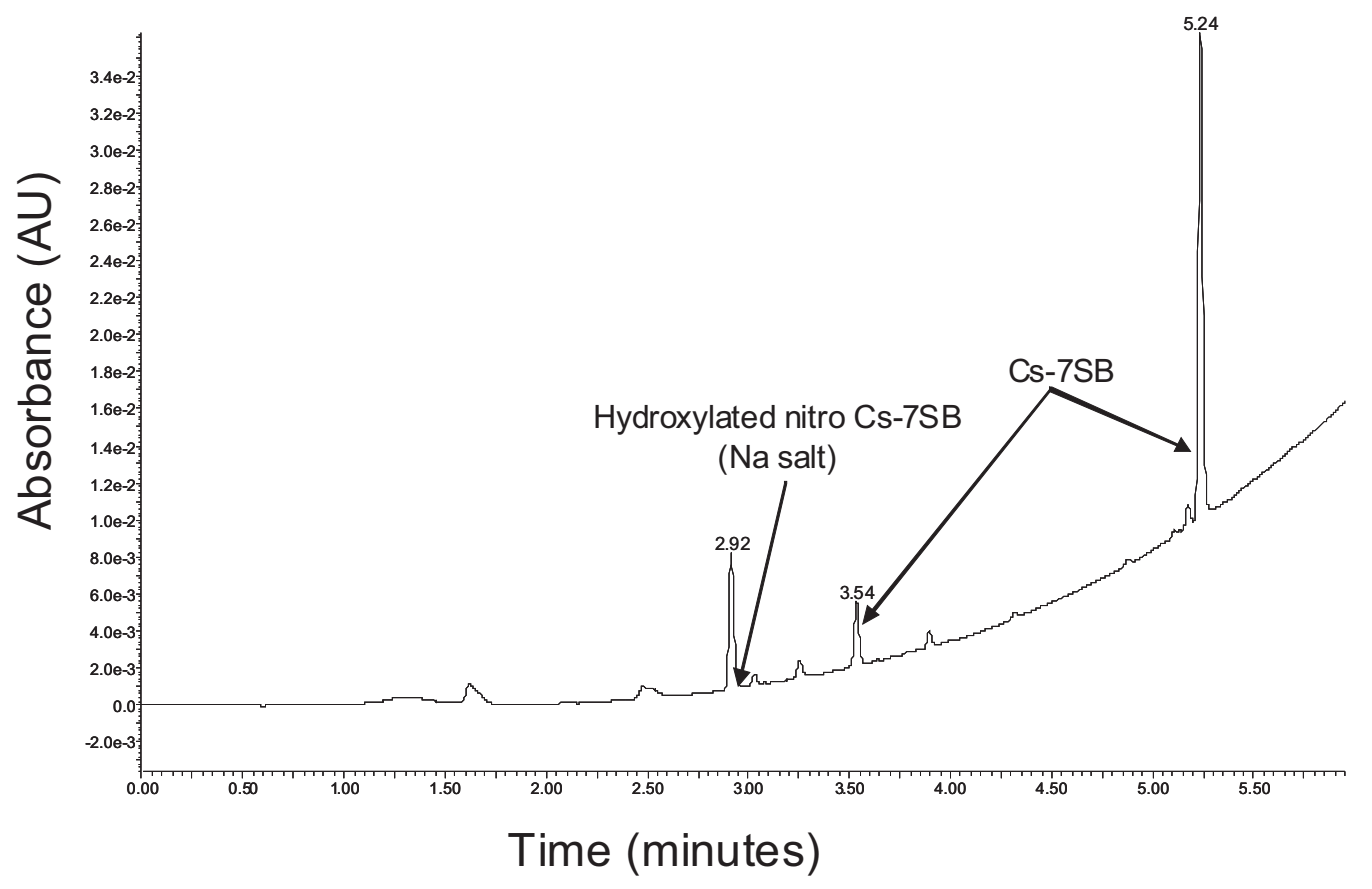

Figure 5.4.a Chromatogram of Cs-7SB orange layer at $254 \mathrm{~nm}$ (LC-UV- MS) Peaks identified are Cs-7SB (3.54 and 5.24 minutes), hydroxylated nitro Cs-7SB compound Na salt (3.06 minutes, the mass spectrum is at this point) 


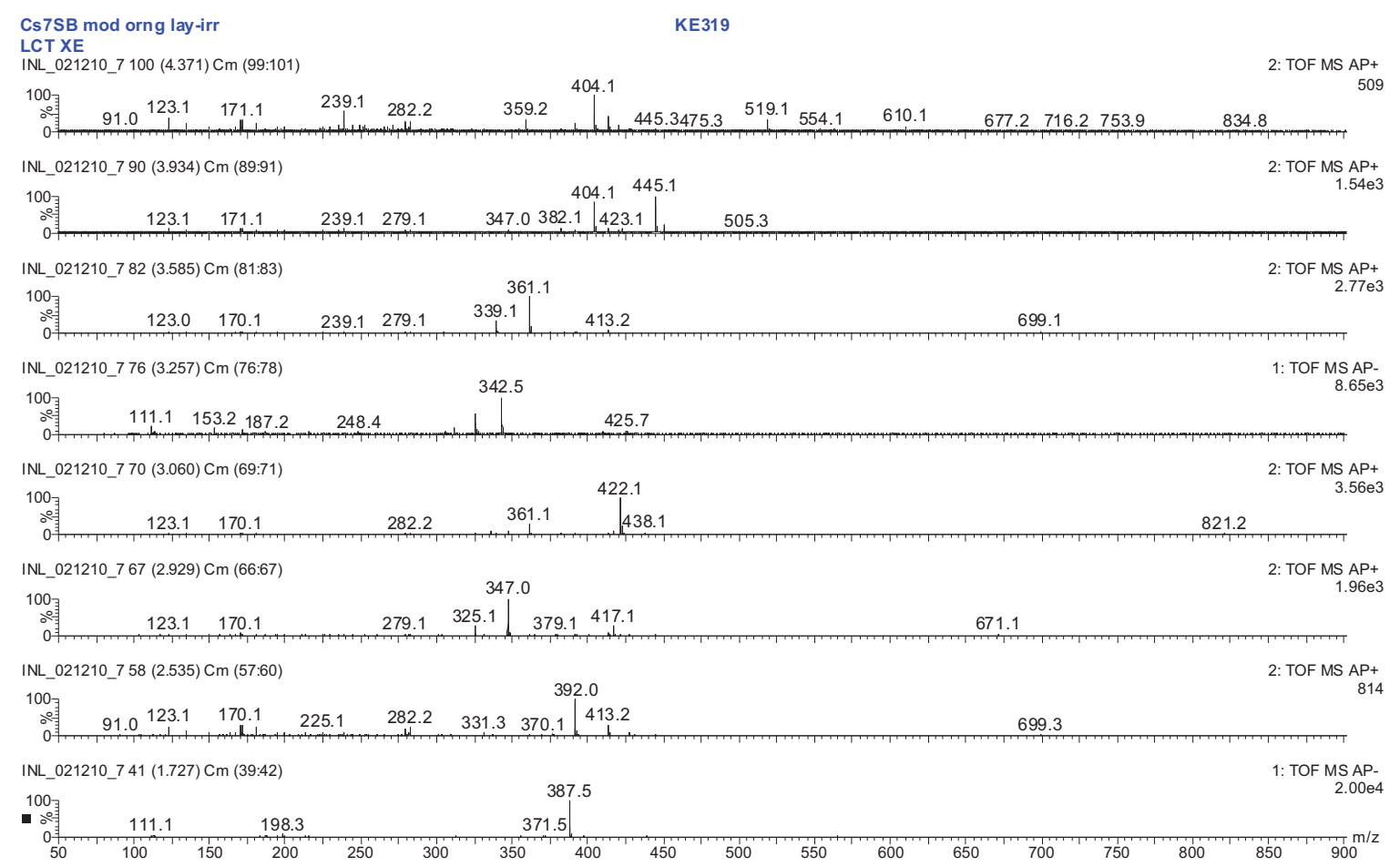

Mass (atomic mass units)

Figure 5.4.b Mass spectra of Cs-7SB orange layer compounds. Mass peaks for Cs-7SB: 339 (3.54 minute), Na salt of Cs-7SB hydroxylated nitro compound: 422 (3.06 minute)

The evidence from these results may be used to predict some products formed in the modifier in contact with nitric acid solution. The nitration of phenyl rings may be initiated by the nitrosonium ion $\left(\mathrm{NO}^{+}\right)$, as shown in equation 89 during thermal reactions and during irradiation. 


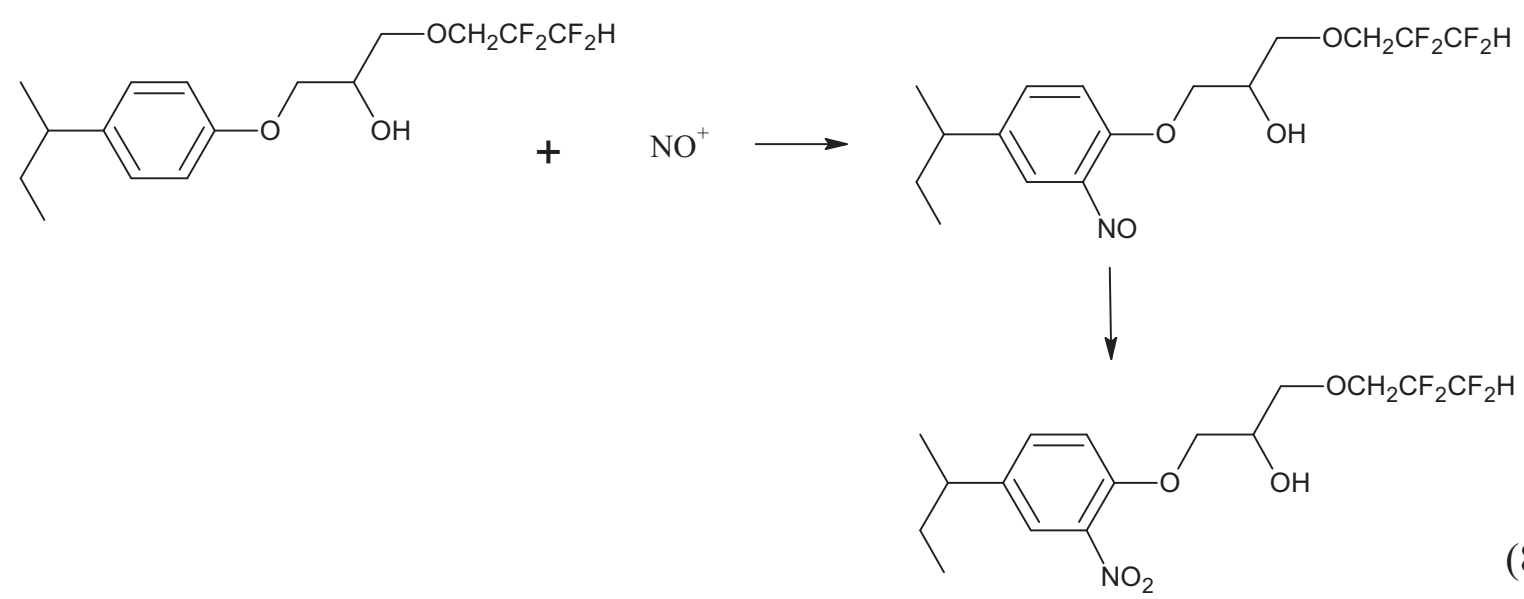

The radiolytic nitration of phenyl rings may be initiated by the hydroxyl radical, ${ }^{[91]}$ and could produce hydroxylated nitro compounds as shown below (equations 90-91).

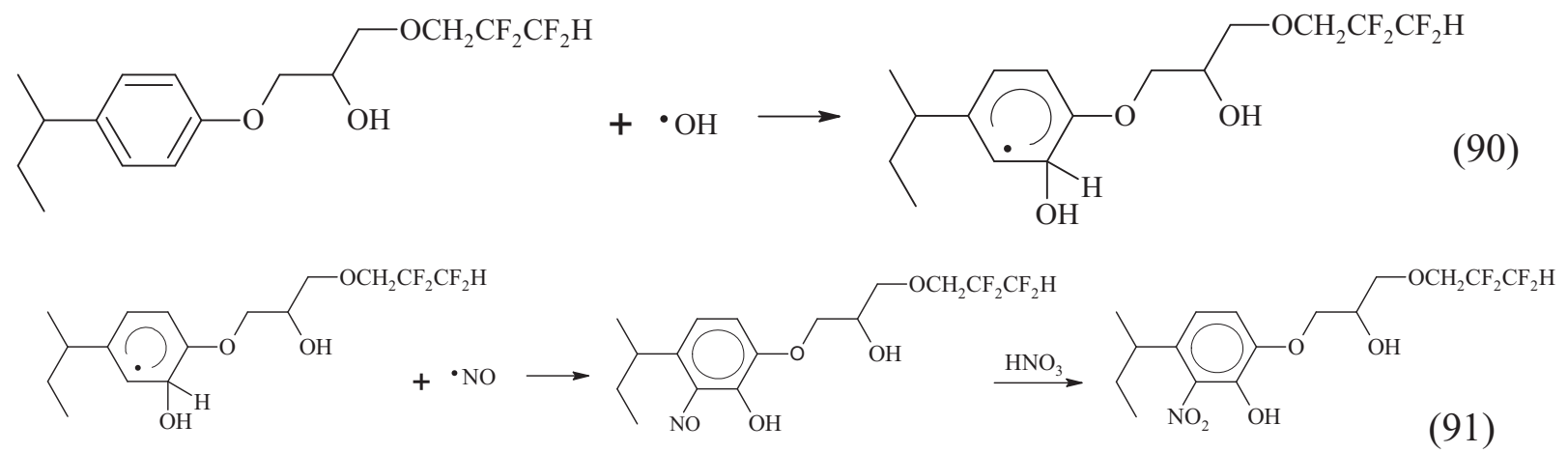

The intermediate product is a cyclohexadienyl radical. For the cyclohexadienyl radical, reactions involving the $\mathrm{NO}$ radical may be important, due to the addition reaction shown in equation 91. The final product is a hydroxylated, nitrated derivative of Cs-7SB. The presence of nitrated oxidation products such as these are probably responsible for the color developed in FPEX when irradiated in the presence of acid, and the appearance of new ECD peaks such as that at 25.5 minutes.

Additional irradiated material was prepared with a 150-kGy irradiation of Cs-7SB in contact with $1.5 \mathrm{M}$ nitric acid. The yellow-orange material in the irradiated solution 
was separated and analyzed by HPLC, spectrofluorometry, and FTIR. HPLC-UV showed three new peaks at $6.34,5.12$, and 3.61-minutes retention times in addition to the modifier peak at 10.1 minutes. The UV spectrum of the 6.34-minute peak was similar to that of the modifier spectrum analogous to the observation of two modifier peaks in LCMS. The UV spectrum of the 5.12-minute peak was similar to that of dinitrophenol. The FTIR analysis results are discussed earlier in this section. Spectrofluorometric results showed quenching of the 294-nm peak normally found for the modifier in the irradiated material. This may be due to the presence of nitrated products; however, this is not unambiguous because it may also be caused by entrained nitrate ion in the material. While the reactions described above are all likely to occur in FPEX solution irradiated in contact with nitric acid, conclusive identification of all the decomposition products has been problematic. However, given the evidence of nitrated and oxidized products in conjunction with anisole-model compound results, the suggested products indicated in equations 89 and 91 are reasonable. 


\section{Chapter 6}

\section{Conclusion}

The reaction mechanisms of anisole (the simplest aryl alkyl ether and a strong ortho-para director) and toluene (an aryl alkyl mild ortho-para director) in nitric acid, neutral nitrate, and neutral nitrite solutions at different temperatures and under $\gamma$ radiolysis and pulse radiolysis were investigated in this research. HPLC with UV detection was primarily used to assess the stable reaction products. GC-ECD was used to investigate product formation in Cs-7SB exposed to nitric acid under irradiation. GCMS, LC-MS, and FTIR were used to confirm the results from HPLC. The distribution of nitrated derivatives of anisole in acidic solution with the predominance of paranitroanisole was the same with and without irradiation, although the concentration of products was higher in the irradiated solution. For anisole in the irradiated acidic condensed phase, radiation-enhanced nitrous acid-catalyzed electrophilic aromatic substitution dominated over radical addition reactions. Therefore, nitration of anisole in acidic solution is predominantly due to nitrosonium ion electrophilic substitution, which is enhanced by the radiolytic production of nitrous acid.

Highly reactive aromatic compounds such as anisole and phenols show catalysis of their nitration by $\mathrm{HNO}_{2}$ in acidic media, whereas it is not common in less reactive aromatic compounds like toluene and benzene. The distribution of nitrated derivatives in unirradiated toluene showed nitronium ion electrophilic substitution in the acidic medium as a result of thermal nitration, but only at elevated temperatures. Free-radical nitration reaction products were found with irradiation, as mainly evidenced by the production of compounds like nitrobenzenes, nitrocresols, and benzaldehydes. The ring substitution is 
by hydroxyl radical mediated cyclohexadienyl ion formation followed by nitrogen oxide radical addition. The compounds produced by side chain oxidation are as a result of freeradical addition of nitrogen oxide or nitrogen dioxide radicals to the carbon centered benzyl radical (as a result of hydrogen abstraction from the alkyl chain) followed by oxidation. These ionic and free-radical mechanisms for anisole, toluene and similar compounds would predominate in acidic solutions such as urban atmospheric aerosols and nuclear fuel dissolutions.

Neutral nitrate anisole and solutions were dominated by mixed nitrosonium/nitronium ion electrophilic aromatic substitution reactions, but with lower product yields. The products were found only in irradiated solution. Trace amounts of nitrous acid is produced in neutral nitrate solutions under this condition. In addition, production of meta isomers and ortho nitrophenol were observed. This product distribution suggests that a combination of electrophilic nitration with $\mathrm{NO}^{+}, \mathrm{NO}_{2}{ }^{+}$, and free-radical reactions with ${ }^{\circ} \mathrm{OH}$ and ${ }^{\circ} \mathrm{NO}_{2}$ occur in irradiated neutral sodium nitrate solution. Solutions such as these might be encountered in water treatment by e-beam irradiation.

In neutral nitrite anisole and toluene solution, radiolytic nitration products approached a statistically random substitution pattern, suggesting a non-electrophilic free-radical reaction involving addition of the ${ }^{\circ} \mathrm{NO}_{2}$ radical. ${ }^{\circ} \mathrm{NO}_{2}$ radicals are mainly produced by the nitrite scavenging of ${ }^{\circ} \mathrm{OH}$ radical. The ${ }^{\circ} \mathrm{NO}_{2}$ radical reaction was not important in the acidic condensed phase due to its low reaction rate constants, because of which it was unable to compete with the ionic nitrating agents. However, in the neutral nitrite solution it is the dominant reaction. These data provide a first step toward a 
predictive ability for the abundances of various possible nitration products under nuclear solvent extraction process conditions.

Towards this end, anisole was used as a surrogate for Cs-7SB, the modifier used in the FPEX formulation for $\mathrm{Cs}$ and $\mathrm{Sr}$ extraction from nuclear waste streams. Anisole and Cs-7SB are aryl ethers. Similarly to anisole, the larger ether molecule, Cs-7SB was also found to form nitro products when irradiated in the presence of nitric acid. It was difficult to identify several of its product nitro compounds. However, an hydroxylated nitro modifier compound was identified which was analogous to the nitrophenol formation in anisole. In addition, the nitrous acid scavenger, hydrazine, prevented color formation in both anisole and Cs-7SB in $\mathrm{HNO}_{3}$, indicating that nitrous acid promoted the formation of these nitro-products. Based on these identical phenomena in both anisole and Cs-7SB, some nitro products were predicted for Cs-7SB. HPLC, LCMS, GC-ECD and FTIR did not definitively identify the Cs-7SB radiolysis products, but their results were consistent with these predictions.

Toluene reacted differently in acid solutions producing dominant free-radical nitration products under irradiation and $\mathrm{NO}_{2}{ }^{+}$ion electrophilic substitution products under high temperature thermal nitration. Thus the nitration mechanisms were different than anisole and Cs-7SB because toluene is a less reactive compound toward electrophiles in general, and $\mathrm{NO}^{+}$ion is a weak electrophile.

The dominant nitration mechanisms of three different types of aromatic organic molecules in acidic and neutral nitrate/nitrite media were determined in this study. The information has implications in different areas of environmental chemistry, in water treatment plants, and in nuclear fuel reprocessing facilities. 


\section{References}

1. Sasaki, J., Aschmann, S. M., Kwok, E.S., Atkinson, R., Arey, J., Products of the gas-phase $\mathrm{OH}$ and $\mathrm{NO}_{3}$ radical-initiated reactions of naphthalene, Environ. Sci. Technol., 1997, 31, 3173.

2. Vione, D., Maurino, V., Minero, C., Borghesi, D., Lucchiari, M., Pelizzetti, E., New processes in the environmental chemistry of nitrite. 2. The role of hydrogen peroxide, Environ. Sci. Technol., 2003, 37, 4635.

3. Atkinson, R., Arey, J., Zielinska, B., Aschmann, S. M., Kinetics and products of the gas-phase reactions of $\mathrm{OH}$ radicals and $\mathrm{N}_{2} \mathrm{O}_{5}$ with naphthalene and biphenyl, Environ. Sci. Technol., 1987, 21, 1014.

4. Vione, D., Maurino, V., Minero, C., Pelizzetti, E., Nitration and photonitration of naphthalene in aqueous systems, Environ. Sci. Technol., 2005, 39, 1101.

5. Vione, D., Maurino, V., Minero, C., Pelizzetti, E., New processes in the environmental chemistry of nitrite: nitration of phenol upon nitrite photoinduced oxidation, Environ. Sci. Technol., 2002, 36, 669.

6. Bunce, N. J., Liu, L., Zhu, J., Lane, D. A., Reaction of naphthalene and its derivatives with hydroxyl radicals in the gas phase, Environ. Sci. Technol., 1997, 31, 2252.

7. Neta, P., Huie, R. E., Rate constants for reactions of $\mathrm{NO}_{3}$ radicals in aqueous solutions, J. Phys. Chem., 1986, 90, 4644.

8. Vione, D., Maurino, V., Minero, C., Pelizzetti, E., Phenol photonitration upon UV irradiation of nitrite in aqueous solution I: Effects of oxygen and 2propanol, Chemosphere, 2001, 45, 893.

9. Herrmann, H., Kinetics of aqueous phase reactions relevant for atmospheric chemistry, Chem. Rev., 2003, 103, 4691.

10. Olah, G. A., Malhotra, R., Narang, S. C., Nitration, Methods and Mechanisms. Wiley-VCH, New York, NY, 1989, and references therein.

11. Kurucz, C. N., Waite, T. D., Cooper, W. J., The Miami electron beam research facility: A large scale wastewater treatment application, Radiat. Phys. Chem., 1995, 45, 299.

12. Dzengel, J., Theurich, J., Bahnemann, D. W., Formation of nitroaromatic compounds in advanced oxidation processes: Photolysis versus photocatalysis, Environ. Sci. Technol., 1999, 33, 294. 
13. Mincher, B. J., Mezyk, S. P., Bauer, W. F., Elias, G., Riddle, C., Peterman, D. R., FPEX $-\gamma$ radiolysis in the presence of nitric acid, Solvent Extr. Ion Exch., 2007, 25, 593.

14. Lamare, V., Dozol, J. F., Allain, F., Virelezier, H., Moulin, C., Jankowski, C., Tabet, J. C., Behavior of calix[4]arene crown 6 under irradiation, Ch. 5 in: Lumetta, G. J., Gopalan, A. S., ACS Symposium Series 757, American Chemical Society, Washington DC, 2005.

15. Lamouroux, C., Aychet, N., Lelie`vre, A., Jankowski, C. K., Moulin, C., High performance liquid chromatography with electrospray ionization mass spectroscopy and diode array detection in the identification and quantification of the degradation products of calix[4]arene crown 6 under radiolysis, Rapid Commun. Mass Spectrom., 2004, 18, 1493.

16. Turney, T. A., Wright, G. A., Nitrous acid and nitrosation, Chem. Rev., 1959, $59,497$.

17. Schramm, R. M., Westheimer, F. H., The mechanism of the nitration of anisole, J. Am. Chem. Soc., 1948, 70, 1782.

18. Olah, G. A., Lin, H. C., Olah, J. A., Narang, S. C., Electrophilic and free radical nitration of benzene and toluene with various nitrating agents, Proc. Nat. Acad. Sci. USA, 1978, 75, 1045.

19. Halfpenny, E., Robinson, P. L., The nitration and hydroxylation of aromatic compounds by pernitrous acid, J. Chem. Soc., 1952, 939.

20. Titov, A. I., The free radical mechanism of nitration, Tetrahedron, 1963, 19, 557.

21. Duchemin, C. R., Engle, N. L., Bonnesen, P. V., Haverlock, T. J., Delmau, L. H., Moyer, B. A., Solvatochromic solvent polarity measurements of alcohol solvent modifiers and correlation with cesium extraction strength, Solvent Extr. Ion Exch., 2001, 19, 1037.

22. Ingold, C. K., Structures and Mechanism in Organic Chemistry, Cornell University Press, 1969.

23. Katsumura, $\mathrm{Y}$., $\mathrm{NO}_{2}{ }^{\circ}$ and $\mathrm{NO}_{3}{ }^{\circ}$ radicals in radiolysis of nitric acid solutions. In: N-centered radicals, Wiley, New York, NY, 1998, p. 397.

24. Morris, R. T., Boyd, R. N., Organic Chemistry, Allyn and Bacon, Inc., Boston, MA, 1973. 
25. Zhou Z., Parr, R. G., Activation hardness: New index for describing the orientation of electrophilic aromatic substitution, J. Am. Chem. Soc., 1990, 112, 5720 .

26. Ridd, J. H., Mechanism of aromatic nitration, Accounts of Chemical Research, 1971, 4, 248.

27. Olah, G. A., Narang, S. C., Olah, J. A., Lammertsma, K., Recent aspects of nitration: New preparative methods and mechanistic studies (A Review), Proc. Natl. Acad. Sci. USA, July 1982, 79, p. 4486.

28. Barnett, J. W., Moodie, R. B., Schofield, K., Weston, J. B., Coombes, R. G., Golding, J. G., Tobin, G. D., Electrophilic aromatic substitution. Part 16. The nitration of anisole, $o$-methylanisole, and $p$-methylanisole in aqueous sulfuric acid, JCS Perkin II, 1977, 248.

29. Dix, L. R., Moodie, R. B., Nitrosation and nitrous acid-catalyzed nitration of anisole and 2,6-dimethylanisole, J. Chem. Soc. Perkin Trans II, 1986, 1097.

30. Atherton, J. H., Moodie, R. B., Noble D. R., Sullivan, B. O., Nitrosation of mxylene, anisole, 4-nitrophenyl ether and toluene in trifluoroacetic acid or in acetic-sulfuric acid mixtures under nitric oxide, J. Chem. Soc. Perkin Trans II, 1997, 663.

31. Ridd, J. H., Some unconventional pathways in aromatic nitration, Acta Chemica Scandinavica, 1998, 52, 11.

32. Rosokha, S. V., Kochi, J. K., The preorganization step in organic reaction mechanisms. Charge-transfer complexes as precursors to electrophilic aromatic substitutions, J. Org. Chem., 2002, 67, 1727.

33. Kochi, J. K., Inner-Sphere electron transfer in organic chemistry. Relevance to electrophilic aromatic nitration, Acc. Chem. Res., 1992, 25, 39.

34. Rosokha, S. V., Kochi, J. K., Fresh look at electron-transfer mechanisms via the donor/acceptor bindings in the critical encounter complex, Acc. Chem. Res., 2008, 41, 641 .

35. Taube, H., Myers, H. J., Rich, R. L., Observations on the mechanism of electron transfer in solution, J. Am. Chem. Soc., 1953, 75, 4118.

36. Taube, H., Electron transfer between metal complexes: retrospective, Science, 1984, 226 (4678), 1028. 
37. Eberson, L., Radner, F., Electron-transfer mechanisms in electrophilic aromatic nitration, Acc. Chem. Res., 1987, 20, 53.

38. Kim, E. K., Bockman, T. M., and Kochi, J. K., The mechanism of chargetransfer nitration of naphthalene, J. Chem. Society-Perkin Trans., 1992, 2, 1879.

39. Attina, M., Cacace, F., Speranza, M., FT-ICR studies of gas-phase ionic nitration of benzene - the role of electron-transfer and proton-transfer processes, Int. J. Mass Spec., 1992, 117, 37.

40. Delaude, L., Lazlo, P., Smith, K., Heightened selectivity in aromatic nitrations and chlorinations by the use of solid supports and catalysts, Acc. Chem. Res., 1993, 26, 607.

41. Goulden, J. D., Millen, D. J., Vibrational spectra of ionic forms of oxides and oxy-acids of nitrogen .6. Raman-spectral evidence of the ionization of dinitrogen tetroxide in nitric acid - the nitrosonium ion, $\mathrm{NO}^{+}$, and the nitrosonium - nitrogen dioxide ion, $\mathrm{N}_{2} \mathrm{O}_{3}{ }^{+}$, J. Chem. Soc., 1950, 2620.

42. Millen, D. J., Watson, D., The ionization of dinitrogen tetroxide in nitric acid evidence from measurements of infrared spectra and magnetic susceptibilities, J. Chem. Soc., 1952, p. 1369.

43. Glazer, J., Hughes, E. D., Ingold, C. K., James, A. T., Jones, G. T., Roberts, E., Kinetics and mechanism of aromatic nitration. 7. Products of nitration of aniline derivatives, especially of dimethylaniline - the concomitant dealkylation of dialkylanilines, J. Chem. Soc., 1950, 46, 2657.

44. Sankararaman, S., Haney, W. A., Kochi, J. K., Aromatic nitration with ion radical pairs $\left[\mathrm{ArH}^{\circ+}, \mathrm{NO}_{2}{ }^{\circ}\right]$ as reactive intermediates. Time-resolved studies of charge-transfer activation of dialkoxybenzenes, J. Am. Chem. Soc., 1987, 109, 5235 .

45. Eberson, L., Radner, F., Electron-transfer reactions in organic-chemistry. Possible role of electron-transfer in aromatic nitration by nitrosonium and nitronium ion Acta Chemica Scandinavica., 1984, 38B, 861.

46. Mancebo, S. G., Santos, P. G., Benito, J. H., Calle, E., Casado, J., Nitrosation of Phenolic Compounds: Inhibition and Enhancement, J. Agric. Food Chem., 1999, 47, 2235.

47. Mulliken, R. S., Molecular compounds and their spectra. II, J. Am. Chem. Soc., 1952, 74, 811. 
48. Mulliken, R. S., Person, W. B., Molecular Complexes, Wiley, New York, NY, 1969.

49. Buxton, G. V., Greenstock, C. L., Helman, W. P., Ross, A. B., J. Phys. Chem. Ref. Data, 1988, 17, 513.

50. Mincher, B. J., Elias, G., Martin, L. R., Radiation chemistry and the fuel cycle, J. Radioanal. Nucl. Chem., 2009, 282, 645.

51. Tabatha, Y., Application of pulse radiolysis methods to study the reactions and structure of biomolecules, Pulse Radiolysis, CRC press, Inc., Boca Raton, FL, 1991.

52. Wardman, P., Application of pulse radiolysis methods to study the reactions and structure of biomolecules, Rep. Prog. Phys. 1978, 41, 259.

53. Katsumura, Y., Jiang, P.Y., Nagaishi, R., Oishi, T., Ishigure. K., Yoshida, Y., Pulse radiolysis study of aqueous nitric acid solutions. Formation mechanism, yield, and reactivity of $\mathrm{NO}_{3}$ radical, J. Phys. Chem., 1991, 95, 4435.

54. Broszkiewicz, R. K., Radiation-induced formation of $\mathrm{NO}_{3}$ in aqueous solutions, Int. J. Appl. Radiat. Isot., 1967, 18, 25.

55. Daniels, M., Radiation chemistry of the aqueous nitrate system. III. Pulse electron radiolysis of concentrated sodium nitrate solutions, J. Phys. Chem., 1969, 73, 3710 .

56. Kozlowska-Milner, E., Broszkiewicz, R. K., Pulse radiolysis of $\mathrm{HNO}_{3}$ and $\mathrm{HNO}_{3}$ (aq), Radiat. Phys. Chem., 1978, 11, 253.

57. Goldstein, S., Rabani, J., Mechanism of nitrite formation by nitrate photolysis in aqueous solutions: The role of peroxynitrite, nitrogen dioxide, and hydroxyl radical, J. Am. Chem. Soc., 2007, 129, 10597.

58. Elliot, A. J., A pulse-radiolysis study of the temperature-dependence of reactions involving $\mathrm{H}, \mathrm{OH}$ and $\mathrm{e}_{\text {aq }}^{-}$in aqueous-solutions, Radiat. Phys. Chem., 1989, 34, 753.

59. Sworski, T. J., Matthews, R.W., Mahlman, H.A., Radiation chemistry of concentrated $\mathrm{NaNO}_{3}$ solutions: Dependence of $\mathrm{G}\left(\mathrm{HNO}_{2}\right)$ on $\mathrm{NaNO}_{3}$ concentration, Adv. Chem. Ser., 1968, 82, 164.

60. Broszkiewicz, R. K., Radiation-induced formation of $\mathrm{NO}_{3}$ in aqueous solutions Int. J. Appl. Radiat. Isot., 1967, 18, 25. 
61. Peiris, S. A., Freeman, G. R., Solvent structure effects on solvated electron reactions with ions in 2-butanol/water mixed solvents, Can. J. Chem., 1991, 69, 884.

62. Benderskii, V. A., Krivenko, A. G., Ponomarev, E. A., Fedorovich, N.V., Protonation rate constants of the $\mathrm{NO}_{3}{ }^{2-}$ radical-ion, Sov. Electrochem., 1987, 23, 1343.

63. Chen, R., Avotinsh, Y., Freeman, G. R., Solvent effects on the reactivity of solvated electrons with ions in isobutanol/water mixed solvents, Can. J. Chem., 1994, 72, 1083.

64. Gordon, S., Hart, E. J., Thomas, J. K., The ultraviolet spectra of transients produced in the radiolysis of aqueous solutions, J. Phys. Chem., 1964, 68, 1262.

65. Ilan, Y. A., Czapski, G., Meisel, D., One-electron transfer redox potentials of free-radicals .1. Oxygen-superoxide system, Biochimica. et Biophysica Acta., 1976, 430, 209.

66. Tripathi, S. C., Ramanujam, A., Gupta, K. K., Bindu, P., Studies on the identification of harmful radiolytic products of $30 \% \mathrm{TBP}-\mathrm{N}$-dodecane- $\mathrm{HNO}_{3}$ by gas-liquid chromatography. II. Formation and characterization of high molecular weight organophosphates, Sep. Sci. Technol., 2001, 36, 2863.

67. Lane, E. S., Performance and degradation of diluents for TBP and cleanup of degraded solvents, Nucl. Sci. Eng., 1963, 17, 620.

68. Tripathi, S. C., Bindu, P., Ramanujam, A., Studies on the identification of harmful radiolytic products of $30 \%$ TNP-n-dodecane- $\mathrm{HNO}_{3}$ by gas liquid chromatography. I. Formation of diluent degradation products and their role in Pu retention behavior, Sep. Sci. Technol., 2001, 36, 1463.

69. Goldstein, S., Samuni, A., Kinetics and mechanisms of peroxyl radical reactions with nitroxide, J. Phys. Chem., 2007, 111, 1066.

70. Vione, D., Maurino, V., Minero, C., Pelizzetti, E., Phenol nitration upon oxidation of nitrite by Mn (III, IV) (hydr) oxides Chemosphere, 2004, 55, 941.

71. Vione, D., Maurino, V., Minero, C., Vincenti, M., Pelizzetti, E., Aromatic photonitration in homogeneous and heterogeneous aqueous systems, Env. Sc. and Pollu. Res., 2003, 10, 321.

72. Minero, C., Maurino, V., Pelizzetti, E., Vione, D., Assessing the steady-state $\left[\mathrm{NO}_{2}\right]$ in environmental samples. Implications for aromatic photonitration processes induced by nitrate and nitrite, Env. Sci. and Pollu. Res., 2007, 14, 
241.

73. Vione, D., Maurino, V., Minero, C., Pelizzetti, E., Phenol photonitration, Annali di Chimica, 2002, 92, 919.

74. Vione, D., Minero, C., Maurino, V., Pelizzetti, E., Seasonal and water column trends of the relative role of nitrate and nitrite as $\bullet \mathrm{OH}$ sources in surface waters, Annali di Chimica, 2007, 97, 699.

75. Schutze, M., Herrmann, H., Uptake of $\mathrm{NO}_{3}$ radical on aqueous surfaces, Journal of Atmospheric Chemistry, 2005, 52, 1.

76. Li, Y., Sun, J., Han, K., He, G., Li, Z., The dynamics of NO radical formation in the UV $266 \mathrm{~nm}$ photodissociation of nitroethane, Chemical Physics Letters, 2006, 421, 232.

77. Buxton, G. V., Stuart, C. R., Reevaluation of the thiocyanate dosimeter for pulse radiolysis, J. Chem. Soc., Faraday Trans., 1995, 91, 279.

78. Whitman, K., Lyons, S., Miller, R., Nett, D., Treas, P., Zante, A., Fessenden, R.W., Thomas, M. D., Wang, Y., Linear accelerator for radiation chemistry research at Notre Dame. In: IEEE Proceedings Particle Accelerator Conference and International Conference on High Energy Accelerators, Dallas, TX, 1995, 131.

79. Mincher, B. J., Mezyk, S. P., Martin, L. R., A pulse radiolysis investigation of the reactions of tributyl phosphate with the radical products of aqueous nitric acid irradiation, J. Phys. Chem. A, 2008, 112, 6275.

80. Shastri, L. V., Huie, R. E., Rate constants for hydrogen abstraction reactions of $\mathrm{NO}_{3}$ in aqueous solution, Int. J. Chem. Kinet., 1990, 22, 505.

81. Mezyk, S. P., Bartels, D. M., Temperature dependence of hydrogen atom reaction with nitrate and nitrite species in aqueous solution, J. Phys. Chem. A, 1997, 101, 6233.

82. Laverne, J. A., Pimblott, S. M., Yields of hydroxyl radical and hydrated electron scavenging reactions in aqueous solutions of biological interest, Rad. Res., 1993, 135, 16.

83. G. L. Hug, Optical spectra of nonmetallic inorganic transient species in aqueous solution, NSRDS-NBS, 69, 1981.

84. Baciocchi, E., Del Giacco, T., Murgia, S. M., Sebastiani, G. V., Rate and mechanism for the reaction of the nitrate radical with aromatic and alkylaromatic compounds in acetonitrile, J. Chem. Soc. Chem. Comm., 1987, 
1246.

85. Mezyk, S. P., Cullen, T., Elias, G., Mincher, B. J., Aqueous nitric acid radiation effects on solvent extraction process chemistry, Nuclear Energy and the Environment, ACS symposium series, in press .

86. Jiang, P. Y., Nagaishi, R., Yotsuyanagi, T., Katsumura, Y., Ishigure, I., $\gamma-$ radiolysis study of concentrated nitric acid solutions, J. Chem. Soc. Faraday Trans., 1994, 90, 93.

87. Vladimirova, M. V., Kulikov, I. A., Yu, I., Steady-state concentrations of nitrous acid in $\gamma$-irradiated nitric acid solutions, Khimiya Vysokikh Energii, 1969, 3, 526 .

88. Lehnig, M., The mechanism of the nitration of donor-activated benzene with nitric and nitrous acid as studied by ${ }^{15} \mathrm{~N}$ CIDNP, Tetrahedron Letters, 1999, 40, 2299.

89. Mincher, B. J., Mezyk, S. P., Radiation chemical effects on radiochemistry: A review of examples important to nuclear power, Radiochim Acta, 2009, 97, 519.

90. Riddle, C. L., Baker, J. D., Law, J. D., McGrath, C. A., Meikrantz, D. H., Mincher, B. J., Peterman, D. R., Todd, T., A., Fission product extraction (FPEX): Development of a novel solvent for the simultaneous separation of strontium and cesium from acidic solutions, Solvent. Extr. Ion Exch., 2005, 23, 449.

91. Eberhardt, M. K., Radiation-induced homolytic aromatic substitution. III. Hydroxylation and nitration of benzene, J. Phys. Chem., 1975, 79, 1067. 


\section{Appendix A}

\section{List of Related Papers Published in Refereed Journals and Symposium Series}

A-1 Elias, G., Mincher, B. J., Mezyk, S. P., Cullen, T. D., Martin, L. R., Anisole nitration during gamma-irradiation of aqueous nitrite and nitrate solutions: Free radical versus ionic mechanisms, Environ. Chem., 2010, 7, 183.

A-2 Elias, G., Mincher, B. J., Mezyk, S. P., Cullen, T. D., Martin, L. R., Nitration mechanisms of anisole during gamma irradiation of aqueous nitrite and nitrate solutions, Nuclear Energy and the Environment, ACS symposium series, in press.

A-3 Mincher, B. J., Elias, G., Martin, L. R., Radiation chemistry and the nuclear fuel cycle, J. Radioanal. Nucl. Chem., 2009, 282, 645.

A-4 Mezyk, S. P., Cullen, T., Elias, G., Mincher, B. J., Aqueous nitric acid radiation effects on solvent extraction process chemistry, Nuclear Energy and the Environment, ACS symposium series, in press.

A-5 Mincher, B. J., Mezyk, S. P., Bauer, W. F., Elias, G., Riddle, C., Peterman, D. R., FPEX- $\gamma$ radiolysis in the presence of nitric acid, Solvent Extr. Ion Exch., 2007, 25, 593.

A-6 Elias, G., Mincher, B. J., Mezyk, S. P., Muller, J., Martin, L. R., The nitration of toluene in irradiated nitrate and nitrite solution, Radiation Physics and Chemistry (in preparation).

A-7 Elias, G., Mincher, B. J., Mezyk, S. P., Bauer, W. F, Muller, J., The radiation chemistry of Cs-7SB, Solvent Extr. Ion Exch. (in preparation). 